\title{
Experimental Design for Hanford Low-Activity Waste Glasses with High Waste Loading
}

\section{July 2015}

GF Piepel

SK Cooley

JD Vienna

JV Crum 


\title{
DISCLAIMER
}

This report was prepared as an account of work sponsored by an agency of the United States Government. Neither the United States Government nor any agency thereof, nor Battelle Memorial Institute, nor any of their employees, makes any warranty, express or implied, or assumes any legal liability or responsibility for the accuracy, completeness, or usefulness of any information, apparatus, product, or process disclosed, or represents that its use would not infringe privately owned rights. Reference herein to any specific commercial product, process, or service by trade name, trademark, manufacturer, or otherwise does not necessarily constitute or imply its endorsement, recommendation, or favoring by the United States Government or any agency thereof, or Battelle Memorial Institute. The views and opinions of authors expressed herein do not necessarily state or reflect those of the United States Government or any agency thereof.

\author{
PACIFIC NORTHWEST NATIONAL LABORATORY \\ operated by \\ BATTELLE \\ for the \\ UNITED STATES DEPARTMENT OF ENERGY \\ under Contract DE-AC05-76RL01830
}

Printed in the United States of America

Available to DOE and DOE contractors from the

Office of Scientific and Technical Information,

P.O. Box 62, Oak Ridge, TN 37831-0062;

ph: (865) 576-8401

fax: $(865) 576-5728$

email: reports $a$ adonis.osti.gov

Available to the public from the National Technical Information Service

5301 Shawnee Rd., Alexandria, VA 22312

ph: (800) 553-NTIS (6847)

email: orders $a$ ntis.gov <http://www.ntis.gov/about/form.aspx >

Online ordering: http://www.ntis.gov

This document was printed on recycled paper.

(8/2010) 
PNNL-24391

EWG-RPT-006, Rev. 0

\title{
Experimental Design for Hanford Low-Activity Waste Glasses with High Waste Loading
}

\author{
GF Piepel \\ SK Cooley \\ JD Vienna \\ JV Crum
}

July 2015

Prepared for

the U.S. Department of Energy

under Contract DE-AC05-76RL01830

Pacific Northwest National Laboratory

Richland, Washington 99352 



\section{Executive Summary}

This report discusses the development of an experimental design for the initial phase of the Hanford low-activity waste (LAW) enhanced glass study. This report is based on a manuscript written for an applied statistics journal. Appendices A, B, and E include additional information relevant to the LAW enhanced glass experimental design that is not included in the journal manuscript.

The glass composition experimental region is defined by single-component constraints (SCCs), linear multiple-component constraints (MCCs), and a nonlinear MCC involving 15 LAW glass components. Traditional methods and software for designing constrained mixture experiments with SCCs and linear MCCs are not directly applicable because of the nonlinear MCC. A modification of existing methodology to account for the nonlinear MCC was developed and is described in this report.

One of the glass components, $\mathrm{SO}_{3}$, has a solubility limit in glass that depends on the composition of the balance of the glass. A goal was to design the experiment so that $\mathrm{SO}_{3}$ would not exceed its predicted solubility limit for any of the experimental glasses. The $\mathrm{SO}_{3}$ solubility limit had previously been modeled by a partial quadratic mixture model expressed in the relative proportions of the 14 other components. The partial quadratic mixture model was used to construct a nonlinear MCC in terms of all 15 components. In addition, there were SCCs and linear MCCs.

This report describes how a layered design was generated to (i) account for the SCCs, linear MCCs, and nonlinear MCC and (ii) meet the goals of the study. A layered design consists of points on an outer layer, and inner layer, and a center point. There were 18 outer-layer glasses chosen using optimal experimental design software to augment 147 existing glass compositions that were within the LAW glass composition experimental region. Then 13 inner-layer glasses were chosen with the software to augment the existing and outer-layer glasses. The experimental design was completed by a center-point glass, a Vitreous State Laboratory glass, and replicates of the center point and Vitreous State Laboratory glasses. 



\section{Acknowledgments}

This work was conducted at Pacific Northwest National Laboratory (PNNL). We gratefully acknowledge the financial support of the U.S. Department of Energy's Waste Treatment and Immobilization Plant Federal Project Office under the direction of Dr. Albert A. Kruger. PNNL is a multiprogram national laboratory operated for the U.S. Department of Energy by Battelle under Contract DE-AC05-76RL01830. The authors thank Brett Amidan (PNNL) who provided technical and software quality assurance reviews of the work, as well as Maura Zimmerschied (PNNL) for copy editing. 



\section{Acronyms and Abbreviations}

$\begin{array}{ll}\text { HLW } & \text { high-level waste } \\ \text { LAW } & \text { low-activity waste } \\ \text { LD } & \text { layered design } \\ \text { MCC } & \text { multiple-component constraint } \\ \text { PNNL } & \text { Pacific Northwest National Laboratory } \\ \text { SCC } & \text { single-component constraint } \\ \text { SFD } & \text { space-filling design } \\ \text { UD } & \text { uniform design } \\ \text { VHT } & \text { Vapor Hydration Test } \\ \text { WTP } & \text { Hanford Tank Waste Treatment and Immobilization Plant }\end{array}$





\section{Contents}

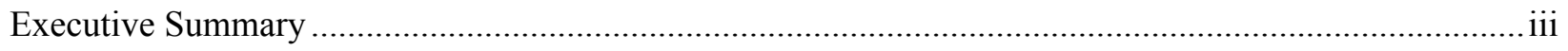

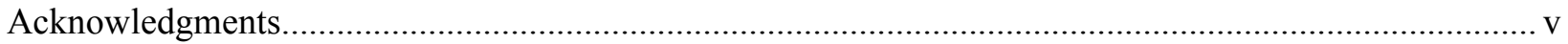

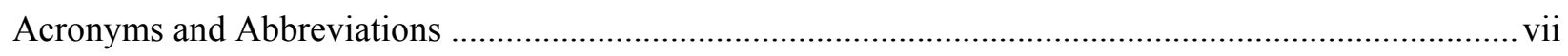

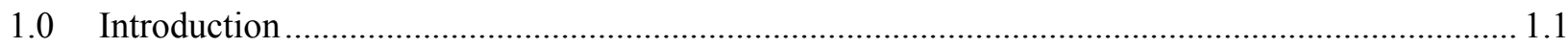

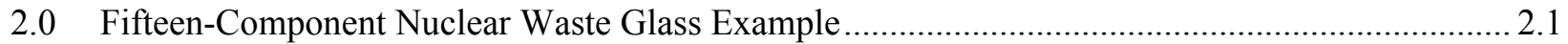

3.0 Multiple-Component Constraints for the 15-Component LAW Glass Example ............................ 3.1

4.0 Modifying an Existing Algorithm to Account for a Nonlinear Multiple-Component

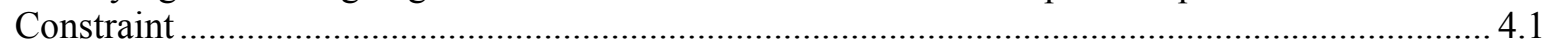

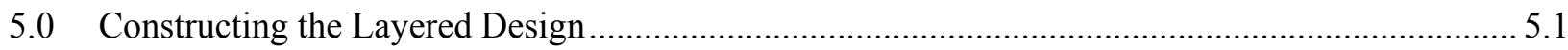

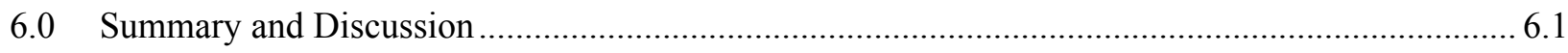

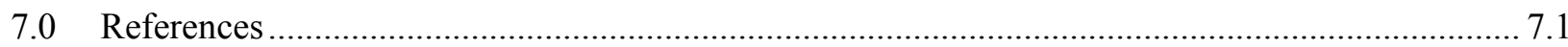

Appendix A Development of the Single-Component Constraints ...................................................... A.1

Appendix B Data and Linear Mixture Model for Viscosity at $1150^{\circ} \mathrm{C}$ of Low-Activity Waste

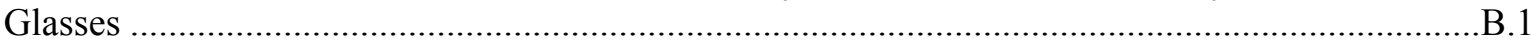

Appendix C Derivation of the Nonlinear Multiple-Component Constraint Involving $\mathrm{SO}_{3}$

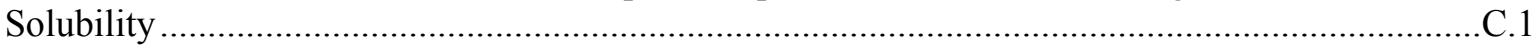

Appendix D Derivation of the Intersection of a Nonlinear Multiple-Component Constraint and an Edge that Connects Two Vertices Outside and Inside the Constraint ......................................... D.1

Appendix E The 147 Existing Low-Activity Waste Glass Compositions ................................................. E.1 


\section{Figures}

5.1. Distributions of Values for (a) $\mathrm{Na}_{2} \mathrm{O}$ and (b) PCT-Li Release for Four Possible Sets of the 13 Inner-Layer LAW Glass Compositions.

5.2. Scatterplot Matrix Display of How Well the Layered Design and Existing Glass

Compositions Cover the LAW Glass Composition Region.

\section{Tables}

2.1. Lower and Upper Bounds of Single-Component Constraints for the Outer and Inner Layers of a 15-Component Low-Activity Waste Glass Composition Region

2.2. Mass Fractions of Components Comprising the Others1 Component for the Experimental Design and for Making the Glasses.

2.3. Lower and Upper Bounds of Multiple-Component Constraints for the Outer and Inner Layers of a 15-Component Low-Activity Waste Glass Composition Region ................................. 2.3

5.1. Compositions of the Layered Design for LAW Glasses ........................................................... 5.3

B.1. Glass Names, Study Names, and References for the 281 Glasses Used to Develop a Model for Viscosity at $1150^{\circ} \mathrm{C}$

B.2. Glass Oxide Compositions for the 281 Glasses Used to Develop a Model for Viscosity at $1150^{\circ} \mathrm{C}$

B.3. Viscosity at $1150^{\circ} \mathrm{C}$ Values and Temperature-Viscosity Pairs One to Seven for the 281 Glasses Used to Develop a Model for Viscosity at $1150^{\circ} \mathrm{C}$.

B.4. Temperature-Viscosity Pairs Eight to Eleven for the 281 Glasses Used to Develop a Model for Viscosity at $1150^{\circ} \mathrm{C}$

E.1 The 147 Existing LAW Glass Compositions Within the Outer-Layer Region SCCs and MCCs Given in Tables 2.1 and 2.3

E.2 Glass Names Corresponding to the Row Numbers of the 147 Existing LAW Glass Compositions in Table E.1 


\subsection{Introduction}

Existing statistical algorithms and software provide for designing mixture experiments when the experimental region is defined by (i) lower and/or upper bounds on each component, referred to as single-component constraints (SCCs), and (ii) lower and/or upper bounds on linear combinations of components, referred to as linear multiple-component constraints (MCCs). Existing algorithms and software do not allow nonlinear MCCs, which may occur in practice. This report uses a case study involving a 15-component nuclear waste glass example with a nonlinear MCC (in addition to SCCs and linear MCCs) to discuss and illustrate how a layered experimental design was generated to account for all of the constraints.

Layered designs (LDs) were first introduced by Piepel et al. (1993) and have subsequently been used many times to investigate waste glass composition regions (e.g., Cooley et al. 2003, Piepel et al. 2005, and the study discussed in this report). LDs consist of design points on two or more layers of an experimental region. LDs are useful when the goal is to boldly explore a larger outer layer, but also more conservatively explore points on the interior of the experimental region (using one or more inner layers plus a center point). Layers may be defined by (i) separate sets of SCCs and MCCs, or (ii) specifying an outer layer defined by one set of SCCs and MCCs and shrinking it to form one or more inner layers. See Piepel et al. (1993) for more discussion of LDs. In this report, we discuss a LD with points on an outer layer, an inner layer, and a center point, where the outer and inner layers are defined by separate sets of SCCs and MCCs.

Section 2 discusses the 15-component nuclear waste glass example in more detail, and presents the separate sets of SCCs, linear MCCs, and nonlinear MCC used to define the outer and inner layers. Section 3 presents and discusses the linear and nonlinear MCCs. Section 4 describes how an existing algorithm for generating vertices of a constrained mixture region was modified to account for a nonlinear MCC. Section 5 describes how the LD was constructed for the 15-component waste glass example using optimal experimental design methods and software. Finally, Section 6 summarizes the approach used this report to account for one nonlinear MCC and discusses possible approaches to account for two or more nonlinear SCCs and/or MCCs.

The work described in this document was performed under the Quality Assurance program of the Enhanced Waste Glass project, which implements the requirements of ASME NQA-1-2008, Quality Assurance Requirements for Nuclear Facility Applications, and NQA-1a-2009, Addenda to ASME NQA-1-2008, Quality Assurance Requirements for Nuclear Facility Applications, graded on the approach presented in NQA-1-2008, Part IV, Subpart 4.2. 



\subsection{Fifteen-Component Nuclear Waste Glass Example}

The Hanford site near Richland, WA is storing approximately 56 million gallons of radioactive chemical waste from the defense mission of the site (which ended years ago) that is stored in 177 underground tanks. The Hanford Tank Waste Treatment and Immobilization Plant (WTP) is being constructed to separate the tank waste into high-level waste (HLW) and low-activity waste (LAW) and separately immobilize the HLW and LAW in borosilicate waste glasses contained in canisters for disposal. The majority of the work so far to develop glass property-composition databases, models, and acceptable glass formulations has focused on the HLW and LAW glasses for the initial few years of WTP operation. Those glasses focus on immobilizing a fraction of the tank waste at relatively low waste loadings. Other work, including the work discussed in this report, is focused on developing glass formulations and property-composition models for the balance of the WTP mission. This other work involves broader regions of HLW and LAW compositions and corresponding glass compositions that will be produced by the WTP at higher waste loadings than for the initial WTP production period.

In this section, we discuss the initial portion of the work to select new LAW glass compositions using a LD with one outer layer, one inner layer, a center point, and two replicates. Specifically, this section focuses on the LAW glass components, as well as the SCCs and MCCs that define the composition regions for the outer and inner layers. The details of how the LD was constructed using the SCCs and MCCs that define the outer and inner layers are discussed in the following section.

Based on estimates of LAW compositions that may result from processing wastes in the Hanford underground tanks, as well as estimates of LAW glass compositions that might be made from those LAW compositions, glass scientists (the third and fourth authors) selected $15 \mathrm{LAW}$ glass components (see Table 2.1) to vary in the experimental design. These components were ones that were known or believed to possibly affect one or more of the several glass properties of interest (e.g., glass durability, viscosity, sulfate solubility). The $15^{\text {th }}$ component, "Others 1 ," comprises the mixture of components shown in Table 2.2. Actual LAW glasses will have many more chemical and radionuclide components with very small mass fractions, but none of those components are expected to affect LAW glass properties. Hence, nonradioactive glasses with a simplified Others 1 component can be tested in the laboratory and the resulting data can be used to (i) develop property-composition models, (ii) identify the region of acceptable LAW glass compositions, and (iii) develop acceptable LAW glass formulations. Table 2.2 lists the mass fractions of the Others 1 components used to construct the experimental design, as well as the mass fractions (to fewer decimal places) actually used to make the glasses. 
Table 2.1. $\quad$ Lower and Upper Bounds of Single-Component Constraints for the Outer and Inner Layers of a 15-Component Low-Activity Waste Glass Composition Region

\begin{tabular}{llcccc}
\hline & \multicolumn{2}{c}{ Outer Layer } & \multicolumn{2}{c}{ Inner Layer } \\
\hline Component & Lower Bound & Upper Bound & Lower Bound & Upper Bound & Center Point \\
\hline $\mathrm{Al}_{2} \mathrm{O}_{3}$ & 0.035 & 0.1385 & 0.0625 & 0.1150 & 0.09 \\
$\mathrm{~B}_{2} \mathrm{O}_{3}$ & 0.06 & 0.1375 & 0.08 & 0.1175 & 0.10 \\
$\mathrm{CaO}$ & 0 & 0.1224 & 0.0275 & 0.09 & 0.055 \\
$\mathrm{Fe}_{2} \mathrm{O}_{3}$ & 0 & 0.015 & 0.0050 & 0.0125 & 0.01 \\
$\mathrm{~K}_{2} \mathrm{O}$ & 0 & 0.015 & 0.002 & 0.01 & 0.004 \\
$\mathrm{Li}_{2} \mathrm{O}$ & 0 & 0.05 & 0.01 & 0.035 & 0.02 \\
$\mathrm{MgO}$ & 0 & 0.035 & 0.005 & 0.025 & 0.015 \\
$\mathrm{Na}_{2} \mathrm{O}$ & 0.10 & 0.26 & 0.15 & 0.23 & 0.19 \\
$\mathrm{SiO}_{2}$ & 0.34 & 0.47 & 0.3675 & 0.4325 & 0.3955 \\
$\mathrm{SO}_{3}$ & 0.001 & 0.02 & 0.004 & 0.013 & 0.007 \\
$\mathrm{SnO}_{2}$ & 0 & 0.05 & 0.01 & 0.035 & 0.02 \\
$\mathrm{~V}_{2} \mathrm{O}_{5}$ & 0 & 0.04 & 0.005 & 0.03 & 0.02 \\
$\mathrm{ZnO}$ & 0.01 & 0.05 & 0.02 & 0.04 & 0.03 \\
$\mathrm{ZrO}_{2}$ & 0 & 0.065 & 0.015 & 0.0475 & 0.03 \\
$\mathrm{Others}$ & 0.004 & 0.03 & 0.075 & 0.02 & 0.0135 \\
\hline
\end{tabular}

(a) The lower and upper bounds of the SCCs are in terms of mass fractions of the components, such that the mass fractions of all 15 components must sum to 1.0000 .

Table 2.2. Mass Fractions of Components Comprising the Others1 Component for the Experimental Design and for Making the Glasses

\begin{tabular}{lcc}
\hline & \multicolumn{2}{c}{ Mass Fraction } \\
\cline { 2 - 3 } Component & $\begin{array}{c}\text { Experimental } \\
\text { Design }\end{array}$ & $\begin{array}{c}\text { Making the } \\
\text { Glasses }\end{array}$ \\
\hline $\mathrm{Cl}$ & 0.155315 & 0.156 \\
$\mathrm{Cr}_{2} \mathrm{O}_{3}$ & 0.104383 & 0.104 \\
$\mathrm{~F}$ & 0.235786 & 0.236 \\
$\mathrm{P}_{2} \mathrm{O}_{5}$ & 0.504516 & 0.504 \\
\hline $\mathrm{Sum}$ & 1.000000 & 1.000 \\
\hline
\end{tabular}

Table 2.1 lists the 15 LAW glass components, as well as lower and upper bounds for the SCCs for the outer and inner layers of LAW glass compositions. The SCC lower and upper bounds for the outer layer were chosen to include a broad range of LAW glass compositions. The lower and upper bounds for the inner-layer SCCs were selected to be in the middles of the component ranges between the center-point values and the lower and upper bounds for the outer-layer SCCs. Additional discussion of how the SCCs for both the outer and inner layers were developed is in Appendix A. For both the outer and inner layers, SCCs alone may allow glass compositions that might be very undesirable, so it was necessary to exclude such glass 
compositions using the four MCCs shown in Table 2.3. The four MCCs are discussed in detail in the following section.

Table 2.3. Lower and Upper Bounds of Multiple-Component Constraints for the Outer and Inner Layers of a 15-Component Low-Activity Waste Glass Composition Region

\begin{tabular}{|c|c|c|c|c|}
\hline \multirow[b]{2}{*}{ Expression (units) $^{(a)}$} & \multicolumn{2}{|c|}{ Outer Layer } & \multicolumn{2}{|c|}{ Inner Layer } \\
\hline & Lower Bound & Upper Bound & Lower Bound & Upper Bound \\
\hline Nalk (mf) & 0.15 & 0.265 & 0.195 & 0.2515 \\
\hline $\mathrm{ZrO}_{2}+\mathrm{SnO}_{2}(\mathrm{mf})$ & 0.03 & 0.11 & 0.04 & 0.08 \\
\hline$\eta_{1150}$ (poise) & 10 & 100 & 30 & 70 \\
\hline $\mathrm{SO}_{3}$ Solubility (wt $\%$ ) & - & Solubility Limit ${ }^{(b)}$ & - & Solubility Limit ${ }^{(\mathrm{b})}$ \\
\hline
\end{tabular}

(a) $\mathrm{mf}=$ mass fraction, $\mathrm{wt} \%=$ weight percent.

(b) The $\mathrm{SO}_{3}$ solubility limit is expressed as a partial quadratic mixture model, as discussed subsequently in the text. 



\subsection{Multiple-Component Constraints for the 15-Component LAW Glass Example}

The first MCC in Table 2.3 (Nalk) involves a normalized alkali-oxide expression

$$
g_{\mathrm{Nalk}}=g_{\mathrm{Na}_{2} \mathrm{O}}+0.66 g_{\mathrm{K}_{2} \mathrm{O}}+2 g_{\mathrm{Li}_{2} \mathrm{O}},
$$

where $g_{i}$ represents the mass fraction of the $i^{\text {th }}$ LAW glass component. Too small a value of $g_{\text {Nalk }}$ in a LAW glass is undesirable because it represents too low a waste loading to be of practical interest for the WTP. Too large a value is undesirable because it will have such poor Vapor Hydration Test (VHT) response (a measure of glass durability) that a numerical value cannot be measured. Table 2.3 lists the lower and upper bounds of the $g_{\text {Nalk }}$ MCCs for the outer and inner layers.

The second MCC in Table 2.3 involves $g_{\mathrm{ZrO}_{2}}+g_{\mathrm{SnO}_{2}}$, which includes the two components most effective at reducing the VHT response of the experimental glasses. Too small a value in a LAW glass is undesirable because the VHT response will become unmeasurable, while too large a value is undesirable because these components will not fully dissolve in the glass. Table 2.3 lists the lower and upper bounds of the $\mathrm{g}_{\mathrm{ZrO}_{2}}+g_{\mathrm{SnO}_{2}} \mathrm{MCCs}$ for the outer and inner layers.

The third MCC in Table 2.3 involves the viscosity of a LAW glass at $1150^{\circ} \mathrm{C}$, which is denoted $\eta_{1150}$. This MCC was implemented using the linear mixture model

$$
\begin{aligned}
\ln \left(\eta_{1150}\right)= & 19.4927\left(g_{\mathrm{Al}_{2} \mathrm{O}_{3}}\right)-8.7644\left(g_{\mathrm{B}_{2} \mathrm{O}_{3}}\right)-2.4344\left(g_{\mathrm{CaO}}\right)-5.8891\left(g_{\mathrm{Fe}_{2} \mathrm{O}_{3}}\right) \\
& -6.6993\left(g_{\mathrm{K}_{2} \mathrm{O}}\right)-35.8273\left(g_{\mathrm{Li}_{2} \mathrm{O}}\right)-4.7596\left(g_{\mathrm{MgO}}\right)-6.2100\left(g_{\mathrm{Na}_{2} \mathrm{O}}\right) \\
& +6.9686\left(g_{\mathrm{SiO}_{2}}\right)+4.2472\left(g_{\mathrm{SO}_{3}}\right)+32.8921\left(g_{\mathrm{SnO}_{2}}\right)+58.1746\left(g_{V_{2} \mathrm{O}_{5}}\right) \\
& -0.7173\left(g_{\mathrm{ZnO} \mathrm{O}}\right)+18.5684\left(g_{\mathrm{ZrO}_{2}}\right)-11.9363\left(g_{\text {Others }}\right)
\end{aligned}
$$

that was fitted to $\ln \left(\eta_{1150}\right)$ values for 281 LAW glasses from previous studies (see Appendix B). The model has $\mathrm{R}^{2}=0.984$, which is the fraction of variation in the dependent variable accounted for by the model. Using a linear mixture model allows the associated MCC to be linear, while the $\mathrm{R}^{2}$ value is large enough for the MCC based on the model to serve its purpose. Having $\eta_{1150}$ a little outside its outer-layer lower and upper limits for some test glasses as a result of model uncertainty is acceptable. Because the model in Equation (2) is for $\ln \left(\eta_{1150}\right)$, the natural logarithms of the lower and upper bounds on $\eta_{1150}$ in Table 2.3 were used in implementing the outer- and inner-layer constraints. Glasses with $\eta_{1150}$ outside the range of 10 to $100 \mathrm{P}$ cannot be efficiently processed in the WTP and therefore those values were used as the bounds for the 
outer layer. The target WTP operating viscosity is $50 \mathrm{P}$ at $1150^{\circ} \mathrm{C}$, so the inner-layer bounds were set to the target value $\pm 20 \mathrm{P}$. Finally, note that the $\ln \left(\eta_{1150}\right)$ model was subsequently modified slightly as documented in Appendix B, but the version in Equation (2) is the one that was used to specify the outer- and inner-layer MCCs on $\eta_{1150}$.

The fourth MCC in Table 2.3 ( $\mathrm{SO}_{3}$ Solubility) requires that the mass fraction of the $\mathrm{SO}_{3}$ component $\left(g_{\mathrm{SO}_{3}}\right)$ of every glass in the LAW glass composition region (and experimental design) be no greater than a model-predicted $\mathrm{SO}_{3}$ solubility limit. It is understood that model prediction uncertainty will cause some of the glasses to have a separated sulfate salt on the melt surface. However, this is useful information, and adjustments can be made for this separated salt by further analyses. The $\mathrm{SO}_{3}$ solubility limit for a given glass composition was predicted using the following model from Vienna et al. (2014):

$$
\begin{aligned}
S L_{\mathrm{SO}_{3}} & =-2.091901\left(x_{\mathrm{Al}_{2} \mathrm{O}_{3}}\right)+3.0440748\left(x_{\mathrm{B}_{2} \mathrm{O}_{3}}\right)+4.4422886\left(x_{\mathrm{CaO}}\right)-22.65353\left(x_{\mathrm{Cl}}\right) \\
& -13.14139\left(x_{\mathrm{Cr}_{2} \mathrm{O}_{3}}\right)+0.615785\left(x_{\mathrm{K}_{2} \mathrm{O}}\right)+2.4739255\left(x_{\mathrm{Li}_{2} \mathrm{O}}\right)+2.8972089\left(x_{\mathrm{Na}_{2} \mathrm{O}}\right) \\
& +4.606083\left(x_{\mathrm{P}_{2} \mathrm{O}_{5}}\right)+0.2407285\left(x_{\mathrm{SiO}_{2}}\right)-1.775325\left(x_{\mathrm{SnO}_{2}}\right)+7.5345478\left(x_{\mathrm{V}_{2} \mathrm{O}_{5}}\right) \\
& -1.871916\left(x_{\mathrm{ZrO}_{2}}\right)-0.280272\left(x_{\mathrm{Others}_{2}}\right)+260.20302\left(x_{\mathrm{Li}_{2} \mathrm{O}}\right)^{2}
\end{aligned}
$$

where $\mathrm{SL}_{\mathrm{SO}_{3}}$ denotes the predicted $\mathrm{SO}_{3}$ solubility limit in weight percent (wt\%) and $x_{i}$ denotes components in that mixture other than $\mathrm{SO}_{3}$. The $x_{i}$ can be expressed as the mass fraction of the $i^{\text {th }}$ component in the LAW glass relative to the total mass fraction of all other components:

$$
x_{i}=\frac{g_{i}}{\sum_{i \neq \mathrm{SO}_{3}} g_{i}}=\frac{g_{i}}{1-g_{\mathrm{SO}_{3}}}, \quad i \neq \mathrm{SO}_{3}
$$

where $g_{i}\left(i=\mathrm{Al}_{2} \mathrm{O}_{3}, \ldots\right.$, Others 1$)$ are the mass fractions of the $15 \mathrm{LAW}$ glass components listed in Table 2.1 (including $\mathrm{SO}_{3}$ ). Hence, the fourth $\mathrm{MCC}$ in Table 2.3 is expressed as

$$
g_{\mathrm{SO}_{3}} \leq \frac{S L_{\mathrm{SO}_{3}}}{100}
$$


Appendix C shows the derivation of the final form of the MCC after substituting Equations (3) and (4) into Equation (5) and rewriting the expression in terms of the mass fractions of the 15 components in Table 2.1 (see Appendix C). The final form of the nonlinear MCC can be written as

$$
\sum_{i=1}^{15} c_{i} g_{i}+b\left(\frac{g_{\mathrm{Li}_{2} \mathrm{O}}^{2}}{1-g_{\mathrm{SO}_{3}}}\right)+100\left(g_{\mathrm{SO}_{3}}^{2}\right) \geq 0
$$

where the $c_{i}(i=1,2, \ldots, 15)$ and $b$ are the coefficients listed in Equation (C.5) of Appendix C. It is seen in Equation (6) that the fourth MCC is not a linear function of the components listed in Table 2.1, because of having squared terms involving $g_{\mathrm{Li}_{2} \mathrm{O}}$ and $g_{\mathrm{SO}_{3}}$. 



\subsection{Modifying an Existing Algorithm to Account for a Nonlinear Multiple-Component Constraint}

The details of how the LD was constructed for the LAW glass example are discussed in the subsequent section. It is sufficient at this point to say that an optimal experimental design approach that used a point-exchange algorithm with a set of candidate points was used to construct the design (Atkinson et al. 2007). Existing commercial software packages can do this, but require that MCCs be written as linear combinations of the mixture components. Hence, existing software could not be used because of the two nonlinear (i.e., squared) terms in the fourth MCC, as seen in Equations (6) and (C.5).

To address this problem, the MCCVRT algorithm in the MIXSOFT software (Piepel 2014) was modified to calculate the vertices of the outer- and inner-layer mixture regions defined by the one nonlinear MCC and three linear MCCs in Table 2.3, as well as the SCCs in Table 2.1. The MCCVRT algorithm (which is based on the CONVRT algorithm discussed by Piepel 1988) starts with a mixture simplex and applies each SCC and linear MCC in turn. As each new constraint is applied (Step $i$ ), the vertices from Step $i-1$ that are eliminated by the new constraint are identified. For each eliminated vertex (denoted A), other vertices (denoted B) still satisfying the new constraint are found such that the A and B vertices form an edge of the constrained mixture experiment region at Step $i-1$. Then, the intersection of the new constraint in Step $i$ with each such edge is calculated. Hence, each eliminated vertex at Step $i$ has the opportunity to be "replaced" by one or more new vertices that satisfy all of the constraints applied up to Step $i$. At the end of Step $i$, all of the vertices for the constraints applied through that step are obtained. This process continues in the MCCVRT routine until all of the SCCs and linear MCCs have been processed. In the modified MCCVRT, the nonlinear MCC was treated as the last MCC.

The calculation to find the mixture for which the new constraint at Step $i$ intersects with an edge (as described above) is very simple when constraints (SCC or MCC) are linear combinations of the mixture components. However, the calculation is more complicated for a MCC of the form in Equations (6) and (A.5), since the nonlinear MCC is a nonlinear surface whereas a linear MCC is a hyperplane. The calculations would be still more complicated if there were more than one nonlinear MCC. However, the LAW glass example involves only one nonlinear MCC, so MCCVRT was modified to address that situation. To simplify matters, the nonlinear MCC in Equation (C.5) was applied as the last MCC, after applying all SCCs and all linear MCCs.

The formula for an edge connecting a vertex A outside the nonlinear MCC $\left[\mathbf{g}_{\mathbf{A}}=\left(g_{A 1}, g_{A 2}, \ldots, g_{A q}\right)\right]$ to a vertex B inside the nonlinear MCC $\left[\mathbf{g}_{\mathbf{B}}=\left(g_{B 1}, g_{B 2}, \ldots, g_{B q}\right)\right]$ is given by

$$
g_{i}=\alpha g_{A i}+(1-\alpha) g_{B i}=\alpha\left(g_{A i}-g_{B i}\right)+g_{B i} .
$$


The equation for the intersection between an edge expressed via Equation (7) and the nonlinear MCC represented by Equations (6) and (C.5) is derived in Appendix D, and is listed as Equation (D.4). The intersection for a given $\mathbf{g}_{\mathbf{A}}$ and $\mathbf{g}_{\mathbf{B}}$ (which determines a new vertex at Step $i$ ) is obtained by solving Equation (D.4) for the corresponding value of $\alpha$. Note that Equation (D.4) is a quadratic equation in $\alpha$ except for the last term associated with the $\left(\mathrm{Li}_{2} \mathrm{O}\right)^{2}$ term in the model for $S L_{\mathrm{SO}_{3}}$. Hence, $\alpha$ could not be solved for explicitly and it was necessary to use a "root finding" algorithm. After the solution $\alpha$ was obtained in this way for a given pair of $\mathbf{g}_{\mathrm{A}}$ and $\mathbf{g}_{\mathrm{B}}$, the values of $\alpha, \mathbf{g}_{\mathbf{A}}$, and $\mathbf{g}_{\mathbf{B}}$ were substituted into (7) to calculate the corresponding new vertex at Step $i$. 


\subsection{Constructing the Layered Design}

Considering the experimental budget and goals of the work, the coauthors (statisticians and materials scientists) concluded that the LD should consist of 18 outer-layer glasses, 13 innerlayer glasses, a glass of interest tested by the Vitreous State Laboratory (VSL) at the Catholic University of America, and one center glass. There were 147 existing glasses with experimental data for the glass properties of interest that fell within the LAW glass composition experimental region defined by the outer-layer SCCs in Table 2.1 and the MCCs in Table 2.3. Table E.1 in Appendix E lists the 147 LAW glass compositions in terms of the mass fractions of the 15 LAW glass components in Table 2.1. Table E.2 lists the names of the glasses, for which there was not room in Table E.1. It was decided to select the outer-layer and inner-layer glasses of the LD to augment the 147 existing glasses, because both the existing and new data will be used in the future to develop glass property-composition models. Finally, it was decided to replicate the VSL and center glasses. Typically, a few additional glasses would be replicated as well, but the set of existing glasses includes several replicates. Also, additional stages of the study in subsequent years will include replicates of the center point and other points. The steps used in generating the LD are described following.

Step 1, Select the 18 Outer-Layer Points: The modified MCCVRT routine was run to generate the 148,630 vertices on the outer layer of the LAW glass region defined by the SCCs, linear MCCs, and nonlinear MCC given in Tables 2.1 and 2.3. It is interesting that of these outer-layer vertices, $\sim 50 \%$ lie on the nonlinear $\mathrm{MCC}\left(\mathrm{SO}_{3}\right.$ solubility constraint) for the outer layer. Next, a point-exchange, optimal-design algorithm in the ACED software (Welch 1984, 1987) was run to augment the 147 existing glasses with 18 outer-layer points from the candidate set of 148,630 outer-layer vertices. A linear mixture experiment model

$$
E(y)=\sum_{i=1}^{15} \beta_{i} x_{i} \quad\left(i=\mathrm{Al}_{2} \mathrm{O}_{3}, \ldots, \text { Others } 1\right)
$$

was used as the basis for selecting the outer-layer (and subsequently the inner-layer) points, which has been found to work well when LDs are used. ACED was used to complete 20 "tries" of selecting 18 outer-layer points using each of the D-, G-, and I-optimality criteria (although Welch uses different abbreviations for these criteria), so that 60 sets of 18 outer-layer points were generated. All 60 sets of 18 outer-layer points were unique. Measures of D-, G-, I-, and A-efficiencies of the designs (147 existing plus 18 outer-layer points) included in the ACED output were assessed to identify four sets of 18 outer-layer points that had optimal or nearoptimal values of all four efficiencies. As a basis for choosing one of the four sets of 18 outer-layer points, the distributions of the values of the (i) 15 LAW glass components and (ii) predicted values of several properties (obtained using models developed during previous work) were assessed graphically. Such plots are illustrated subsequently in Step 2. The chosen set of 18 outer-layer glasses is listed in Table 5.1. 
Step 2, Select the 13 Inner-Layer Points: The modified MCCVRT routine was run to generate the 174,242 vertices on the inner layer of the LAW glass region defined by the SCCs, linear MCCs, and nonlinear MCC given in Tables 2.1 and 2.3. It is interesting that of these inner-layer vertices, $\sim 46 \%$ lie on the nonlinear $\mathrm{MCC}\left(\mathrm{SO}_{3}\right.$ solubility constraint) for the inner layer. Next, the ACED software (Welch 1984, 1987) was run to augment the 147 existing glasses plus 18 outer-layer points (selected in Step 1) with 13 inner-layer points from the candidate set of 174,242 inner-layer vertices. ACED was used to complete 20 "tries" of selecting 13 inner-layer points using each of the D-, G-, and I-optimality criteria, so that 60 sets of 13 inner-layer points were generated (although not all sets were unique). Measures of D-, G-, I-, and A-efficiencies of the designs (147 existing + 18 outer-layer +13 inner-layer points) included in the ACED output were assessed to identify four sets of 13 inner-layer points that had optimal or near-optimal values of all four efficiencies. As a basis for choosing one of the four sets of 13 inner-layer points, the distributions of the values of the (i) 15 LAW glass components and (ii) predicted values of several properties (obtained using models developed during previous work) were assessed graphically. Figure 5.1 illustrates these types of plots for $\mathrm{Na}_{2} \mathrm{O}$ (the major component of LAW) and a glass durability property (referred to as PCT-Li release). The y-axis (Index) is used to spread out the values for the four sets of glasses so they can be differentiated. Although not illustrated here, other plots were used to assess the distributions of components and predicted property values for the four sets of 13 inner-layer points relative to the distributions of the values for the existing $147 \mathrm{LAW}$ glasses, the 18 outer-layer glasses selected in Step 1, and the other two glasses listed in Table 5.1. The chosen set of 13 inner-layer glasses is listed in Table 5.1.
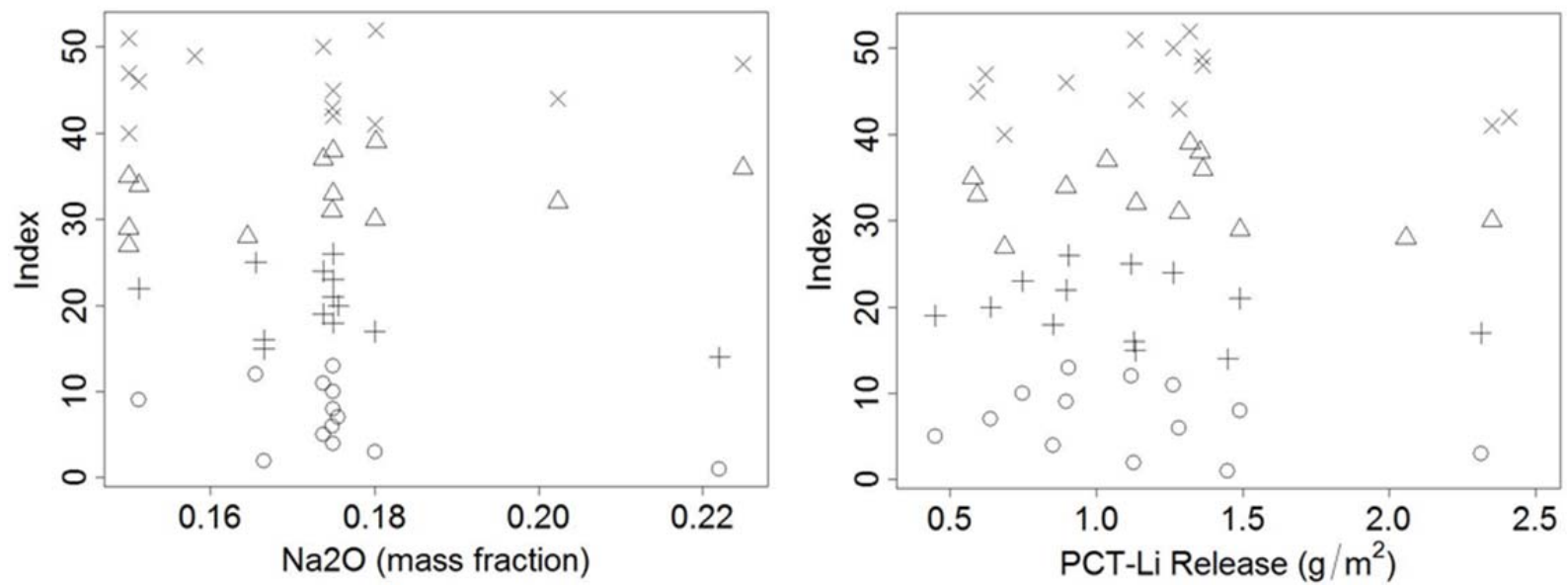

Figure 5.1. Distributions of Values for (a) $\mathrm{Na}_{2} \mathrm{O}$ and (b) PCT-Li Release for Four Possible Sets (the four plotting symbols) of the 13 Inner-Layer LAW Glass Compositions. The triangles represent the chosen set. 
Table 5.1. Compositions of the Layered Design for LAW Glasses

\begin{tabular}{|c|c|c|c|c|c|c|c|c|c|c|c|c|c|c|c|c|}
\hline \multicolumn{2}{|c|}{ LAW Glass } & \multicolumn{15}{|c|}{ Component } \\
\hline$\#$ & Point $^{(\mathrm{a})}$ & $\mathrm{Al}_{2} \mathbf{O}_{3}$ & $\mathbf{B}_{2} \mathbf{O}_{3}$ & $\mathrm{CaO}$ & $\mathrm{Fe}_{2} \mathrm{O}_{3}$ & $\mathbf{K}_{2} \mathbf{O}$ & $\mathbf{L i}_{2} \mathbf{O}$ & MgO & $\mathrm{Na}_{2} \mathrm{O}$ & $\mathrm{SiO}_{2}$ & $\mathrm{SO}_{3}$ & $\mathrm{SnO}_{2}$ & $\mathrm{~V}_{2} \mathrm{O}_{5}$ & $\mathrm{ZnO}$ & $\mathrm{ZrO}_{2}$ & Others1 \\
\hline 1 & OL-01 & 0.1240 & 0.1375 & 0.1224 & 0.0000 & 0.0150 & 0.0201 & 0.0350 & 0.1000 & 0.3400 & 0.0010 & 0.0000 & 0.0000 & 0.0100 & 0.0650 & 0.0300 \\
\hline 2 & OL-02 & 0.1385 & 0.0600 & 0.0004 & 0.0150 & 0.0150 & 0.0201 & 0.0350 & 0.1000 & 0.4700 & 0.0010 & 0.0000 & 0.0000 & 0.0500 & 0.0650 & 0.0300 \\
\hline 3 & OL-03 & 0.0350 & 0.0615 & 0.1224 & 0.0000 & 0.0150 & 0.0500 & 0.0350 & 0.1551 & 0.3400 & 0.0010 & 0.0000 & 0.0400 & 0.0500 & 0.0650 & 0.0300 \\
\hline 4 & OL-04 & 0.0350 & 0.0600 & 0.1224 & 0.0000 & 0.0150 & 0.0000 & 0.0350 & 0.2551 & 0.3925 & 0.0010 & 0.0300 & 0.0400 & 0.0100 & 0.0000 & 0.0040 \\
\hline 5 & OL-05 & 0.0350 & 0.1375 & 0.0165 & 0.0150 & 0.0000 & 0.0500 & 0.0000 & 0.1650 & 0.4700 & 0.0010 & 0.0300 & 0.0400 & 0.0100 & 0.0000 & 0.0300 \\
\hline 6 & OL-06 & 0.1385 & 0.0600 & 0.1224 & 0.0150 & 0.0000 & 0.0500 & 0.0000 & 0.1140 & 0.3400 & 0.0010 & 0.0500 & 0.0291 & 0.0500 & 0.0000 & 0.0300 \\
\hline 7 & OL-07 & 0.0350 & 0.0600 & 0.1117 & 0.0150 & 0.0000 & 0.0000 & 0.0350 & 0.1500 & 0.4700 & 0.0010 & 0.0500 & 0.0183 & 0.0500 & 0.0000 & 0.0040 \\
\hline 8 & OL-08 & 0.0350 & 0.1375 & 0.0298 & 0.0000 & 0.0150 & 0.0000 & 0.0000 & 0.1401 & 0.4700 & 0.0010 & 0.0000 & 0.0400 & 0.0500 & 0.0516 & 0.0300 \\
\hline 9 & OL-09 & & 0.1375 & 0.1224 & 0.0150 & 0.0150 & 0.0000 & 0.0000 & 0.1401 & 0.3400 & 0.0010 & 0.0450 & 0.0266 & 0.0500 & 0.0650 & 0.0074 \\
\hline 10 & OL-10 & 0.1385 & 0.0890 & 0.1224 & 0.0000 & 0.0000 & 0.0250 & 0.0350 & 0.1000 & 0.3400 & 0.0010 & 0.0441 & 0.0000 & 0.0100 & 0.0650 & 0.0300 \\
\hline 11 & OL-11 & 0.1385 & 0.1305 & 0.0000 & 0.0000 & 0.0000 & 0.0500 & 0.0350 & 0.1650 & 0.3400 & 0.0010 & 0.0500 & 0.0360 & 0.0500 & 0.0000 & 0.0040 \\
\hline 12 & OL-12 & 0.0350 & 0.1375 & 0.0000 & 0.0150 & 0.0150 & 0.0500 & 0.0350 & 0.1510 & 0.3400 & 0.0175 & 0.0450 & 0.0400 & 0.0500 & 0.0650 & 0.0040 \\
\hline 13 & OL-13 & & & 0.0000 & 0.0000 & & & 0.0350 & 0.1551 & 0.3425 & 0.0164 & 0.0300 & & 0.0100 & 0.0000 & 0.0300 \\
\hline 14 & OL-14 & 0.0350 & 0.0600 & 0.0189 & 0.0000 & 0.0000 & 0.0000 & 0.0350 & 0.2600 & 0.4700 & 0.0091 & 0.0320 & 0.0000 & 0.0500 & 0.0000 & 0.0300 \\
\hline 15 & OL-15 & 0.1195 & 0.0600 & 0.1000 & 0.0150 & 0.0150 & 0.0500 & 0.0000 & 0.1551 & 0.3400 & 0.0154 & 0.0500 & 0.0000 & 0.0500 & 0.0000 & 0.0300 \\
\hline 16 & OL-16 & 0.0350 & 0.0600 & 0.1224 & 0.0150 & 0.0000 & 0.0500 & 0.0350 & 0.1619 & 0.3400 & 0.0182 & 0.0450 & 0.0125 & 0.0100 & 0.0650 & 0.0300 \\
\hline 17 & OL-17 & 0.0350 & 0.0600 & 0.1224 & 0.0150 & 0.0150 & 0.0000 & 0.0000 & 0.1860 & 0.4417 & 0.0149 & 0.0300 & 0.0400 & 0.0100 & 0.0000 & 0.0300 \\
\hline 18 & OL-18 & 0.1344 & 0.1375 & 0.0030 & 0.0150 & 0.0150 & 0.0201 & 0.0350 & 0.1000 & 0.4700 & 0.0060 & 0.0500 & 0.0000 & 0.0100 & 0.0000 & 0.0040 \\
\hline 19 & IL-01 & 0.0625 & 0.0800 & 0.0900 & 0.0125 & 0.0020 & 0.0350 & 0.0250 & 0.1500 & 0.4315 & 0.0040 & 0.0350 & 0.0300 & 0.0200 & 0.0150 & 0.0075 \\
\hline 20 & IL-02 & 0.0625 & 0.1175 & 0.0275 & 0.0125 & 0.0100 & 0.0350 & 0.0050 & 0.1645 & 0.4325 & 0.0130 & 0.0350 & 0.0300 & 0.0200 & 0.0150 & 0.0200 \\
\hline 21 & IL-03 & 0.0625 & 0.1175 & 0.0275 & 0.0125 & 0.0020 & 0.0350 & 0.0250 & 0.1500 & 0.3975 & 0.0130 & 0.0350 & 0.0300 & 0.0400 & 0.0450 & 0.0075 \\
\hline 22 & IL-04 & 0.0625 & 0.1175 & 0.0275 & 0.0125 & 0.0020 & 0.0350 & 0.0250 & 0.1800 & 0.3675 & 0.0130 & 0.0350 & 0.0300 & 0.0400 & 0.0450 & 0.0075 \\
\hline 23 & IL-05 & 0.0625 & 0.1175 & 0.0275 & 0.0125 & 0.0020 & 0.0350 & 0.0250 & 0.1748 & 0.4242 & 0.0040 & 0.0100 & 0.0300 & 0.0200 & 0.0475 & 0.0075 \\
\hline 24 & IL-06 & 0.0625 & 0.0800 & 0.0900 & 0.0125 & 0.0100 & 0.0100 & 0.0250 & 0.2023 & 0.3872 & 0.0130 & 0.0350 & 0.0300 & 0.0200 & 0.0150 & 0.0075 \\
\hline
\end{tabular}


Table 5.1. Compositions of the Layered Design for LAW Glasses (contd)

\begin{tabular}{|c|c|c|c|c|c|c|c|c|c|c|c|c|c|c|c|c|}
\hline \multicolumn{2}{|c|}{ LAW Glass } & \multicolumn{15}{|c|}{ Components } \\
\hline$\#$ & Point ${ }^{(a)}$ & $\mathrm{Al}_{2} \mathbf{O}_{3}$ & $\mathbf{B}_{2} \mathbf{O}_{3}$ & $\mathrm{aO}$ & $\mathrm{Fe}_{2} \mathrm{O}_{3}$ & $\mathrm{~K}_{2} \mathrm{O}$ & $\mathbf{L i}_{2} \mathbf{O}$ & MgO & $\mathrm{Na}_{2} \mathrm{O}$ & $\mathrm{SiO}_{2}$ & $\mathrm{SO}_{3}$ & $\mathrm{SnO}_{2}$ & $\mathrm{~V}_{2} \mathrm{O}_{5}$ & $\mathrm{ZnO}$ & $\mathrm{ZrO}_{2}$ & Others1 \\
\hline 25 & IL-07 & 0.1150 & 0.0800 & 0900 & 0.0125 & 0.0100 & 0.0350 & 0.0050 & 0.1749 & 0.3741 & 0.0040 & 0.0270 & 0.0300 & 0200 & 0.0150 & 75 \\
\hline 26 & & & & 275 & & & 50 & 0 & & 325 & 13 & 350 & .0050 & 200 & 150 & 0. \\
\hline 21 & & & & 0.0353 & 0.0125 & 0.0020 & 0.0350 & 0.0250 & & 4325 & 0.0102 & 0.0350 & & 0.0400 & 0.0150 & \\
\hline 28 & IL-10 & & & & & & & 0 & & & & 50 & & & & \\
\hline 29 & IL-11 & 0625 & . & 0.0900 & 0.0125 & 0.0020 & 0.0100 & 0.0250 & 737 & 939 & 130 & 0.0350 & 0.0300 & 0.0200 & 150 & 200 \\
\hline 30 & IL-12 & 125 & 0.1022 & 0.0275 & 0.0125 & 0.0100 & 0.0 & 0.0050 & 749 & 675 & 0.0129 & 0.0350 & 0.0300 & 0.0400 & 0.0150 & 0.0200 \\
\hline 31 & IL-13 & 1150 & 0.0931 & 0.0275 & 0.0050 & 0.0020 & 0.0350 & 0.0250 & 0.1802 & 3675 & 0.0127 & 0.0320 & 0.0300 & 0.0400 & 0.0150 & 0.0200 \\
\hline 32 & Center & 0.0900 & 0.1000 & 0.0550 & 0.0100 & 0.0040 & 0.0200 & 0.0150 & 0.1900 & 0.3955 & 0.0070 & 0.0200 & 0.0200 & 0.0300 & 0.0300 & 0.0135 \\
\hline 33 & Other Lab & 0.1015 & 0.1204 & 0.0801 & 0.0100 & 0.0016 & 0.0000 & 0.0100 & 0.2098 & 0.3714 & 0.0106 & 0.0000 & 0.0100 & 0.0300 & 0.0300 & $0.0146^{(\mathrm{b})}$ \\
\hline 34 & Rep \#32 & 0.0900 & 0.1000 & 0.0550 & 0.0100 & 0.0040 & 0.0200 & 0.0150 & 0.1900 & 0.3955 & 0.0070 & 0.0200 & 0.0200 & 0.0300 & 0.0300 & 0.0135 \\
\hline 35 & Rep \#34 & 0.1015 & 0.1204 & 0.0801 & 0.0100 & 0.0016 & 0.0000 & 0.0100 & 0.2098 & 0.3714 & 0.0106 & 0.0000 & 0.0100 & 0.0300 & 0.0300 & $0.0146^{(\mathrm{b})}$ \\
\hline
\end{tabular}

(a) $\mathrm{OL}=$ outer layer, $\mathrm{IL}=$ inner layer

(b) This glass has a different number and mixture of Other components than Others1 shown in Table 2.2. 
Step 3, Select Other Design Points: As noted previously, the LD also contained a center-point glass composition, a glass tested at VSL, and a replicate of each of these two glasses. The center point was selected to be near the middle of both the outer- and inner-layer regions. The only exception was to select $g_{L_{2} O}=0.02$ even though the average points of the outer- and inner-layer regions have $g_{L_{2} O}=0.025$ and 0.0225 , respectively. The 0.02 concentration moved the center point closer to the median value for the experimental glasses used to determine the $\mathrm{Li}_{2} \mathrm{O}$ range and to the expected distribution of glasses from plant operation. The center-point and VSL glasses are listed in Table 5.1.

Figure 5.2 displays a scatterplot matrix of the 147 existing, 18 outer-layer, 13 inner-layer, center-point, and VSL glasses. This figure shows that the new glasses in the LD, along with the 147 existing glass compositions, cover reasonably well the boundary and interior of the constrained LAW glass composition region defined by the outer-layer SCCs and MCCs in Tables 2.1 and 2.3. The $\mathrm{Na}_{2} \mathrm{O}-\mathrm{SO}_{3}$ plot, and to a lesser extent the $\mathrm{SiO}_{2}-\mathrm{SO}_{3}$ plot, show no new glasses in the upper right portions of the plots, which occurs because of the $\mathrm{SO}_{3}$-solubility constraint. 


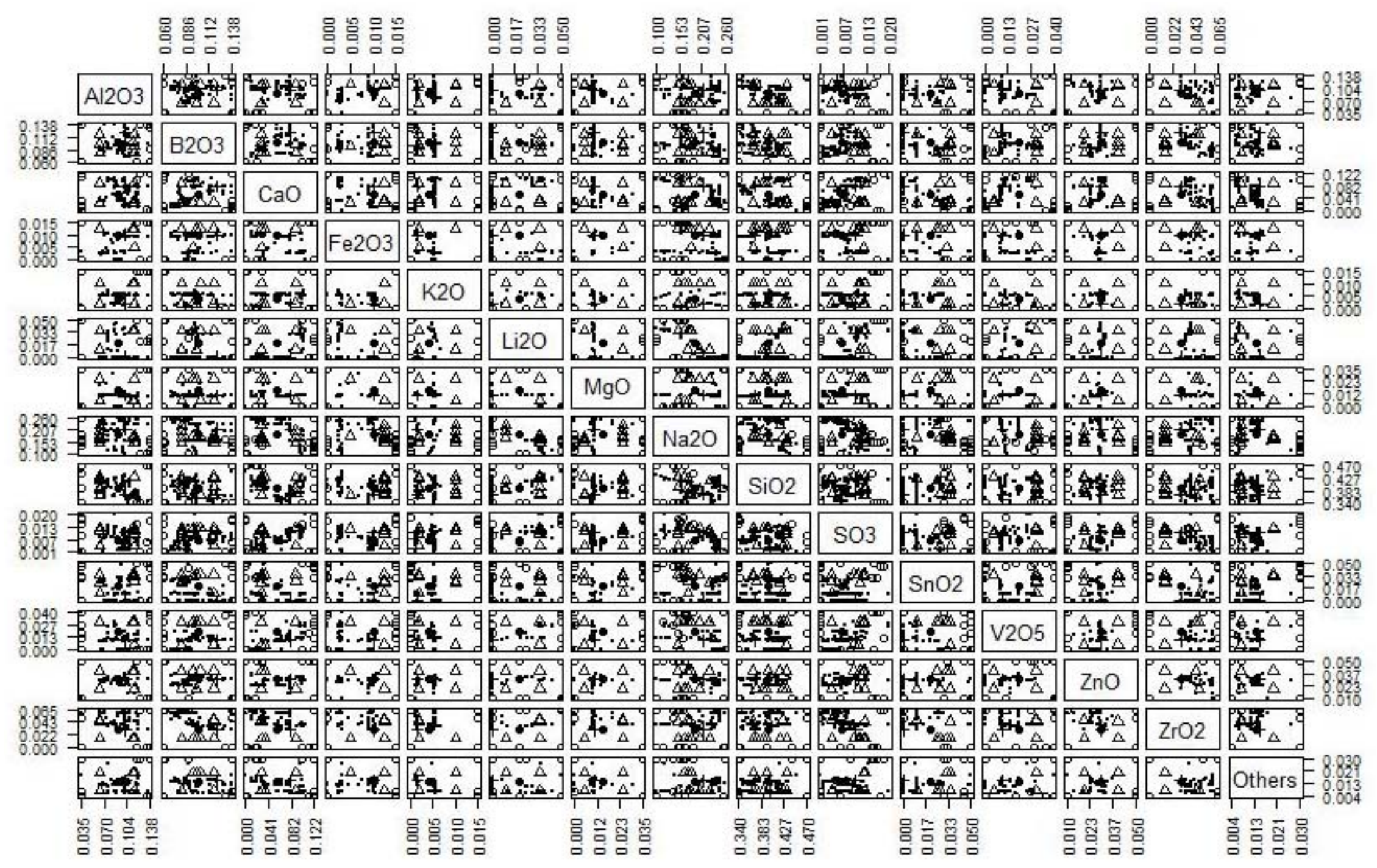

Figure 5.2. Scatterplot Matrix Display of How Well the Layered Design and Existing Glass Compositions Cover the LAW Glass Composition Region. The plotting symbols are "." for the 147 existing glasses, "•" for the centroid composition, "+" for the VSL glass, "०" for the 18 outer-layer glasses, and " $\Delta$ " for the 13 inner-layer glasses. 


\subsection{Summary and Discussion}

This report discusses the construction of a LD for a 15-component mixture experiment problem involving immobilizing LAW in glass. A LD was constructed to obtain glass compositions on a "bold" outer layer and "reasonable" inner layer. This approach was chosen to support developing glass property-composition models and ultimately identify the subregion of glasses containing as much LAW as possible that meets all requirements after accounting for model and other uncertainties. The outer and inner layers were specified using SCCs, linear MCCs, and one nonlinear MCC. Existing algorithms and software for designing experiments for a constrained region involving mixture components (and/or non-mixture variables) do not allow for nonlinear MCCs, so modifications were necessary.

To generate the LD, first the vertices of the outer and inner layers of the LAW glass experimental region were generated using a modified MCCVRT algorithm to account for the nonlinear MCC in addition to the SCCs and linear MCCs. Then, the ACED software (Welch 1984, 1987) was used to augment 147 existing glass compositions (in the outer-layer constrained region) with 18 outer-layer glasses and 13 inner-layer glasses. A center glass and a glass from another lab were also included in the experimental design. ACED was used to generate 20 possible sets of 18 outer-layer glasses, and subsequently 20 possible sets of 13 inner-layer glasses for each of three optimality criteria (D-, I-, and G-optimality). Efficiency values corresponding to these optimality criteria were considered simultaneously to select four of the possible 60 sets for each of 18 outer-layer and 13 inner-layer glasses. Then, graphical and analytical methods were used to compare the four sets of outer-layer glasses, and subsequently the four sets of inner-layer glasses, by assessing the distributions of values of the $15 \mathrm{LAW}$ glass components and several glass properties predicted using models available from previous studies. Glass scientists and statisticians collaborated to choose one of the four sets of 18 outer-layer glasses and one of the four sets of 13 inner-layer glasses for the final experimental design.

It is unfortunate that most commercial optimal-design software only generates a single experimental design at a time. Some software will generate different designs if the software is rerun additional times (because of different random starts). However, such software provides no easy way to compare the optimality statistics for the multiple resulting designs. We used the ACED software because it (i) can generate D-, I-, and G-optimal designs for as many "tries" as desired and (ii) outputs summary tables of several optimality statistics that provide for easily comparing optimality statistics over all the "tries." Over many years we have found it very useful to down-select many possible optimal or near-optimal mixture experiment designs to a small number (2 to 4 ), with statisticians and discipline scientists then comparing the small number of candidate designs in other ways to select the final design.

Finally, the question arises about what to do if there are two or more nonlinear SCCs or MCCs. Modifying the MCCVRT algorithm to account for that situation would require deriving much more complicated equations and more complicated computational methods to generate the vertices of a constrained region (e.g., outer layer or inner layer) involving mixture components 
(and/or non-mixture variables). Rather than doing that and using the point-exchange algorithm (Atkinson et al. 2007), it would be preferable to modify existing software to enable specifying one or more nonlinear SCCs and/or MCCs in addition to any linear SCCs and MCCs, and then use a coordinate-exchange algorithm (Meyer and Nachtsheim 1995; Piepel et al. 2005; Atkinson et al. 2007). Coordinate-exchange algorithms do not require first generating candidate points to construct an optimal experimental design. However, having nonlinear SCCs and/or MCCs will likely require modifications to existing coordinate-exchange algorithms. Such modifications may be less complicated than those required for the MCCVRT algorithm.

The LD approach to constructing an experimental design could still be used with a coordinate-exchange algorithm that accounts for nonlinear SCCs and/or MCCs. A space-filling design (SFD) or uniform design (UD) is an alternative to a LD that would include points throughout the constrained experimental region. However, existing algorithms for SFDs or UDs will likely need modifications to account for nonlinear SCCs and/or MCCs in addition to linear SCCs and MCCs. Also, depending on the specifics of a problem, algorithms for SFDs and UDs over irregular constrained regions can place most if not all design points on or near the boundary of the experimental region as the number of design variables increases. This can occur even with as few as five or six design variables (Borkowski and Piepel 2009). This is a larger problem than whether SCCs and MCCs are linear or nonlinear, and hence needs future research.

In conclusion, the approach proposed in this article is a good one when the experimental region is specified by one nonlinear MCC in addition to linear SCCs and MCCs and it is desired to have some points on the boundary of the region and some on the interior. We recommend using the described methods to down-select many possible optimal or near-optimal designs to a few, and then comparing the few designs to select the final design. Additional research is needed to address problems with two or more nonlinear SCCs and/or MCCs. 


\subsection{References}

Atkinson AC, AN Donev, and RD Tobias. 2007. Optimum Experimental Designs, with SAS. Oxford University Press, Oxford, U.K.

Borkowski JJ and GF Piepel. 2009. "Uniform Designs for Highly Constrained Mixture Experiments." Journal of Quality Technology, 41:35-47.

Cooley SK, GF Piepel, H Gan, WK Kot, and IL Pegg. 2003. "A Two-Stage Layered Mixture Experiment Design for a Nuclear Waste Glass Application (Parts 1 and 2)." 2003 Proceedings of the American Statistical Association, 1036-1051. American Statistical Association, Alexandria, Virginia.

Feng X, PR Hrma, JH Westsik, NR Brown, MJ Schweiger, H Li, JD Vienna, G Chen, GF Piepel, DE Smith, BP McGrail, SE Palmer, DS Kim, Y Peng, WK Hahn, AJ Bakel, WL Ebert, DK Peeler, and C Chang. 1996. Glass Optimization for Vitrification of Hanford Site Low-Level Tank Waste. PNNL-10918, Pacific Northwest National Laboratory, Richland, Washington.

Meyer RK and CJ Nachtsheim. 1995. "The Coordinate-Exchange Algorithm for Constructing Exact Optimal Experimental Designs.” Technometrics, 37:60-69.

Muller IS and IL Pegg. 2003a. Baseline LAW Glass Formulation Testing. VSL-03R3460-1 (ORP-55237), Vitreous State Laboratory, The Catholic University of America, Washington, D.C.

Muller IS and IL Pegg. 2003b. LAW Glass Formulation to Support Melter Runs with Simulants. VSL-03R3460-2 (ORP-58837), Vitreous State Laboratory, The Catholic University of America, Washington, D.C.

Muller IS, I Joseph, and IL Pegg. 2005. Comparison of LAW Simulant, Actual Waste, and Melter Glasses. VSL-05R5460-1 (ORP-58839), Vitreous State Laboratory, The Catholic University of America, Washington, D.C.

Muller IS, WK Kot, HK Pasieka, K Gilbo, FC Perez-Cardenas, I Joseph, and IL Pegg. 2012. Compilation and Management of ORP Glass Formulation Database. VSL-12R2470-1 (ORP-53934), Vitreous State Laboratory, The Catholic University of America, Washington, D.C.

Piepel GF. 1988. "Programs for Generating Extreme Vertices and Centroids of Linearly Constrained Experimental Regions.” Journal of Quality Technology, 20:125-139.

Piepel GF, CM Anderson, and PE Redgate. 1993. "Response Surface Designs for Irregularly-Shaped Regions (Parts 1, 2, and 3)." 1993 Proceedings of the Section on Physical and Engineering Sciences, 205-227, American Statistical Association, Alexandria, Virginia.

Piepel GF, SK Cooley, and B Jones. 2005. "Construction of a 21-Component Layered Mixture Experiment Design using a New Mixture Coordinate-Exchange Algorithm.” Quality Engineering, 17:579-594. 
Piepel GF, SK Cooley, IS Muller, H Gan, I Joseph, and IL Pegg. 2007. ILAW PCT, VHT, Viscosity and Electrical Conductivity Model Development. VSL-07R1230-1 (ORP-56502), Vitreous State Laboratory, The Catholic University of America, Washington D.C.

Piepel GF. 2014. MIXSOFT TM Software for the Design and Analysis of Mixture and Other Constrained Region Experiments, User's Guide, Version 2.4.2, MIXSOFT-Mixture Experiment Software, Richland, Washington.

Rielley E, IS Muller, and IL Pegg. 2004. Preparation and Testing of LAW Matrix Glasses to Support WTP Property-Composition Model Development. VSL-04R4480-1 (ORP-58838), Vitreous State Laboratory, The Catholic University of America, Washington, D.C.

Vienna JD, D-S Kim, I Muller, GF Piepel, and A Kruger. 2014. "Toward Understanding the Effect of Low-Activity Waste Glass Composition on Sulfur Solubility." Journal of the American Ceramic Society, 97:3135-3142.

Welch WJ. 1984. "Computer-aided Design of Experiments for Response Estimation." Technometrics, 26:217-224.

Welch WJ. 1987. ACED, Algorithms for the Construction of Experimental Designs, Users Guide Version 1.6.1, University of Waterloo, Waterloo, Ontario, Canada. 


\section{Appendix A}

\section{Development of the Single-Component Constraints}





\section{Appendix A}

\section{Development of the Single-Component Constraints}

This appendix describes the processes used to select the single-component constraints (SCCs) for the outer and inner layers of the low-activity waste (LAW) glass composition experimental region used to construct a layered design.

A set of experiments was performed to determine the maximum waste loading of a series of representative LAW compositions in borosilicate glasses while still meeting a set of minimum property requirements (Muller et al. 2012). The data from the experimental program were analyzed to determine the key variables that limit waste loading. The key variables were the alkali content of the waste $\left(w_{A L K}=w_{\mathrm{Na}_{2} \mathrm{O}}+0.66 w_{\mathrm{K}_{2} \mathrm{O}}\right)$ and the sulfur trioxide concentration $\left(w_{\mathrm{SO}_{3}}\right)$, where $w_{i}$ represents the mass fraction of the $i^{\text {th }}$ oxide (or oxide group) in the waste. The initial set of SCC bounds was based on the ranges of component concentrations from the experimental glasses used to define the maximum waste loading as a function of $w_{A L K}$ and $w_{S_{3}}$ including glasses that (i) met all property requirements and (ii) failed one or more requirements.

A few changes were made to the preliminary outer-layer SCCs based on the experimental results and revisions to the Hanford Tank Waste Treatment and Immobilization Plant (WTP) operating strategy. ${ }^{(a)}$ Fourteen percent of the experimental glasses contained $g_{\mathrm{Fe}_{2} \mathrm{O}_{3}}>0.015$, but the WTP no longer plans to add $\mathrm{Fe}_{2} \mathrm{O}_{3}$ as a glass former. Hence, the $g_{\mathrm{Fe}_{2} \mathrm{O}_{3}}$ limits of 0 to 0.015 were selected to span the range of $\mathrm{Fe}_{2} \mathrm{O}_{3}$ that may come from waste. High $\mathrm{K}_{2} \mathrm{O}$ concentration glasses were investigated $\left(0.015<g_{K_{2} O}<0.0575\right)$ but less than $5 \%$ of the waste will generate glasses with $\mathrm{K}_{2} \mathrm{O}$ concentrations that high. Further, such waste is currently planned to be processed by the WTP in the first year of operation. Hence, the $g_{K_{2} O}$ limits of 0 to 0.015 were used. All glasses tested with $g_{\mathrm{MgO}}>0.035$ and $g_{\mathrm{Na}_{2} \mathrm{O}}>0.15$ failed to meet an important glass durability constraint (Vapor Hydration Test response). Because $\mathrm{MgO}$ is a controllable additive, it can be limited to a maximum of 0.035 . Less than $5 \%$ of the test glasses contained $g_{\mathrm{Na}_{2} \mathrm{O}}>$ 0.10 and concentrations that high are sufficiently far from the glasses of interest at Hanford that they need not be considered. Hence, a limit of $g_{\mathrm{Na}_{2} \mathrm{O}} \leq 0.10$ was set. Fourteen percent of the experimental glasses contained $\mathrm{TiO}_{2}$, but WTP no longer plans to add $\mathrm{TiO}_{2}$ as an additive and it is not in $\mathrm{LAW}$ in measureable concentrations. Hence, $\mathrm{TiO}_{2}$ was not included as a component to be varied in the experimental design. The outer-layer SCCs after these changes are listed in Table 2.1.

\footnotetext{
(a) In the discussion that follows, $g_{i}$ represents the mass fraction of the $i^{\text {th }}$ LAW glass component.
} 
The lower and upper bounds for the inner-layer SCCs were taken to be in the middle of the ranges between the center point and the lower and upper bounds for the outer-layer SCCs (with rounding of mass fractions to 0.0025 for minor components and 0.005 for major components). 


\section{Appendix B}

Data and Linear Mixture Model for Viscosity at $1150^{\circ} \mathrm{C}$ of Low-Activity Waste Glasses 



\section{Appendix B}

\section{Data and Linear Mixture Model for Viscosity at $1150^{\circ} \mathrm{C}$ of Low-Activity Waste Glasses}

Section B.1 discusses the glass compositions and viscosity property data used to develop a linear mixture model for viscosity at $1150^{\circ} \mathrm{C}$. Section B.2 presents an updated linear mixture model for viscosity at $1150^{\circ} \mathrm{C}$ that was developed subsequent to the generation of the experimental design discussed in this report.

\section{B.1 Data Used to Develop the Linear Mixture Model for Viscosity at $1150^{\circ} \mathrm{C}$ of Low-Activity Waste Glasses}

Table B.1 lists for each of the 281 glasses used to develop the viscosity model the (i) names of the glasses, (ii) the names of the studies in which the glasses were tested, and (iii) references for the studies. Table B.2 lists the oxide compositions of the glasses. Table B.3 lists the viscosity at $1150^{\circ} \mathrm{C}$ values as well as the first seven (when that many exist) temperatureviscosity pairs $\left(T_{i}, \eta_{i}, i=1,2, \ldots, 7\right)$ obtained from experimentally measuring viscosity at various temperatures. Table B.4 lists the remaining temperature-viscosity pairs $\left(T_{i}, \eta_{i}, i=8,9,10,11\right)$ when that many pairs exist.

The viscosity at $1150^{\circ} \mathrm{C}$ value $\left(\eta_{150}\right)$ for each of the $281 \mathrm{LAW}$ glasses was obtained as follows. First, all of the $\left(T_{i}, \eta_{i}\right)$ pairs for the $i^{\text {th }}$ glass $(i=1,2, \ldots, 281)$ were used to fit the Vogel-Fulcher-Tammann equation

$$
\log (\eta)=A+\frac{B}{T-T_{0}}
$$

where $T$ is temperature in $\mathrm{K}$, and $A, B$, and $T_{0}$ are the fitted coefficients using ordinary least squares regression. Then, $T=1423.15 \mathrm{~K}$ corresponding to $1150^{\circ} \mathrm{C}$ was substituted into each fitted equation to calculate the $\log \left(\eta_{1150}\right)$ and hence $\eta_{1150}$ values for each LAW glass.

\section{B.2 Updated Linear Mixture Model for Viscosity at $1150^{\circ} \mathrm{C}$ of Low-Activity Waste Glasses}

Subsequent to the use of the linear mixture model for viscosity of low-activity waste glasses at $1150^{\circ} \mathrm{C}$ listed in Equation (2) to develop the experimental design, a minor error in the model fitting process was found and corrected. The revised coefficients 


$$
\begin{aligned}
\ln \left(\eta_{1150}\right)= & 19.4941\left(g_{\mathrm{Al}_{2} \mathrm{O}_{3}}\right)-8.7662\left(g_{\mathrm{B}_{2} \mathrm{O}_{3}}\right)-2.4337\left(g_{\mathrm{CaO}}\right)-5.8848\left(g_{\mathrm{Fe}_{2} \mathrm{O}_{3}}\right) \\
& -6.6987\left(g_{\mathrm{K}_{2} \mathrm{O}}\right)-35.8198\left(g_{\mathrm{Li}_{2} \mathrm{O}}\right)-4.7447\left(g_{\mathrm{MgO}}\right)-6.2078\left(g_{\mathrm{Na}_{2} \mathrm{O}}\right) \\
& +6.9677\left(g_{\mathrm{SiO}_{2}}\right)+4.2701\left(g_{\mathrm{SO}_{3}}\right)+32.8907\left(g_{\mathrm{SnO}_{2}}\right)+58.1617\left(g_{\mathrm{V}_{2} \mathrm{O}_{5}}\right) \\
& -0.7274\left(g_{\mathrm{ZnO}}\right)+18.5704\left(g_{\mathrm{ZrO}_{2}}\right)-11.9474\left(g_{\text {Others } 1}\right)
\end{aligned}
$$

are only slightly different from the coefficients of the model in Equation (2). The above model has $\mathrm{R}^{2}=0.984$. Predictions of $\eta_{1150}$ for the glass compositions in the experimental design in Table 5.1 were compared using both Equations (2) and (B.2), and the largest relative difference was a very small fraction of a percent. Hence, it was concluded there was no substantive impact from using Equation (2) to implement the multiple-component constraints on $\eta_{1150}$ compared to using Equation (B.2). 
Table B.1. Glass Names, Study Names, and References for the 281 Glasses Used to Develop a Model for Viscosity at $1150^{\circ} \mathrm{C}$

\begin{tabular}{|c|c|c|c|}
\hline Row \# & Glass Name & Glass Study & Reference \\
\hline 1 & LAWA171 & ORP Advanced Glass Formulation & Muller et al. 2012 \\
\hline 2 & LAWA172 & ORP Advanced Glass Formulation & Muller et al. 2012 \\
\hline 3 & LAWA173 & ORP Advanced Glass Formulation & Muller et al. 2012 \\
\hline 4 & LAWA174 & ORP Advanced Glass Formulation & Muller et al. 2012 \\
\hline 5 & LAWA175 & ORP Advanced Glass Formulation & Muller et al. 2012 \\
\hline 6 & LAWA176 & ORP Advanced Glass Formulation & Muller et al. 2012 \\
\hline 7 & LAWA179 & ORP Advanced Glass Formulation & Muller et al. 2012 \\
\hline 8 & LAWA180 & ORP Advanced Glass Formulation & Muller et al. 2012 \\
\hline 9 & LAWA183 & ORP Advanced Glass Formulation & Muller et al. 2012 \\
\hline 10 & LAWA184 & ORP Advanced Glass Formulation & Muller et al. 2012 \\
\hline 11 & LAWA185 & ORP Advanced Glass Formulation & Muller et al. 2012 \\
\hline 12 & LAWA186 & ORP Advanced Glass Formulation & Muller et al. 2012 \\
\hline 13 & LAWA187 & ORP Advanced Glass Formulation & Muller et al. 2012 \\
\hline 14 & LAWA188 & ORP Advanced Glass Formulation & Muller et al. 2012 \\
\hline 15 & LAWA189 & ORP Advanced Glass Formulation & Muller et al. 2012 \\
\hline 16 & LAWA190 & ORP Advanced Glass Formulation & Muller et al. 2012 \\
\hline 17 & LAWA191 & ORP Advanced Glass Formulation & Muller et al. 2012 \\
\hline 18 & LAWA192 & ORP Advanced Glass Formulation & Muller et al. 2012 \\
\hline 19 & LAWA193 & ORP Advanced Glass Formulation & Muller et al. 2012 \\
\hline 20 & LAWA194 & ORP Advanced Glass Formulation & Muller et al. 2012 \\
\hline 21 & LAWA195 & ORP Advanced Glass Formulation & Muller et al. 2012 \\
\hline 22 & LAWA196 & ORP Advanced Glass Formulation & Muller et al. 2012 \\
\hline 23 & LAWA197 & ORP Advanced Glass Formulation & Muller et al. 2012 \\
\hline 24 & LAWB100 & ORP Advanced Glass Formulation & Muller et al. 2012 \\
\hline 25 & LAWB101 & ORP Advanced Glass Formulation & Muller et al. 2012 \\
\hline 26 & LAWB102 & ORP Advanced Glass Formulation & Muller et al. 2012 \\
\hline 27 & LAWB103 & ORP Advanced Glass Formulation & Muller et al. 2012 \\
\hline 28 & LAWB105 & ORP Advanced Glass Formulation & Muller et al. 2012 \\
\hline 29 & LAWB97 & ORP Advanced Glass Formulation & Muller et al. 2012 \\
\hline 30 & LAWB98 & ORP Advanced Glass Formulation & Muller et al. 2012 \\
\hline 31 & LAWB99 & ORP Advanced Glass Formulation & Muller et al. 2012 \\
\hline 32 & LAWC100R1 & ORP Advanced Glass Formulation & Muller et al. 2012 \\
\hline 33 & LAWC101 & ORP Advanced Glass Formulation & Muller et al. 2012 \\
\hline 34 & LAWC102 & ORP Advanced Glass Formulation & Muller et al. 2012 \\
\hline 35 & LAWC103 & ORP Advanced Glass Formulation & Muller et al. 2012 \\
\hline 36 & ORPLA1 & ORP Advanced Glass Formulation & Muller et al. 2012 \\
\hline 37 & ORPLA2 & ORP Advanced Glass Formulation & Muller et al. 2012 \\
\hline
\end{tabular}


Table B.1. Glass Names, Study Names, and References for the 281 Glasses Used to Develop a Model for Viscosity at $1150^{\circ} \mathrm{C}$ (contd)

\begin{tabular}{|c|c|c|c|}
\hline Row \# & Glass Name & Glass Study & Reference \\
\hline 38 & ORPLA3 & ORP Advanced Glass Formulation & Muller et al. 2012 \\
\hline 39 & ORPLA5 & ORP Advanced Glass Formulation & Muller et al. 2012 \\
\hline 40 & ORPLA6 & ORP Advanced Glass Formulation & Muller et al. 2012 \\
\hline 41 & ORPLA7 & ORP Advanced Glass Formulation & Muller et al. 2012 \\
\hline 42 & ORPLA9 & ORP Advanced Glass Formulation & Muller et al. 2012 \\
\hline 43 & ORPLA10 & ORP Advanced Glass Formulation & Muller et al. 2012 \\
\hline 44 & ORPLA11 & ORP Advanced Glass Formulation & Muller et al. 2012 \\
\hline 45 & ORPLA12 & ORP Advanced Glass Formulation & Muller et al. 2012 \\
\hline 46 & ORPLA13 & ORP Advanced Glass Formulation & Muller et al. 2012 \\
\hline 47 & ORPLA14 & ORP Advanced Glass Formulation & Muller et al. 2012 \\
\hline 48 & ORPLA15 & ORP Advanced Glass Formulation & Muller et al. 2012 \\
\hline 49 & ORPLA16 & ORP Advanced Glass Formulation & Muller et al. 2012 \\
\hline 50 & ORPLA17 & ORP Advanced Glass Formulation & Muller et al. 2012 \\
\hline 51 & ORPLA18 & ORP Advanced Glass Formulation & Muller et al. 2012 \\
\hline 52 & ORPLA19 & ORP Advanced Glass Formulation & Muller et al. 2012 \\
\hline 53 & ORPLA20 & ORP Advanced Glass Formulation & Muller et al. 2012 \\
\hline 54 & ORPLA33-1 & ORP Advanced Glass Formulation & Muller et al. 2012 \\
\hline 55 & ORPLA38-1 & ORP Advanced Glass Formulation & Muller et al. 2012 \\
\hline 56 & ORPLB1 & ORP Advanced Glass Formulation & Muller et al. 2012 \\
\hline 57 & ORPLB2 & ORP Advanced Glass Formulation & Muller et al. 2012 \\
\hline 58 & ORPLB3 & ORP Advanced Glass Formulation & Muller et al. 2012 \\
\hline 59 & ORPLB4 & ORP Advanced Glass Formulation & Muller et al. 2012 \\
\hline 60 & ORPLC2 & ORP Advanced Glass Formulation & Muller et al. 2012 \\
\hline 61 & ORPLC5 & ORP Advanced Glass Formulation & Muller et al. 2012 \\
\hline 62 & ORPLD1 & ORP Advanced Glass Formulation & Muller et al. 2012 \\
\hline 63 & ORPLD4 & ORP Advanced Glass Formulation & Muller et al. 2012 \\
\hline 64 & ORPLD5 & ORP Advanced Glass Formulation & Muller et al. 2012 \\
\hline 65 & ORPLD6 & ORP Advanced Glass Formulation & Muller et al. 2012 \\
\hline 66 & ORPLD7 & ORP Advanced Glass Formulation & Muller et al. 2012 \\
\hline 67 & ORPLD8 & ORP Advanced Glass Formulation & Muller et al. 2012 \\
\hline 68 & ORPLD9 & ORP Advanced Glass Formulation & Muller et al. 2012 \\
\hline 69 & ORPLE1 & ORP Advanced Glass Formulation & Muller et al. 2012 \\
\hline 70 & ORPLE2 & ORP Advanced Glass Formulation & Muller et al. 2012 \\
\hline 71 & ORPLE3 & ORP Advanced Glass Formulation & Muller et al. 2012 \\
\hline 72 & ORPLE4 & ORP Advanced Glass Formulation & Muller et al. 2012 \\
\hline 73 & ORPLE5 & ORP Advanced Glass Formulation & Muller et al. 2012 \\
\hline 74 & ORPLE6 & ORP Advanced Glass Formulation & Muller et al. 2012 \\
\hline 75 & ORPLE7 & ORP Advanced Glass Formulation & Muller et al. 2012 \\
\hline 76 & ORPLE8 & ORP Advanced Glass Formulation & Muller et al. 2012 \\
\hline 77 & ORPLE9 & ORP Advanced Glass Formulation & Muller et al. 2012 \\
\hline 78 & ORPLE10 & ORP Advanced Glass Formulation & Muller et al. 2012 \\
\hline
\end{tabular}


Table B.1. Glass Names, Study Names, and References for the 281 Glasses Used to Develop a Model for Viscosity at $1150^{\circ} \mathrm{C}$ (contd)

\begin{tabular}{|c|c|c|c|}
\hline Row \# & Glass Name & Glass Study & Reference \\
\hline 79 & ORPLE11 & ORP Advanced Glass Formulation & Muller et al. 2012 \\
\hline 80 & ORPLE12 & ORP Advanced Glass Formulation & Muller et al. 2012 \\
\hline 81 & ORPLF1 & ORP Advanced Glass Formulation & Muller et al. 2012 \\
\hline 82 & ORPLF2 & ORP Advanced Glass Formulation & Muller et al. 2012 \\
\hline 83 & ORPLF3 & ORP Advanced Glass Formulation & Muller et al. 2012 \\
\hline 84 & ORPLF4 & ORP Advanced Glass Formulation & Muller et al. 2012 \\
\hline 85 & ORPLF7 & ORP Advanced Glass Formulation & Muller et al. 2012 \\
\hline 86 & ORPLF9 & ORP Advanced Glass Formulation & Muller et al. 2012 \\
\hline 87 & ORPLF10 & ORP Advanced Glass Formulation & Muller et al. 2012 \\
\hline 88 & ORPLF13 & ORP Advanced Glass Formulation & Muller et al. 2012 \\
\hline 89 & ORPLF14 & ORP Advanced Glass Formulation & Muller et al. 2012 \\
\hline 90 & WVY-G-95A-1 & ORP Advanced Glass Formulation & Muller et al. 2012 \\
\hline 91 & L4-615 & Hanford LLW Glass Formulation & Feng et al. 1996 \\
\hline 92 & L4-96 & Hanford LLW Glass Formulation & Feng et al. 1996 \\
\hline 93 & L4-912 & Hanford LLW Glass Formulation & Feng et al. 1996 \\
\hline 94 & L4-129 & Hanford LLW Glass Formulation & Feng et al. 1996 \\
\hline 95 & L4-1215 & Hanford LLW Glass Formulation & Feng et al. 1996 \\
\hline 96 & L5-96 & Hanford LLW Glass Formulation & Feng et al. 1996 \\
\hline 97 & L5-129 & Hanford LLW Glass Formulation & Feng et al. 1996 \\
\hline 98 & L5-1215 & Hanford LLW Glass Formulation & Feng et al. 1996 \\
\hline 99 & L6-3312 & Hanford LLW Glass Formulation & Feng et al. 1996 \\
\hline 100 & L6-546 & Hanford LLW Glass Formulation & Feng et al. 1996 \\
\hline 101 & L6-549 & Hanford LLW Glass Formulation & Feng et al. 1996 \\
\hline 102 & L6-5412 & Hanford LLW Glass Formulation & Feng et al. 1996 \\
\hline 103 & L6-5415 & Hanford LLW Glass Formulation & Feng et al. 1996 \\
\hline 104 & L6-669 & Hanford LLW Glass Formulation & Feng et al. 1996 \\
\hline 105 & L6-6612 & Hanford LLW Glass Formulation & Feng et al. 1996 \\
\hline 106 & L7-15 & Hanford LLW Glass Formulation & Feng et al. 1996 \\
\hline 107 & L 7-25 & Hanford LLW Glass Formulation & Feng et al. 1996 \\
\hline 108 & L7-35 & Hanford LLW Glass Formulation & Feng et al. 1996 \\
\hline 109 & L8-1 & Hanford LLW Glass Formulation & Feng et al. 1996 \\
\hline 110 & L8-2 & Hanford LLW Glass Formulation & Feng et al. 1996 \\
\hline 111 & L8-3 & Hanford LLW Glass Formulation & Feng et al. 1996 \\
\hline 112 & L8-4 & Hanford LLW Glass Formulation & Feng et al. 1996 \\
\hline 113 & L8-5 & Hanford LLW Glass Formulation & Feng et al. 1996 \\
\hline 114 & L8-6 & Hanford LLW Glass Formulation & Feng et al. 1996 \\
\hline 115 & L8-7 & Hanford LLW Glass Formulation & Feng et al. 1996 \\
\hline 116 & L8-8 & Hanford LLW Glass Formulation & Feng et al. 1996 \\
\hline 117 & LD4-912 & Hanford LLW Glass Formulation & Feng et al. 1996 \\
\hline 118 & LD5-912 & Hanford LLW Glass Formulation & Feng et al. 1996 \\
\hline 119 & LD6-5314 & Hanford LLW Glass Formulation & Feng et al. 1996 \\
\hline
\end{tabular}


Table B.1. Glass Names, Study Names, and References for the 281 Glasses Used to Develop a Model for Viscosity at $1150^{\circ} \mathrm{C}$ (contd)

\begin{tabular}{|c|c|c|c|}
\hline Row \# & Glass Name & Glass Study & Reference \\
\hline 120 & LD6-5412 & Hanford LLW Glass Formulation & Feng et al. 1996 \\
\hline 121 & LD6-5510 & Hanford LLW Glass Formulation & Feng et al. 1996 \\
\hline 122 & LDM-912 & Hanford LLW Glass Formulation & Feng et al. 1996 \\
\hline 123 & LDM-1 & Hanford LLW Glass Formulation & Feng et al. 1996 \\
\hline 124 & LDM-2 & Hanford LLW Glass Formulation & Feng et al. 1996 \\
\hline 125 & LDM-3 & Hanford LLW Glass Formulation & Feng et al. 1996 \\
\hline 126 & LDM-4 & Hanford LLW Glass Formulation & Feng et al. 1996 \\
\hline 127 & LDM-5412 & Hanford LLW Glass Formulation & Feng et al. 1996 \\
\hline 128 & LDMS-1 & Hanford LLW Glass Formulation & Feng et al. 1996 \\
\hline 129 & LRM-912 & Hanford LLW Glass Formulation & Feng et al. 1996 \\
\hline 130 & LRM-1 & Hanford LLW Glass Formulation & Feng et al. 1996 \\
\hline 131 & LRM-2 & Hanford LLW Glass Formulation & Feng et al. 1996 \\
\hline 132 & LRM-3 & Hanford LLW Glass Formulation & Feng et al. 1996 \\
\hline 133 & LRM-4 & Hanford LLW Glass Formulation & Feng et al. 1996 \\
\hline 134 & LRM-5412 & Hanford LLW Glass Formulation & Feng et al. 1996 \\
\hline 135 & LRMS-1 & Hanford LLW Glass Formulation & Feng et al. 1996 \\
\hline 136 & SSHTM-3 & Hanford LLW Glass Formulation & Feng et al. 1996 \\
\hline 137 & Duratek & Hanford LLW Glass Formulation & Feng et al. 1996 \\
\hline 138 & PEI & Hanford LLW Glass Formulation & Feng et al. 1996 \\
\hline 139 & Vectra & Hanford LLW Glass Formulation & Feng et al. 1996 \\
\hline 140 & WSTC & Hanford LLW Glass Formulation & Feng et al. 1996 \\
\hline 141 & LAWB61 & WTP LAW & Muller and Pegg 2003a \\
\hline 142 & LAWB87 & WTP LAW & Muller and Pegg 2003a \\
\hline 143 & LAWB93R1 & WTP LAW & Muller and Pegg 2003a \\
\hline 144 & LAWC31R1 & WTP LAW & Muller and Pegg 2003a \\
\hline 145 & A1C1-1 & WTP LAW & Muller and Pegg 2003b \\
\hline 146 & A1C1-2 & WTP LAW & Muller and Pegg 2003b \\
\hline 147 & A2B1-1 & WTP LAW & Muller and Pegg 2003b \\
\hline 148 & A2B1-2 & WTP LAW & Muller and Pegg 2003b \\
\hline 149 & A2B1-3 & WTP LAW & Muller and Pegg 2003b \\
\hline 150 & A3C2-1 & WTP LAW & Muller and Pegg 2003b \\
\hline 151 & $\mathrm{~A} 3 \mathrm{C} 2-2$ & WTP LAW & Muller and Pegg 2003b \\
\hline 152 & A3C2-3 & WTP LAW & Muller and Pegg 2003b \\
\hline 153 & A2-AP101 & WTP LAW & Rielley et al. 2004 \\
\hline 154 & A3-AN104 & WTP LAW & Rielley et al. 2004 \\
\hline 155 & $\mathrm{~A} 88 \mathrm{Si}+15$ & WTP LAW & Rielley et al. 2004 \\
\hline 156 & A88Si-15 & WTP LAW & Rielley et al. 2004 \\
\hline 157 & B1-AZ101 & WTP LAW & Rielley et al. 2004 \\
\hline 158 & C100-G-136B & WTP LAW & Rielley et al. 2004 \\
\hline 159 & C1-AN107 & WTP LAW & Rielley et al. 2004 \\
\hline 160 & C22AN107 & WTP LAW & Rielley et al. 2004 \\
\hline
\end{tabular}


Table B.1. Glass Names, Study Names, and References for the 281 Glasses Used to Develop a Model for Viscosity at $1150^{\circ} \mathrm{C}$ (contd)

\begin{tabular}{|c|c|c|c|}
\hline Row \# & Glass Name & Glass Study & Reference \\
\hline 161 & $\mathrm{C} 22 \mathrm{Si}+15$ & WTP LAW & Rielley et al. 2004 \\
\hline 162 & $\mathrm{C} 22 \mathrm{Si}-15$ & WTP LAW & Rielley et al. 2004 \\
\hline 163 & C2-AN102C35 & WTP LAW & Rielley et al. 2004 \\
\hline 164 & LAWA102R1 & WTP LAW & Rielley et al. 2004 \\
\hline 165 & LAWA126 & WTP LAW & Rielley et al. 2004 \\
\hline 166 & LAWA128R1 & WTP LAW & Rielley et al. 2004 \\
\hline 167 & LAWA130 & WTP LAW & Rielley et al. 2004 \\
\hline 168 & LAWA134 & WTP LAW & Rielley et al. 2004 \\
\hline 169 & LAWA135 & WTP LAW & Rielley et al. 2004 \\
\hline 170 & LAWA136 & WTP LAW & Rielley et al. 2004 \\
\hline 171 & LAWA44R10 & WTP LAW & Rielley et al. 2004 \\
\hline 172 & LAWB60 & WTP LAW & Rielley et al. 2004 \\
\hline 173 & LAWB62 & WTP LAW & Rielley et al. 2004 \\
\hline 174 & LAWB63 & WTP LAW & Rielley et al. 2004 \\
\hline 175 & LAWB64 & WTP LAW & Rielley et al. 2004 \\
\hline 176 & LAWB65 & WTP LAW & Rielley et al. 2004 \\
\hline 177 & LAWB66 & WTP LAW & Rielley et al. 2004 \\
\hline 178 & LAWB67 & WTP LAW & Rielley et al. 2004 \\
\hline 179 & LAWB68 & WTP LAW & Rielley et al. 2004 \\
\hline 180 & LAWB69 & WTP LAW & Rielley et al. 2004 \\
\hline 181 & LAWB70 & WTP LAW & Rielley et al. 2004 \\
\hline 182 & LAWB71 & WTP LAW & Rielley et al. 2004 \\
\hline 183 & LAWB72 & WTP LAW & Rielley et al. 2004 \\
\hline 184 & LAWB73 & WTP LAW & Rielley et al. 2004 \\
\hline 185 & LAWB74 & WTP LAW & Rielley et al. 2004 \\
\hline 186 & LAWB75 & WTP LAW & Rielley et al. 2004 \\
\hline 187 & LAWB76 & WTP LAW & Rielley et al. 2004 \\
\hline 188 & LAWB77 & WTP LAW & Rielley et al. 2004 \\
\hline 189 & LAWB78 & WTP LAW & Rielley et al. 2004 \\
\hline 190 & LAWB79 & WTP LAW & Rielley et al. 2004 \\
\hline 191 & LAWB80 & WTP LAW & Rielley et al. 2004 \\
\hline 192 & LAWB81 & WTP LAW & Rielley et al. 2004 \\
\hline 193 & LAWB82 & WTP LAW & Rielley et al. 2004 \\
\hline 194 & LAWB83 & WTP LAW & Rielley et al. 2004 \\
\hline 195 & LAWB84 & WTP LAW & Rielley et al. 2004 \\
\hline 196 & LAWB85 & WTP LAW & Rielley et al. 2004 \\
\hline 197 & LAWB86 & WTP LAW & Rielley et al. 2004 \\
\hline 198 & LAWB89 & WTP LAW & Rielley et al. 2004 \\
\hline 199 & LAWB90 & WTP LAW & Rielley et al. 2004 \\
\hline 200 & LAWB92 & WTP LAW & Rielley et al. 2004 \\
\hline 201 & LAWB94 & WTP LAW & Rielley et al. 2004 \\
\hline
\end{tabular}


Table B.1. Glass Names, Study Names, and References for the 281 Glasses Used to Develop a Model for Viscosity at $1150^{\circ} \mathrm{C}$ (contd)

\begin{tabular}{|c|c|c|c|}
\hline Row \# & Glass Name & Glass Study & Reference \\
\hline 202 & LAWB95 & WTP LAW & Rielley et al. 2004 \\
\hline 203 & LAWC27 & WTP LAW & Rielley et al. 2004 \\
\hline 204 & LAWC29 & WTP LAW & Rielley et al. 2004 \\
\hline 205 & LAWC30 & WTP LAW & Rielley et al. 2004 \\
\hline 206 & LAWC32 & WTP LAW & Rielley et al. 2004 \\
\hline 207 & LAWM01 & WTP LAW & Rielley et al. 2004 \\
\hline 208 & LAWM10 & WTP LAW & Rielley et al. 2004 \\
\hline 209 & LAWM11 & WTP LAW & Rielley et al. 2004 \\
\hline 210 & LAWM13 & WTP LAW & Rielley et al. 2004 \\
\hline 211 & LAWM14 & WTP LAW & Rielley et al. 2004 \\
\hline 212 & LAWM15 & WTP LAW & Rielley et al. 2004 \\
\hline 213 & LAWM16 & WTP LAW & Rielley et al. 2004 \\
\hline 214 & LAWM17 & WTP LAW & Rielley et al. 2004 \\
\hline 215 & LAWM18 & WTP LAW & Rielley et al. 2004 \\
\hline 216 & LAWM19 & WTP LAW & Rielley et al. 2004 \\
\hline 217 & LAWM02 & WTP LAW & Rielley et al. 2004 \\
\hline 218 & LAWM20 & WTP LAW & Rielley et al. 2004 \\
\hline 219 & LAWM21 & WTP LAW & Rielley et al. 2004 \\
\hline 220 & LAWM22 & WTP LAW & Rielley et al. 2004 \\
\hline 221 & LAWM23 & WTP LAW & Rielley et al. 2004 \\
\hline 222 & LAWM24 & WTP LAW & Rielley et al. 2004 \\
\hline 223 & LAWM25R1 & WTP LAW & Rielley et al. 2004 \\
\hline 224 & LAWM26 & WTP LAW & Rielley et al. 2004 \\
\hline 225 & LAWM27 & WTP LAW & Rielley et al. 2004 \\
\hline 226 & LAWM28 & WTP LAW & Rielley et al. 2004 \\
\hline 227 & LAWM29 & WTP LAW & Rielley et al. 2004 \\
\hline 228 & LAWM03 & WTP LAW & Rielley et al. 2004 \\
\hline 229 & LAWM30 & WTP LAW & Rielley et al. 2004 \\
\hline 230 & LAWM31 & WTP LAW & Rielley et al. 2004 \\
\hline 231 & LAWM32 & WTP LAW & Rielley et al. 2004 \\
\hline 232 & LAWM33R1 & WTP LAW & Rielley et al. 2004 \\
\hline 233 & LAWM34 & WTP LAW & Rielley et al. 2004 \\
\hline 234 & LAWM35 & WTP LAW & Rielley et al. 2004 \\
\hline 235 & LAWM36 & WTP LAW & Rielley et al. 2004 \\
\hline 236 & LAWM37 & WTP LAW & Rielley et al. 2004 \\
\hline 237 & LAWM38 & WTP LAW & Rielley et al. 2004 \\
\hline 238 & LAWM39 & WTP LAW & Rielley et al. 2004 \\
\hline 239 & LAWM04 & WTP LAW & Rielley et al. 2004 \\
\hline 240 & LAWM40 & WTP LAW & Rielley et al. 2004 \\
\hline 241 & LAWM41 & WTP LAW & Rielley et al. 2004 \\
\hline 242 & LAWM42 & WTP LAW & Rielley et al. 2004 \\
\hline
\end{tabular}


Table B.1. Glass Names, Study Names, and References for the 281 Glasses Used to Develop a Model for Viscosity at $1150^{\circ} \mathrm{C}$ (contd)

\begin{tabular}{|c|c|c|c|}
\hline Row \# & Glass Name & Glass Study & Reference \\
\hline 243 & LAWM43 & WTP LAW & Rielley et al. 2004 \\
\hline 244 & LAWM44 & WTP LAW & Rielley et al. 2004 \\
\hline 245 & LAWM45 & WTP LAW & Rielley et al. 2004 \\
\hline 246 & LAWM46 & WTP LAW & Rielley et al. 2004 \\
\hline 247 & LAWM47 & WTP LAW & Rielley et al. 2004 \\
\hline 248 & LAWM48 & WTP LAW & Rielley et al. 2004 \\
\hline 249 & LAWM49 & WTP LAW & Rielley et al. 2004 \\
\hline 250 & LAWM05 & WTP LAW & Rielley et al. 2004 \\
\hline 251 & LAWM50 & WTP LAW & Rielley et al. 2004 \\
\hline 252 & LAWM51 & WTP LAW & Rielley et al. 2004 \\
\hline 253 & LAWM52 & WTP LAW & Rielley et al. 2004 \\
\hline 254 & LAWM53 & WTP LAW & Rielley et al. 2004 \\
\hline 255 & LAWM54R1 & WTP LAW & Rielley et al. 2004 \\
\hline 256 & LAWM55 & WTP LAW & Rielley et al. 2004 \\
\hline 257 & LAWM56 & WTP LAW & Rielley et al. 2004 \\
\hline 258 & LAWM06 & WTP LAW & Rielley et al. 2004 \\
\hline 259 & LAWM07 & WTP LAW & Rielley et al. 2004 \\
\hline 260 & LAWM08 & WTP LAW & Rielley et al. 2004 \\
\hline 261 & LAWM09 & WTP LAW & Rielley et al. 2004 \\
\hline 262 & A1-AN105R2 & WTP LAW & Muller et al. 2005, Piepel et al. 2007 \\
\hline 263 & LAWB88 & WTP LAW Comparison & Muller et al. 2005, Piepel et al. 2007 \\
\hline 264 & LAWC21rev2 & WTP LAW Comparison & Muller et al. 2005, Piepel et al. 2007 \\
\hline 265 & LAWA127R1 & WTP LAW Correlation & Piepel et al. 2007 \\
\hline 266 & LAWE10H & WTP LAW Correlation & Piepel et al. 2007 \\
\hline 267 & LAWE11 & WTP LAW Correlation & Piepel et al. 2007 \\
\hline 268 & LAWE12 & WTP LAW Correlation & Piepel et al. 2007 \\
\hline 269 & LAWE13 & WTP LAW Correlation & Piepel et al. 2007 \\
\hline 270 & LAWE16 & WTP LAW Correlation & Piepel et al. 2007 \\
\hline 271 & LAWE2H & WTP LAW Correlation & Piepel et al. 2007 \\
\hline 272 & LAWE3 & WTP LAW Correlation & Piepel et al. 2007 \\
\hline 273 & LAWE3H & WTP LAW Correlation & Piepel et al. 2007 \\
\hline 274 & LAWE4 & WTP LAW Correlation & Piepel et al. 2007 \\
\hline 275 & LAWE4H & WTP LAW Correlation & Piepel et al. 2007 \\
\hline 276 & LAWE5 & WTP LAW Correlation & Piepel et al. 2007 \\
\hline 277 & LAWE5H & WTP LAW Correlation & Piepel et al. 2007 \\
\hline 278 & LAWE7 & WTP LAW Correlation & Piepel et al. 2007 \\
\hline 279 & LAWE7H & WTP LAW Correlation & Piepel et al. 2007 \\
\hline 280 & LAWE9H & WTP LAW Correlation & Piepel et al. 2007 \\
\hline 281 & LAWA129R1 & WTP LAW Correlation & Piepel et al. 2007 \\
\hline
\end{tabular}


Table B.2. Glass Oxide Compositions (mass fractions) ${ }^{(a)}$ for the 281 Glasses Used to Develop a Model for Viscosity at $1150^{\circ} \mathrm{C}$

\begin{tabular}{|c|c|c|c|c|c|c|c|c|c|c|c|c|c|c|c|}
\hline \multirow{2}{*}{$\begin{array}{c}\text { Row } \\
\#^{(\mathbf{b})}\end{array}$} & \multicolumn{15}{|c|}{ Component } \\
\hline & $\mathbf{A l}_{2} \mathbf{O}_{3}$ & $\mathbf{B}_{2} \mathbf{O}_{3}$ & $\mathrm{CaO}$ & $\mathrm{Fe}_{2} \mathrm{O}_{3}$ & $\mathrm{~K}_{2} \mathrm{O}$ & $\mathbf{L i}_{2} \mathbf{O}$ & MgO & $\mathrm{Na}_{2} \mathrm{O}$ & $\mathrm{SiO}_{2}$ & $\mathrm{SO}_{3}$ & $\mathrm{SnO}_{2}$ & $\mathrm{~V}_{2} \mathbf{O}_{5}$ & $\mathrm{ZnO}$ & $\mathrm{ZrO}_{2}$ & Others1 \\
\hline 1 & 0.1017 & .1369 & 0.0565 & 0.0100 & 0.0051 & 0.0000 & 0.0100 & 0.2302 & .3661 & 0.0067 & 0.0000 & 0.0100 & 0.0300 & 0.0300 & 0.0067 \\
\hline 2 & 0.1066 & 1280 & 0.0799 & 0091 & 0051 & 0.0000 & 0091 & 01 & 38 & 68 & 000 & 98 & 300 & 00 & 0067 \\
\hline 3 & 0.1066 & 1130 & 0.0800 & 0.0091 & 0.0051 & 0.0000 & 0.0091 & 0.2302 & 3488 & 0.0066 & 0.0000 & 0.0098 & 0.0300 & 50 & 0.0067 \\
\hline 4 & 0.1065 & 0979 & & & & .0000 & & & & & & & & & \\
\hline 5 & 0.1215 & .1129 & & & & 0.0000 & & & & & 0.0000 & & 300 & & .0067 \\
\hline 6 & 0.1366 & & 0.0799 & & & & & & & & 0.0000 & & 0.0300 & 00 & 0067 \\
\hline 7 & 0.1086 & 0.0926 & 0.0798 & 0.0091 & 0.0056 & 0.0000 & 0.0091 & 0.2501 & 0.3534 & 0.0069 & 0.0000 & 0.0094 & 0.0235 & 0.0445 & 0.0073 \\
\hline 8 & 0.1085 & 0776 & & & & 0.0000 & 0.0091 & & & 0.0070 & 0.0000 & & 0.0235 & 95 & 0.0073 \\
\hline 9 & & & & & & & & & & & & & & & \\
\hline 10 & & & & & & & & & & & & & & & \\
\hline 11 & 0.1215 & 0979 & 0.0799 & 0.0091 & 0.0051 & 0.0000 & 0.0091 & 0.2301 & 0.3689 & 0.0070 & 0.0000 & 0.0150 & 0.0195 & 300 & 0.0067 \\
\hline 12 & 0.1164 & 0.0930 & 0.0799 & & 0.0051 & 0.0000 & 0.0091 & & & & 00 & & 45 & & \\
\hline 13 & & & & & & & & & & & & & & & \\
\hline 14 & & & & & & & & & & & & & & & \\
\hline 15 & 0.1066 & 1130 & 0.0750 & 0.0091 & 0.0051 & 0.0000 & 0.0091 & 0.23 & 0.3490 & 0.0061 & 0.0000 & 0.0 & 0.0300 & 0.0 & 0.0 \\
\hline 16 & 0.1217 & 0.1131 & 0.0599 & & 0.0051 & 0.0000 & 0.0091 & 0.2 & & 0.0 & 0.0000 & 0.0 & 0.0300 & & 17 \\
\hline 17 & & & & & & & & & & & & & 300 & & \\
\hline 18 & & & & & & & & & & & & & & & \\
\hline 19 & & & & & & & & & & & & & 300 & & \\
\hline 20 & 0.1087 & 0.0777 & & & & 0.0000 & 0.0091 & 0 . & & & 0.0100 & 0. & 35 & & 73 \\
\hline 21 & 0.1087 & 0.0777 & 0.0649 & 91 & 0.0 & 0.0000 & 91 & 0 . & 37 & 0. & 0.0100 & 0. & 235 & 96 & 124 \\
\hline 22 & & & & & & & & & & & & & 35 & & 0.0073 \\
\hline 23 & & 0.0777 & & & & 0.0000 & & & & & 0.0000 & & 0.0235 & 596 & 0.0124 \\
\hline 24 & & & & & & & & & & & & & & & 0.0022 \\
\hline 25 & 0.1017 & 0.1003 & 0.1123 & 0.0115 & 0.00 & 0.0355 & 0.0115 & 0 . & 0.4 & 0.0 & 0.0000 & 0.0124 & 0.0355 & 55 & 0.0022 \\
\hline 26 & 0.0917 & 0.1004 & 0.1224 & & 0.0041 & 0.0355 & 0.0115 & 0.1003 & & & 0.0000 & 0.0124 & & & 0.0022 \\
\hline 27 & 0.0916 & 0.1003 & 0.0921 & 0.0115 & 0.0041 & 0.0405 & 0.0115 & 0.1002 & 0.4566 & 0.0061 & 0.0000 & 0.0124 & 0.0355 & 0.0355 & 0.0022 \\
\hline 28 & 0.0616 & 0.1305 & 0.0922 & 0.0115 & 0.0041 & 0.0355 & 0.0115 & 0.1002 & 0.4618 & 0.0055 & 0.0000 & 0.0124 & 0.0355 & 0.0355 & 0.0022 \\
\hline 29 & 0.0916 & 0.1002 & 0.0921 & 0.0115 & 0.0041 & 0.0354 & 0.0115 & 0.1001 & 0.4615 & 0.0063 & 0.0000 & 0.0124 & 0.0354 & 0.0354 & 0.0022 \\
\hline 30 & 0.1017 & 0.1103 & 0.0922 & 0.0115 & 0.0041 & 0.0355 & 0.0115 & 0.1002 & 0.4416 & 0.0058 & 0.0000 & 0.0124 & 0.0355 & 0.0355 & 0.0022 \\
\hline
\end{tabular}


Table B.2. Glass Oxide Compositions (mass fractions) ${ }^{(a)}$ for the 281 Glasses Used to Develop a Model for Viscosity at $1150^{\circ} \mathrm{C}$ (contd)

\begin{tabular}{|c|c|c|c|c|c|c|c|c|c|c|c|c|c|c|c|}
\hline \multirow{2}{*}{$\begin{array}{c}\text { Row } \\
\#^{(\mathbf{b})}\end{array}$} & \multicolumn{15}{|c|}{ Component } \\
\hline & $\mathbf{A l}_{\mathbf{2}} \mathbf{O}_{3}$ & $\mathbf{B}_{2} \mathbf{O}_{3}$ & $\mathrm{CaO}$ & $\mathrm{Fe}_{2} \mathrm{O}_{3}$ & $\mathbf{K}_{2} \mathbf{O}$ & $\mathbf{L i}_{2} \mathbf{O}$ & MgO & $\mathrm{Na}_{2} \mathrm{O}$ & $\mathrm{SiO}_{2}$ & $\mathrm{SO}_{3}$ & $\mathrm{SnO}_{2}$ & $\mathbf{V}_{2} \mathbf{O}_{5}$ & $\mathrm{ZnO}$ & $\mathrm{ZrO}_{2}$ & Others1 \\
\hline 31 & 0.1016 & .1102 & 1022 & 0.0115 & 0.0041 & 0.0354 & 0115 & 0.1001 & 0.4313 & 0.0064 & & & 0.0354 & & 0.0022 \\
\hline 32 & 0.1019 & 372 & 0.0804 & & & 0.0000 & 0.0100 & 0.2005 & 0.3672 & 0.0094 & 0.0000 & 100 & & & 117 \\
\hline 33 & 0.1019 & & & & & & & & 0.3673 & & 00 & & & & 17 \\
\hline 34 & 866 & & 804 & 0 & & 0000 & 0100 & & 0.3669 & & 0.0000 & & 01 & & \\
\hline 35 & & & & & & & & & & & & & & & \\
\hline 36 & & & & & & & & & & & & & & & \\
\hline 37 & & & & & & & & & & & & & & & \\
\hline 38 & 0.1000 & 9900 & 0304 & 1 & 0056 & 0.0000 & .0135 & 0.2500 & 4131 & 0.0 & 0.0000 & 00 & 36 & & 39 \\
\hline 39 & & & & & & & & & & & & & & & \\
\hline 40 & & & & & & & & & & & & & & & \\
\hline 41 & & & & & & & & & & & & & & & \\
\hline 42 & 090 & 30 & 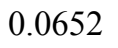 & & 6 & 0 & 91 & & 52 & & 0.0200 & & & & 39 \\
\hline 43 & & & & & & & & & & & & & & & \\
\hline 44 & & & & & & & & & & & & & & & \\
\hline 45 & & & & & & & & & & & & & & & \\
\hline 46 & 083 & 707 & 0201 & & 5 & 0.0000 & 0.0092 & 0.2 & 1 & & 72 & & & & \\
\hline 47 & & & 0205 & & & & & & & & & & & & \\
\hline 48 & & & & & & & & & & & & & & & \\
\hline 49 & & & & & & & & & & & & & & & \\
\hline 50 & & & & & & & & & & & & & & & \\
\hline 51 & & & & & & & & & & & & & & & \\
\hline 52 & 970 & & & 0 & & 0 & & & & & 83 & & 76 & & 18 \\
\hline 53 & & & & & & & & & & & & & & & \\
\hline 54 & 0.0674 & & & 0.0026 & & & & 0.2303 & 0.4229 & 0.0081 & 0.0246 & & 286 & & \\
\hline 55 & & & & 0.0026 & 0.0053 & 0.0000 & & & & & 0.0266 & & & & \\
\hline 56 & & & & & & & 0.01 & 0.2 & 00 & 0.0048 & 0.0108 & 0.0200 & 65 & 0. & 60 \\
\hline 57 & & & & & & & & & & & & & & & 0.0160 \\
\hline 58 & 0.0989 & 0.0858 & 0.0300 & 0.0096 & 0.0011 & 0.0000 & 0.0093 & 0.2402 & 0.4010 & 0.0047 & 0.0100 & 0.0100 & 0.0237 & 0.0605 & 0.0151 \\
\hline 59 & & & & & & 0.0000 & & 0.2403 & 0.4011 & 0.0045 & 0.0100 & 0.0200 & 0.0237 & 0.0605 & 0.0151 \\
\hline 60 & & & & 0.0090 & & 0.0000 & & 0.2351 & & 0.0049 & 0.0099 & 0.0147 & 0.0297 & 0.0346 & 0.0146 \\
\hline 61 & 0.1004 & 0.0852 & 0.0191 & 0.0097 & 0.0054 & 0.0000 & 0.0093 & 0.2358 & 0.4012 & 0.0048 & 0.0100 & 0.0200 & 0.0237 & 0.0604 & 0.0149 \\
\hline
\end{tabular}


Table B.2. Glass Oxide Compositions (mass fractions) ${ }^{(a)}$ for the 281 Glasses Used to Develop a Model for Viscosity at $1150^{\circ} \mathrm{C}$ (contd)

\begin{tabular}{|c|c|c|c|c|c|c|c|c|c|c|c|c|c|c|c|}
\hline \multirow{2}{*}{$\begin{array}{c}\text { Row } \\
\#^{(\mathbf{b})}\end{array}$} & \multicolumn{15}{|c|}{ Component } \\
\hline & $\mathbf{A l}_{2} \mathbf{O}_{3}$ & $\mathbf{B}_{2} \mathbf{O}_{3}$ & $\mathrm{CaO}$ & $\mathrm{Fe}_{2} \mathrm{O}_{3}$ & $\mathbf{K}_{2} \mathbf{O}$ & $\mathbf{L i}_{2} \mathbf{O}$ & MgO & $\mathrm{Na}_{2} \mathrm{O}$ & $\mathrm{SiO}_{2}$ & $\mathrm{SO}_{3}$ & $\mathrm{SnO}_{2}$ & $\mathbf{V}_{2} \mathbf{O}_{5}$ & ZnO & $\mathrm{ZrO}_{2}$ & Others1 \\
\hline 62 & 0.1015 & 0.1204 & 801 & 0.0100 & .0016 & 0.0000 & 0100 & 0.2098 & 3714 & 0.0106 & .0000 & 0.0100 & .0300 & .0300 & 47 \\
\hline 63 & .1019 & 0.1209 & 0804 & .0030 & 0016 & .0000 & 0100 & & 3797 & 0085 & 0000 & 0100 & .0301 & 301 & \\
\hline 64 & 020 & 005 & & & & & & & & & & & & & \\
\hline 65 & & & & & & & & & & & & & & & \\
\hline 66 & 1009 & 0988 & 792 & .0030 & 017 & 0000 & 099 & & 738 & 0.0087 & 00 & 00 & 297 & & \\
\hline 67 & & & & & & 0.0000 & & & & & & & 0.0299 & & \\
\hline 68 & & 51 & 35 & 29 & 18 & 000 & & & 76 & 0.0 & 00 & & 99 & & \\
\hline 69 & & & & & & & & & & & & & & & \\
\hline 70 & 3 & 48 & & & & 00 & & & & & & & & & \\
\hline 71 & & & & & & & & & & & & & & & \\
\hline 72 & 65 & 3 & & 23 & & 10 & & & & & & & & & \\
\hline 73 & & & & & & & & & & & & & & & \\
\hline 74 & & & & & & & & & & & & & & & \\
\hline 75 & & & & & & & & & & & & & & & \\
\hline 76 & 61 & 46 & 6 & 05 & 55 & 00 & 5 & 0 & & & 00 & 0 & 22 & & \\
\hline 77 & & & & & & & & & & & & & 22 & & \\
\hline 78 & 879 & 45 & 24 & & & & & & & & & & 22 & & \\
\hline 79 & & & & & & & & & & & & & & & \\
\hline 80 & & & & & & & & & & & & & & & \\
\hline 81 & 1010 & 0982 & & 0.0 & 41 & 78 & & 0.1 & 0.4 & & & & 0.0302 & & \\
\hline 82 & 9995 & 0.0967 & 0.0992 & 0.0030 & 45 & 72 & 00 & & 02 & & & 0. & 298 & & \\
\hline 83 & & & & & & & & & & & & & & & \\
\hline 84 & & & & & & & & & & & & & & & \\
\hline 85 & & & & & & & & & 0.4240 & & & & & & \\
\hline 86 & 0.0764 & 0.0890 & 0.0977 & 0.0030 & 0.0050 & 0.0352 & 99 & 0. & 0.4204 & 0.0 & 85 & 0. & 0.0293 & 90 & 66 \\
\hline 87 & & & & & & & & & & & & & & & \\
\hline 88 & 0.0860 & 0.0950 & 0.1056 & 0.0000 & 0.0050 & 0.0350 & 0.0000 & 0.1199 & 0.4212 & 0.0197 & 0.0100 & 0.0272 & 0.0291 & 0.0395 & 0.0069 \\
\hline 89 & 0.0860 & 0.0950 & & & & & & & 0.4213 & 0.0196 & 0.0100 & & 0.0291 & 0.0395 & 0.0069 \\
\hline 90 & 0.1017 & & & & & & & & & & & & 0.0300 & 0.0300 & 0.0127 \\
\hline 91 & 0.1500 & 0.0600 & 0.0000 & 0.0000 & 0.0033 & 0.0000 & 0.0000 & 0.2000 & 0.5678 & 0.0032 & 0.0000 & 0.0000 & 0.0000 & 0.0000 & 0.0157 \\
\hline 92 & 0.0600 & 0.0900 & 0.0000 & 0.0000 & 0.0033 & 0.0000 & 0.0000 & 0.2000 & 0.6278 & 0.0032 & 0.0000 & 0.0000 & 0.0000 & 0.0000 & 0.0157 \\
\hline
\end{tabular}


Table B.2. Glass Oxide Compositions (mass fractions) ${ }^{(a)}$ for the 281 Glasses Used to Develop a Model for Viscosity at $1150^{\circ} \mathrm{C}$ (contd)

\begin{tabular}{|c|c|c|c|c|c|c|c|c|c|c|c|c|c|c|c|}
\hline \multirow{2}{*}{$\begin{array}{c}\text { Row } \\
\#^{(\mathbf{b})}\end{array}$} & \multicolumn{15}{|c|}{ Component } \\
\hline & $\mathrm{Al}_{2} \mathrm{O}_{3}$ & $\mathbf{B}_{2} \mathbf{O}_{3}$ & $\mathrm{CaO}$ & $\mathrm{Fe}_{2} \mathrm{O}_{3}$ & $\mathbf{K}_{2} \mathbf{O}$ & $\mathbf{L i}_{2} \mathbf{O}$ & MgO & $\mathrm{Na}_{2} \mathrm{O}$ & $\mathrm{SiO}_{2}$ & $\mathrm{SO}_{3}$ & $\mathrm{SnO}_{2}$ & $\mathbf{V}_{2} \mathbf{O}_{5}$ & $\mathrm{ZnO}$ & $\mathrm{ZrO}_{2}$ & Others1 \\
\hline 93 & 0.1200 & 0.0900 & 0.0000 & 0.0000 & 0.0033 & 0.0000 & 0.0000 & 0.2000 & 0.5678 & 0.0032 & 0.0000 & 0.0000 & 0.0000 & 0.0000 & 0.0157 \\
\hline 94 & 0.0900 & 0.1200 & 0.0000 & 0.0000 & 0.0033 & 0.0000 & 0.0000 & 0.2000 & 0.5678 & 0.0032 & 0.0000 & 0.0000 & 0.0000 & 0.0000 & 0.0157 \\
\hline 95 & 0.1500 & 0.1200 & 0.0000 & 0.0000 & 0.0033 & 0.0000 & 0.0000 & 0.2000 & 0.5078 & 0.0032 & 0.0000 & 0.0000 & 0.0000 & 0.0000 & 0.0157 \\
\hline 96 & 0.0600 & 0.0000 & 0.0900 & 0.0000 & 0.0033 & 0.0000 & 0.0000 & 0.2000 & 0.6278 & 0.0032 & 0.0000 & 0.0000 & 0.0000 & 0.0000 & 0.0157 \\
\hline 97 & 0.0900 & 0.0000 & 0.1200 & 0.0000 & 0.0033 & 0.0000 & 0.0000 & 0.2000 & 0.5678 & 0.0032 & 0.0000 & 0.0000 & 0.0000 & 0.0000 & 0.0157 \\
\hline 98 & 0.1500 & 0.0000 & 0.1200 & 0.0000 & 0.0033 & 0.0000 & 0.0000 & 0.2000 & 0.5078 & 0.0032 & 0.0000 & 0.0000 & 0.0000 & 0.0000 & 0.0157 \\
\hline 99 & 0.1200 & 0.0300 & 0.0300 & 0.0000 & 0.0033 & 0.0000 & 0.0000 & 0.2000 & 0.5978 & 0.0032 & 0.0000 & 0.0000 & 0.0000 & 0.0000 & 0.0157 \\
\hline 100 & 0.0600 & 0.0500 & 0.0400 & 0.0000 & 0.0033 & 0.0000 & 0.0000 & 0.2000 & 0.6278 & 0.0032 & 0.0000 & 0.0000 & 0.0000 & 0.0000 & 0.0157 \\
\hline 101 & 0.0900 & 0.0500 & 0.0400 & 0.0000 & 0.0033 & 0.0000 & 0.0000 & 0.2000 & 0.5978 & 0.0032 & 0.0000 & 0.0000 & 0.0000 & 0.0000 & \\
\hline 102 & 0.1200 & 0.0500 & 0.0400 & & 0.0033 & 0.0000 & 0.0000 & & & & & 0.0000 & & 00 & \\
\hline 103 & 0.1500 & 0.0500 & 0.0400 & 0.0000 & 0.0033 & 0.0000 & 0.0000 & 0.2000 & 0.5378 & 0.0032 & 0.0000 & 0.0000 & 0.0000 & 0.0000 & 0.0157 \\
\hline 104 & 0.0900 & 0.0600 & 0.0600 & 0.0000 & 0.0033 & 0.0000 & 0.0000 & 0.2000 & 0.5678 & 0.0032 & 0.0000 & 0.0000 & 0.0000 & 0.0000 & 0.0157 \\
\hline 105 & 0.1200 & 0.0600 & 0.0600 & 0.0000 & 0.0033 & 0.0000 & 0.0000 & 0.2000 & 0.5378 & 0.0032 & 0.0000 & 0.0000 & 0.0000 & 0.0000 & 0.0157 \\
\hline 106 & & & & & & & & & & & & & & & \\
\hline 107 & 0.1155 & 0.0461 & 0.0369 & 0.0000 & 0.0041 & 0.0000 & 0.0000 & 0.2500 & 0.5238 & 0.0040 & 0.0000 & 0.0000 & 0.0000 & 0.0001 & 0.0195 \\
\hline 108 & 0.1065 & 0.0384 & 0.0307 & 0.0001 & 0.0057 & 0.0000 & 0.0000 & 0.3500 & 0.4357 & 0.0056 & 0.0000 & 0.0000 & 0.0000 & 0.0001 & 0.0273 \\
\hline 109 & 0.0900 & 0.0600 & 0.0000 & 0.0000 & 0.0033 & 0.0000 & 0.0000 & 0.2000 & 0.5678 & 0.0032 & 0.0000 & 0.0000 & 0.0000 & 0.0600 & 0.0157 \\
\hline 110 & 0.0900 & 0.0000 & 0.0600 & 0.0000 & 0.0033 & 0.0000 & 0.0000 & 0.2000 & 0.5678 & 0.0032 & 0.0000 & 0.0000 & 0.0000 & 0.0600 & 57 \\
\hline 111 & 0.0900 & & & & & 0.0000 & 0.0000 & 0.2000 & & & 0.0000 & 0.0000 & 0.0000 & 0.0600 & \\
\hline 112 & 0.0900 & 0.0600 & 0.0000 & 0.0600 & 0.0033 & 0.0000 & 0.0000 & 0.2000 & 0.5678 & 0.0032 & 0.0000 & 0.0000 & 0.0000 & 0.0000 & 0.0157 \\
\hline 113 & 0.0900 & 0.0000 & 0.0600 & 0.0600 & 0.0033 & 0.0000 & 0.0000 & 0.2000 & 0.5678 & 0.0032 & 0.0000 & 0.0000 & 0.0000 & 0.0000 & 0.0157 \\
\hline 114 & 0.0900 & 0.0300 & 0.0300 & 0.0600 & 0.0033 & 0.0000 & 0.0000 & 0.2000 & 0.5678 & 0.0032 & 0.0000 & 0.0000 & 0.0000 & 0.0000 & 0.0157 \\
\hline 115 & 0.0900 & 0.0600 & 0.0000 & 0.0300 & 0.0033 & 0.0000 & 0.0000 & 0.2000 & 0.5678 & 0.0032 & 0.0000 & 0.0000 & 0.0000 & 0.0300 & 0.0157 \\
\hline 116 & 0.0900 & 0.0500 & 0.0000 & 0.0000 & 0.0033 & 0.0000 & 0.0400 & 0.2000 & 0.5979 & 0.0032 & 0.0000 & 0.0000 & 0.0000 & 0.0000 & 0.0156 \\
\hline 117 & 0.1200 & 0.0900 & 0.0000 & 0.0000 & 0.0146 & 0.0000 & 0.0000 & 0.2000 & 0.5591 & 0.0022 & 0.0000 & 0.0000 & 0.0000 & 0.0000 & 0.0141 \\
\hline 118 & 0.1200 & 0.0000 & 0.0900 & 0.0000 & 0.0146 & 0.0000 & 0.0000 & 0.2000 & 0.5591 & 0.0022 & 0.0000 & 0.0000 & 0.0000 & 0.0000 & 0.0141 \\
\hline 119 & 0.1400 & 0.0500 & 0.0300 & 0.0000 & 0.0146 & 0.0000 & 0.0000 & 0.2000 & 0.5491 & 0.0022 & 0.0000 & 0.0000 & 0.0000 & 0.0000 & 0.0141 \\
\hline 120 & 0.1200 & 0.0500 & 0.0400 & 0.0000 & 0.0146 & 0.0000 & 0.0000 & 0.2000 & 0.5591 & 0.0022 & 0.0000 & 0.0000 & 0.0000 & 0.0000 & 0.0141 \\
\hline 121 & 0.1000 & 0.0500 & 0.0500 & 0.0000 & 0.0146 & 0.0000 & 0.0000 & 0.2000 & 0.5691 & 0.0022 & 0.0000 & 0.0000 & 0.0000 & 0.0000 & 0.0141 \\
\hline 122 & 0.1200 & 0.0000 & 0.0900 & 0.0000 & 0.0143 & 0.0000 & 0.0000 & 0.2000 & 0.5514 & 0.0021 & 0.0000 & 0.0000 & 0.0000 & 0.0000 & 0.0222 \\
\hline 123 & 0.1200 & 0.0200 & 0.0200 & 0.0600 & 0.0143 & 0.0000 & 0.0000 & 0.2000 & 0.5014 & 0.0021 & 0.0000 & 0.0000 & 0.0000 & 0.0400 & 0.0222 \\
\hline
\end{tabular}


Table B.2. Glass Oxide Compositions (mass fractions) ${ }^{(a)}$ for the 281 Glasses Used to Develop a Model for Viscosity at $1150^{\circ} \mathrm{C}$ (contd)

\begin{tabular}{|c|c|c|c|c|c|c|c|c|c|c|c|c|c|c|c|}
\hline \multirow{2}{*}{$\begin{array}{c}\text { Row } \\
\#^{(\mathbf{b})}\end{array}$} & \multicolumn{15}{|c|}{ Component } \\
\hline & $\mathbf{A l}_{2} \mathbf{O}_{3}$ & $\mathbf{B}_{2} \mathbf{O}_{3}$ & $\mathrm{CaO}$ & $\mathrm{Fe}_{2} \mathrm{O}_{3}$ & $\mathbf{K}_{2} \mathbf{O}$ & $\mathbf{L i}_{2} \mathbf{O}$ & MgO & $\mathrm{Na}_{2} \mathrm{O}$ & $\mathrm{SiO}_{2}$ & $\mathrm{SO}_{3}$ & $\mathrm{SnO}_{2}$ & $\mathbf{V}_{2} \mathbf{O}_{5}$ & ZnO & $\mathrm{ZrO}_{2}$ & Others1 \\
\hline 124 & 0.1200 & 0.0000 & 0.0600 & 0.0600 & 0.0143 & 0.0000 & 0.0000 & 0.2000 & 0.5214 & 0.0021 & 0.0000 & 0.0000 & 0.0000 & 0.0000 & 0.0222 \\
\hline 125 & 0.1200 & 0.0600 & 0.0000 & 0.0000 & 0.0143 & 0.0000 & 0.0000 & 0.2000 & 0.5214 & 0.0021 & 0.0000 & 0.0000 & 0.0000 & 0.0600 & 0.0222 \\
\hline 126 & 1000 & 0.0600 & 0.0600 & 0.0600 & 0.0143 & 0.0000 & 0.0000 & 0.2000 & 0.4414 & 0.0021 & 0.0000 & 0.0000 & 0.0000 & 0.0400 & 0.0222 \\
\hline 127 & .1200 & 0.0500 & 0.0400 & 0.0000 & 0.0143 & 0.0000 & 0.0000 & 0.2000 & 0.5514 & 0.0021 & 0.0000 & 0.0000 & 0.0000 & 0.0000 & 0.0222 \\
\hline 128 & 0.1200 & 0.0200 & 0.0200 & 0.0600 & 0.0143 & 0.0000 & 0.0000 & 0.2000 & 0.5014 & 0.0021 & 0.0000 & 0.0000 & 0.0000 & 0.0400 & 0.0222 \\
\hline 129 & 0.1200 & 0.0000 & 0.0900 & 0.0000 & 0.0003 & 0.0000 & 0.0000 & 0.2000 & 0.5454 & 0.0101 & 0.0000 & 0.0000 & 0.0000 & 0.0000 & 0.0342 \\
\hline 130 & 0.1200 & 0.0200 & 0.0200 & 0.0600 & 0.0003 & 0.0100 & 0.0000 & 0.2000 & 0.4854 & 0.0101 & 0.0000 & 0.0000 & 0.0000 & 0.0400 & 0.0342 \\
\hline 131 & 0.1200 & 0.0000 & 0.0600 & 0.0600 & 0.0003 & 0.0000 & 0.0000 & 0.2000 & 0.5154 & 0.0101 & 0.0000 & 0.0000 & 0.0000 & 0.0000 & 0.0342 \\
\hline 132 & 0.1200 & 0.0600 & 0.0000 & 0.0000 & 0.0003 & 0.0000 & 0.0000 & 0.2000 & 0.5154 & 0.0101 & 0.0000 & 0.0000 & 0.0000 & 0.0600 & 0.0342 \\
\hline 133 & 0.1000 & 0.0600 & 0.0600 & 0.0600 & 0.0003 & 0.0050 & 0.0000 & 0.2000 & 0.4304 & 0.0101 & 0.0000 & 0.0000 & 0.0000 & 0.0400 & 0.0342 \\
\hline 134 & 0.1200 & 0.0500 & 0.0400 & 0.0000 & 0.0003 & 0.0000 & 0.0000 & 0.2000 & 0.5454 & 0.0101 & 0.0000 & 0.0000 & 0.0000 & 0.0000 & 0.0342 \\
\hline 135 & 0.1200 & 0.0200 & 0.0200 & 0.0600 & 0.0003 & 0.0100 & 0.0000 & 0.2000 & 0.4854 & 0.0101 & 0.0000 & 0.0000 & 00 & 100 & 42 \\
\hline 136 & 0.1200 & 0.0500 & 0.0400 & 0.0000 & 0.0146 & 0.0000 & 0.0000 & 0.2000 & 0.5591 & 0.0022 & 0.0000 & 0.0000 & 0.0000 & 0.0000 & 0.0141 \\
\hline 137 & & 0.0615 & & & & 0.0000 & 0.0000 & 0.1882 & 0.4223 & 0.0020 & 0.0000 & 0.0000 & 0.0000 & 0.0509 & \\
\hline 138 & 0.0600 & 0.0000 & 0.0973 & 0.0100 & 0.0150 & 0.0000 & 0.0013 & 0.1882 & 0.5922 & 0.0021 & 0.0000 & 0.0000 & 0.0000 & 0.0200 & 0.0139 \\
\hline 139 & 0.1000 & 0.0800 & 0.0290 & 0.0100 & 0.0146 & 0.0000 & 0.0210 & 0.2000 & 0.5290 & 0.0022 & 0.0000 & 0.0000 & 0.0000 & 0.0000 & 0.0142 \\
\hline 140 & 0.1822 & 0.0945 & 0.0465 & 0.0000 & 0.0144 & 0.0083 & 0.0000 & 0.1882 & 0.4290 & 0.0022 & 0.0000 & 0.0000 & 0.0000 & 0.0210 & 0.0137 \\
\hline 141 & 0.0620 & & & & & & & & 0.4862 & & & & & 0.0317 & \\
\hline 142 & 0.0649 & 0.1301 & 0.0611 & 0.0503 & 0.0020 & 0.0470 & 0.0141 & 0.0501 & 0.4916 & 0.0081 & 0.0000 & 0.0000 & 0.0489 & 0.0319 & 0.0000 \\
\hline 143 & 0.0619 & 0.1004 & 0.0679 & 0.0530 & 0.0019 & 0.0467 & 0.0297 & 0.0479 & 0.4900 & 0.0065 & 0.0000 & 0.0000 & 0.0485 & 0.0316 & 0.0141 \\
\hline 144 & 0.0612 & 0.1005 & 0.0741 & 0.0443 & 0.0014 & 0.0273 & 0.0150 & 0.1196 & 0.4675 & 0.0048 & 0.0000 & 0.0000 & 0.0402 & 0.0302 & 0.0137 \\
\hline 145 & 0.0609 & 0.0913 & 0.0274 & 0.0650 & 0.0035 & 0.0062 & 0.0185 & 0.1917 & 0.4448 & 0.0024 & 0.0000 & 0.0000 & 0.0295 & 0.0296 & 0.0293 \\
\hline 146 & 0.0607 & 0.0942 & 0.0352 & 0.0613 & 0.0025 & 0.0125 & 0.0173 & 0.1767 & 0.4514 & 0.0028 & 0.0000 & 0.0000 & 0.0298 & 0.0297 & 0.0257 \\
\hline 147 & 0.0576 & 0.0988 & 0.0318 & 0.0548 & 0.0290 & 0.0107 & 0.0185 & 0.1523 & 0.4518 & 0.0046 & 0.0000 & 0.0000 & 0.0341 & 0.0301 & 0.0257 \\
\hline 148 & 0.0590 & 0.0992 & 0.0437 & 0.0540 & 0.0200 & 0.0215 & 0.0223 & 0.1198 & 0.4629 & 0.0052 & 0.0000 & 0.0000 & 0.0389 & 0.0306 & 0.0227 \\
\hline 149 & 0.0604 & 0.0997 & 0.0558 & 0.0535 & 0.0109 & 0.0322 & 0.0260 & 0.0873 & 0.4743 & 0.0059 & 0.0000 & 0.0000 & 0.0436 & 0.0311 & 0.0192 \\
\hline 150 & 0.0606 & 0.0980 & 0.0561 & 0.0492 & 0.0027 & 0.0267 & 0.0148 & 0.1398 & 0.4641 & 0.0043 & 0.0000 & 0.0000 & 0.0328 & 0.0300 & 0.0208 \\
\hline 151 & 0.0607 & 0.0968 & 0.0620 & 0.0448 & 0.0021 & 0.0286 & 0.0148 & 0.1332 & 0.4671 & 0.0050 & 0.0000 & 0.0000 & 0.0351 & 0.0300 & 0.0197 \\
\hline 152 & 0.0606 & 0.0955 & 0.0677 & 0.0404 & 0.0015 & 0.0306 & 0.0149 & 0.1265 & 0.4698 & 0.0057 & 0.0000 & 0.0000 & 0.0375 & 0.0300 & 0.0191 \\
\hline 153 & 0.0562 & 0.0982 & 0.0199 & 0.0553 & 0.0381 & 0.0000 & 0.0148 & 0.1847 & 0.4401 & 0.0040 & 0.0000 & 0.0000 & 0.0294 & 0.0296 & 0.0296 \\
\hline 154 & 0.0605 & 0.0992 & 0.0503 & 0.0537 & 0.0033 & 0.0248 & 0.0148 & 0.1464 & 0.4609 & 0.0037 & 0.0000 & 0.0000 & 0.0304 & 0.0300 & 0.0219 \\
\hline
\end{tabular}


Table B.2. Glass Oxide Compositions (mass fractions) ${ }^{(a)}$ for the 281 Glasses Used to Develop a Model for Viscosity at $1150^{\circ} \mathrm{C}$ (contd)

\begin{tabular}{|c|c|c|c|c|c|c|c|c|c|c|c|c|c|c|c|}
\hline \multirow{2}{*}{$\begin{array}{c}\text { Row } \\
\#^{(\mathbf{b})}\end{array}$} & \multicolumn{15}{|c|}{ Component } \\
\hline & $\mathbf{A l}_{2} \mathbf{O}_{3}$ & $\mathbf{B}_{2} \mathbf{O}_{3}$ & $\mathrm{CaO}$ & $\mathrm{Fe}_{2} \mathrm{O}_{3}$ & $\mathbf{K}_{2} \mathbf{O}$ & $\mathbf{L i}_{2} \mathbf{O}$ & MgO & $\mathrm{Na}_{2} \mathrm{O}$ & $\mathrm{SiO}_{2}$ & $\mathrm{SO}_{3}$ & $\mathrm{SnO}_{2}$ & $\mathbf{V}_{2} \mathbf{O}_{5}$ & ZnO & $\mathrm{ZrO}_{2}$ & Others1 \\
\hline 155 & 0.0614 & 0.0948 & 0.0193 & 0.0535 & 0.0237 & 0.0000 & 0.0143 & 0.2218 & 0.4255 & 0.0031 & 0.0000 & 0.0000 & 0.0285 & 0.0289 & 0.0251 \\
\hline 156 & 0.0605 & 0.1022 & 0.0207 & 0.0576 & 0.0188 & 0.0000 & 0.0154 & 0.1767 & 0.4587 & 0.0025 & 0.0000 & 0.0000 & 0.0307 & 0.0311 & 0.0249 \\
\hline 157 & 0.0618 & 0.1003 & 0.0677 & 0.0528 & 0.0018 & 0.0431 & 0.0298 & 0.0548 & 0.4858 & 0.0065 & 0.0000 & 0.0000 & 0.0485 & 0.0317 & 0.0155 \\
\hline 158 & 0.0613 & 0.1009 & 0.0641 & 0.0648 & 0.0015 & 0.0273 & 0.0151 & 0.1187 & 0.4673 & 0.0063 & 0.0000 & 0.0000 & 0.0301 & 0.0302 & 0.0123 \\
\hline 159 & 0.0607 & 0.1003 & 0.0510 & 0.0542 & 0.0007 & 0.0251 & 0.0151 & 0.1447 & 0.4664 & 0.0038 & 0.0000 & 0.0000 & 0.0306 & 0.0302 & 0.0174 \\
\hline 160 & 0.0611 & 0.1008 & 0.0511 & 0.0559 & 0.0009 & 0.0251 & 0.0151 & 0.1443 & 0.4661 & 0.0031 & 0.0000 & 0.0000 & 0.0306 & 0.0302 & 0.0156 \\
\hline 161 & 0.0604 & 0.0984 & 0.0499 & 0.0536 & 0.0010 & 0.0246 & 0.0148 & 0.1620 & 0.4558 & 0.0034 & 0.0000 & 0.0000 & 0.0300 & 0.0296 & 0.0165 \\
\hline 162 & 0.0616 & 0.1029 & 0.0522 & 0.0555 & 0.0008 & 0.0257 & 0.0155 & 0.1281 & 0.4768 & 0.0027 & 0.0000 & 0.0000 & 0.0314 & 0.0310 & 0.0158 \\
\hline 163 & 0.0607 & 0.0943 & 0.0736 & 0.0360 & 0.0009 & 0.0325 & 0.0149 & 0.1198 & 0.4728 & 0.0063 & 0.0000 & 0.0000 & 0.0399 & 0.0300 & .0182 \\
\hline 164 & 0.0604 & 0.0996 & 0.0504 & 0.0538 & 0.0026 & 0.0249 & 0.0148 & 0.1449 & 0.4631 & 0.0250 & 0.0000 & 0.0000 & 0.0305 & 0.0301 & 0.0000 \\
\hline 165 & 0.0564 & 0.0982 & 0.0199 & 0.0554 & 0.0388 & 0.0000 & 0.0148 & 0.1845 & 0.4410 & 0.0035 & 0.0000 & 0.0000 & 0.0296 & 0.0299 & 0.0282 \\
\hline 166 & 0.0603 & 0.0707 & 0.0208 & 0.0579 & 0.0388 & 0.0000 & 0.0118 & 0.1845 & 0.4606 & 0.0035 & 0.0000 & 0.0000 & 09 & 13 & 92 \\
\hline 167 & 0.0603 & 0.0894 & 0.0208 & 0.0286 & 0.0388 & 0.0000 & 0.0118 & 0.1845 & 0.4605 & 0.0035 & 0.0000 & 0.0000 & 0.0414 & 0.0313 & 0.0293 \\
\hline 168 & 0.0565 & 0.0996 & 0.0202 & & & 0.0000 & 0.0150 & & 0.4475 & 0.0033 & 0.0000 & 0.0000 & 0.0300 & 0.0304 & 0.0267 \\
\hline 169 & 0.0566 & 0.1009 & 0.0205 & 0.0570 & 0.0358 & 0.0000 & 0.0152 & 0.1702 & 0.4530 & 0.0032 & 0.0000 & 0.0000 & 0.0304 & 0.0308 & 0.0266 \\
\hline 170 & 0.0566 & 0.1009 & 0.0305 & 0.0570 & 0.0358 & 0.0000 & 0.0152 & 0.1702 & 0.4430 & 0.0032 & 0.0000 & 0.0000 & 0.0304 & 0.0308 & 0.0266 \\
\hline 171 & 0.0620 & 0.0890 & 0.0199 & 0.0698 & 0.0050 & 0.0000 & 0.0199 & 0.2001 & 0.4456 & 0.0010 & 0.0000 & 0.0000 & 0.0297 & 0.0299 & 0.0280 \\
\hline 172 & & & & & & & & & 0.4796 & & & & & & \\
\hline 173 & 0.0619 & 0.0995 & 0.1200 & 0.0000 & 0.0026 & 0.0581 & 0.0297 & 0.0549 & 0.4854 & 0.0128 & 0.0000 & 0.0000 & 0.0316 & 0.0316 & 0.0119 \\
\hline 174 & 0.0658 & 0.0995 & 0.0935 & 0.0000 & 0.0026 & 0.0505 & 0.0297 & 0.0549 & 0.4894 & 0.0128 & 0.0000 & 0.0000 & 0.0582 & 0.0316 & 0.0114 \\
\hline 175 & 0.0621 & 0.0997 & 0.0671 & 0.0330 & 0.0026 & 0.0582 & 0.0298 & 0.0550 & 0.4864 & 0.0128 & 0.0000 & 0.0000 & 0.0518 & 0.0317 & 0.0098 \\
\hline 176 & 0.0619 & 0.0994 & 0.0669 & 0.0530 & 0.0026 & 0.0430 & 0.0297 & 0.0548 & 0.4849 & 0.0128 & 0.0000 & 0.0000 & 0.0466 & 0.0316 & 0.0128 \\
\hline 177 & 0.0620 & 0.0996 & 0.0821 & 0.0531 & 0.0026 & 0.0431 & 0.0298 & 0.0549 & 0.4861 & 0.0128 & 0.0000 & 0.0000 & 0.0317 & 0.0317 & 0.0105 \\
\hline 178 & 0.0619 & 0.0994 & 0.0519 & 0.0530 & 0.0026 & 0.0430 & 0.0297 & 0.0549 & 0.4850 & 0.0128 & 0.0000 & 0.0000 & 0.0316 & 0.0316 & 0.0427 \\
\hline 179 & 0.0619 & 0.0844 & 0.0820 & 0.0530 & 0.0026 & 0.0431 & 0.0297 & 0.0548 & 0.4852 & 0.0128 & 0.0000 & 0.0000 & 0.0467 & 0.0316 & 0.0123 \\
\hline 180 & 0.0615 & 0.1233 & 0.1046 & 0.0000 & 0.0023 & 0.0461 & 0.0297 & 0.0662 & 0.4796 & 0.0078 & 0.0000 & 0.0000 & 0.0457 & 0.0315 & 0.0016 \\
\hline 181 & 0.0616 & 0.1235 & 0.0663 & 0.0325 & 0.0023 & 0.0462 & 0.0297 & 0.0663 & 0.4802 & 0.0078 & 0.0000 & 0.0000 & 0.0516 & 0.0315 & 0.0005 \\
\hline 182 & 0.0616 & 0.1080 & 0.0663 & 0.0326 & 0.0023 & 0.0462 & 0.0298 & 0.0663 & 0.4805 & 0.0078 & 0.0000 & 0.0000 & 0.0516 & 0.0316 & 0.0154 \\
\hline 183 & 0.0615 & 0.1234 & 0.0713 & 0.0325 & 0.0023 & 0.0411 & 0.0297 & 0.0662 & 0.4798 & 0.0078 & 0.0000 & 0.0000 & 0.0515 & 0.0315 & 0.0012 \\
\hline 184 & 0.0619 & 0.0995 & 0.0934 & 0.0191 & 0.0026 & 0.0505 & 0.0297 & 0.0549 & 0.4853 & 0.0128 & 0.0000 & 0.0000 & 0.0467 & 0.0316 & 0.0120 \\
\hline 185 & 0.0622 & 0.1011 & 0.0873 & 0.0191 & 0.0026 & 0.0533 & 0.0298 & 0.0551 & 0.4873 & 0.0128 & 0.0000 & 0.0000 & 0.0469 & 0.0317 & 0.0107 \\
\hline
\end{tabular}


Table B.2. Glass Oxide Compositions (mass fractions) ${ }^{(a)}$ for the 281 Glasses Used to Develop a Model for Viscosity at $1150^{\circ} \mathrm{C}$ (contd)

\begin{tabular}{|c|c|c|c|c|c|c|c|c|c|c|c|c|c|c|c|}
\hline \multirow{2}{*}{$\begin{array}{c}\text { Row } \\
\#^{(\mathbf{b})}\end{array}$} & \multicolumn{15}{|c|}{ Component } \\
\hline & $\mathbf{A l}_{2} \mathbf{O}_{3}$ & $\mathbf{B}_{2} \mathbf{O}_{3}$ & $\mathrm{CaO}$ & $\mathrm{Fe}_{2} \mathrm{O}_{3}$ & $\mathbf{K}_{2} \mathbf{O}$ & $\mathbf{L i}_{2} \mathbf{O}$ & MgO & $\mathrm{Na}_{2} \mathrm{O}$ & $\mathrm{SiO}_{2}$ & $\mathrm{SO}_{3}$ & $\mathrm{SnO}_{2}$ & $\mathbf{V}_{2} \mathbf{O}_{5}$ & ZnO & $\mathrm{ZrO}_{2}$ & Others1 \\
\hline 186 & 0.0619 & 0.1179 & 0.0868 & 0.0191 & 0.0026 & 0.0530 & 0.0150 & 0.0548 & 0.4848 & 0.0128 & 0.0000 & 0.0000 & 0.0466 & 0.0316 & 0.0129 \\
\hline 187 & 0.0618 & 0.1178 & 0.0868 & 0.0190 & 0.0026 & 0.0580 & 0.0150 & 0.0548 & 0.4933 & 0.0128 & 0.0000 & 0.0000 & 0.0466 & 0.0316 & 0.0000 \\
\hline 188 & 0616 & 0.1235 & 0.0663 & 0.0220 & 0.0023 & 0.0412 & 0.0297 & 0.0663 & 0.4803 & 0.0078 & 0.0000 & 0.0000 & 0.0516 & 0.0316 & 0.0158 \\
\hline 189 & .0616 & 0.1235 & 0.0713 & 0.0326 & 0.0023 & 0.0306 & 0.0298 & 0.0980 & 0.4708 & 0.0078 & 0.0000 & 0.0000 & 0.0401 & 0.0316 & 0.0002 \\
\hline 190 & 0.0616 & 0.1234 & 0.0713 & 0.0325 & 0.0023 & 0.0351 & 0.0297 & 0.0863 & 0.4775 & 0.0078 & 0.0000 & 0.0000 & 0.0400 & 0.0315 & 0.0009 \\
\hline 191 & 0.0616 & 0.1234 & 0.0713 & 0.0325 & 0.0199 & 0.0351 & 0.0297 & 0.0663 & 0.4799 & 0.0078 & 0.0000 & 0.0000 & 0.0400 & 0.0315 & 0.0009 \\
\hline 192 & 0.0615 & 0.1234 & 0.0713 & 0.0325 & 0.0023 & 0.0426 & 0.0297 & 0.0663 & 0.4799 & 0.0078 & 0.0000 & 0.0000 & 0.0500 & 0.0315 & 0.0011 \\
\hline 193 & 0.0616 & 0.1010 & 0.0713 & 0.0952 & 0.0023 & 0.0427 & 0.0148 & 0.0663 & 0.4553 & 0.0078 & 0.0000 & 0.0000 & 0.0501 & 0.0316 & 0.0000 \\
\hline 194 & 0.0618 & 0.1004 & 0.0678 & 0.0529 & 0.0019 & 0.0431 & 0.0297 & 0.0547 & 0.4862 & 0.0065 & 0.0000 & 0.0000 & 0.0484 & 0.0316 & .0148 \\
\hline 195 & 0.0619 & 0.1004 & 0.0669 & 0.0530 & 0.0019 & 0.0440 & 0.0297 & 0.0548 & 0.4865 & 0.0065 & 0.0000 & 0.0000 & 0.0485 & 0.0316 & 0.0143 \\
\hline 196 & 0.0618 & 0.1153 & 0.0528 & 0.0529 & 0.0019 & 0.0431 & 0.0297 & 0.0547 & 0.4863 & 0.0065 & 0.0000 & 0.0000 & 0.0484 & 0.0316 & 0.0148 \\
\hline 197 & 0.0619 & 0.1243 & 0.0574 & 0.0530 & 0.0019 & 0.0436 & 0.0297 & 0.0548 & 0.4866 & 0.0065 & 0.0000 & 0.0000 & 185 & 16 & 03 \\
\hline 198 & 0.0619 & 0.1004 & 0.0679 & 0.0530 & 0.0019 & 0.0501 & 0.0297 & 0.0408 & 0.4935 & 0.0065 & 0.0000 & 0.0000 & 0.0484 & 0.0316 & 0.0143 \\
\hline 199 & 0.0619 & & & & & 0.0362 & 0.0298 & & & 0.0065 & 0.0000 & 0.0000 & 0.0485 & 0.0317 & 0.0133 \\
\hline 200 & 0.0619 & 0.1004 & 0.0679 & 0.0530 & 0.0019 & 0.0222 & 0.0297 & 0.1012 & 0.4610 & 0.0065 & 0.0000 & 0.0000 & 0.0485 & 0.0316 & 0.0142 \\
\hline 201 & 0.0619 & 0.1003 & 0.0678 & 0.0529 & 0.0019 & 0.0536 & 0.0297 & 0.0338 & 0.4966 & 0.0065 & 0.0000 & 0.0000 & 0.0484 & 0.0316 & 0.0149 \\
\hline 202 & 0.0619 & 0.1003 & 0.0678 & 0.0530 & 0.0019 & 0.0576 & 0.0297 & 0.0246 & 0.5021 & 0.0065 & 0.0000 & 0.0000 & 0.0484 & 0.0316 & 0.0145 \\
\hline 203 & & & & & & & & & & & & & & 0.0302 & 0.0144 \\
\hline 204 & 0.0655 & 0.1005 & 0.0962 & 0.0001 & 0.0014 & 0.0273 & 0.0150 & 0.1196 & 0.4718 & 0.0048 & 0.0000 & 0.0000 & 0.0537 & 0.0302 & 0.0140 \\
\hline 205 & 0.0612 & 0.1005 & 0.0641 & 0.0410 & 0.0014 & 0.0273 & 0.0150 & 0.1196 & 0.4675 & 0.0048 & 0.0000 & 0.0000 & 0.0535 & 0.0302 & 0.0137 \\
\hline 206 & 0.0649 & 0.1005 & 0.0904 & 0.0242 & 0.0014 & 0.0273 & 0.0150 & 0.1196 & 0.4674 & 0.0048 & 0.0000 & 0.0000 & 0.0402 & 0.0302 & 0.0141 \\
\hline 207 & 0.0904 & 0.0603 & 0.1005 & 0.0804 & 0.0402 & 0.0452 & 0.0000 & 0.0502 & 0.4467 & 0.0100 & 0.0000 & 0.0000 & 0.0502 & 0.0000 & 0.0258 \\
\hline 208 & 0.0901 & 0.1301 & 0.1001 & 0.0000 & 0.0000 & 0.0450 & 0.0000 & 0.1307 & 0.4017 & 0.0029 & 0.0000 & 0.0000 & 0.0100 & 0.0400 & 0.0494 \\
\hline 209 & 0.0350 & 0.1301 & 0.0941 & 0.0531 & 0.0400 & 0.0450 & 0.0000 & 0.1148 & 0.4678 & 0.0100 & 0.0000 & 0.0000 & 0.0100 & 0.0000 & 0.0000 \\
\hline 210 & 0.0350 & 0.0600 & 0.1000 & 0.0800 & 0.0379 & 0.0000 & 0.0000 & 0.2201 & 0.4001 & 0.0052 & 0.0000 & 0.0000 & 0.0216 & 0.0000 & 0.0401 \\
\hline 211 & 0.0350 & 0.0600 & 0.0205 & 0.0000 & 0.0000 & 0.0088 & 0.0500 & 0.2200 & 0.5200 & 0.0052 & 0.0000 & 0.0000 & 0.0500 & 0.0000 & 0.0306 \\
\hline 212 & 0.0900 & 0.0936 & 0.0000 & 0.0628 & 0.0000 & 0.0000 & 0.0372 & 0.2200 & 0.4347 & 0.0016 & 0.0000 & 0.0000 & 0.0100 & 0.0000 & 0.0501 \\
\hline 213 & 0.0801 & 0.1201 & 0.0801 & 0.0650 & 0.0010 & 0.0300 & 0.0100 & 0.1001 & 0.4248 & 0.0040 & 0.0000 & 0.0000 & 0.0500 & 0.0100 & 0.0248 \\
\hline 214 & 0.0500 & 0.1200 & 0.0222 & 0.0650 & 0.0200 & 0.0050 & 0.0350 & 0.1701 & 0.4202 & 0.0024 & 0.0000 & 0.0000 & 0.0500 & 0.0350 & 0.0051 \\
\hline 215 & 0.0800 & 0.1201 & 0.0800 & 0.0650 & 0.0010 & 0.0300 & 0.0100 & 0.1001 & 0.4203 & 0.0040 & 0.0000 & 0.0000 & 0.0200 & 0.0250 & 0.0444 \\
\hline 216 & 0.0800 & 0.1200 & 0.0800 & 0.0200 & 0.0200 & 0.0050 & 0.0100 & 0.1317 & 0.4199 & 0.0033 & 0.0000 & 0.0000 & 0.0500 & 0.0350 & 0.0253 \\
\hline
\end{tabular}


Table B.2. Glass Oxide Compositions (mass fractions) ${ }^{(a)}$ for the 281 Glasses Used to Develop a Model for Viscosity at $1150^{\circ} \mathrm{C}$ (contd)

\begin{tabular}{|c|c|c|c|c|c|c|c|c|c|c|c|c|c|c|c|}
\hline \multirow{2}{*}{$\begin{array}{c}\text { Row } \\
\#^{(\mathbf{b})}\end{array}$} & \multicolumn{15}{|c|}{ Component } \\
\hline & $\mathrm{Al}_{2} \mathbf{O}_{3}$ & $\mathbf{B}_{2} \mathbf{O}_{3}$ & $\mathrm{CaO}$ & $\mathrm{Fe}_{2} \mathrm{O}_{3}$ & $\mathbf{K}_{2} \mathbf{O}$ & $\mathbf{L i}_{2} \mathbf{O}$ & MgO & $\mathrm{Na}_{2} \mathrm{O}$ & $\mathrm{SiO}_{2}$ & $\mathrm{SO}_{3}$ & $\mathrm{SnO}_{2}$ & $\mathrm{~V}_{2} \mathbf{O}_{5}$ & $\mathrm{ZnO}$ & $\mathrm{ZrO}_{2}$ & Others1 \\
\hline 217 & 0.0351 & 0602 & 1003 & 0.0803 & 0000 & .0452 & & & 4716 & .0100 & 0.0000 & .0000 & .0502 & .0000 & 9469 \\
\hline 218 & 0500 & 9700 & 0800 & .0200 & 0200 & 0226 & 0350 & 1700 & 4201 & 0024 & 0000 & & & & \\
\hline 219 & & & & & & & & & & & & & & & \\
\hline 220 & & & & & & & & & & & & & & & \\
\hline 221 & 501 & 702 & 0802 & .0200 & 0200 & 0.0301 & 100 & & 55 & & & & 01 & & \\
\hline 222 & 0800 & & & & & & & & & & & & 200 & & \\
\hline 223 & 1 & & 0 & & 00 & & & & & & & & 00 & & \\
\hline 224 & & & & & & & & & & & & & & & \\
\hline 225 & & & & & & & & & & & & & & & \\
\hline 226 & & & & & & & & & & & & & & & \\
\hline 227 & & & 00 & & & & & & & & & & & & \\
\hline 228 & & & & & & & & & & & & & & & \\
\hline 229 & & & & & & & & & & & & & & & \\
\hline 230 & & & & & & & & & & & & & & & \\
\hline 31 & 15 & 00 & 00 & & 0 & & 0 & & & & & & & & \\
\hline 32 & & & & & & & & & & & & & 00 & & \\
\hline 233 & & & & & & & & & & & & & 00 & & \\
\hline 234 & & & & & & & & & & & & & & & \\
\hline 235 & & & & & & & & & & & & & & & \\
\hline 236 & & & 0.0701 & & & & 50 & & & & & & & & \\
\hline 237 & 700 & 0800 & 0.0700 & 0.0 & 15 & 50 & & & & & & & & & 02 \\
\hline 238 & & & 0.0500 & 0.0 & 0 & & & & 05 & 35 & & & & & 90 \\
\hline 239 & & & & & & & & & & & & & & & \\
\hline 240 & & & & & & & & & & & & & & & \\
\hline 241 & 0.0700 & 0.0800 & 0.0700 & 0.0500 & 0030 & 0.0100 & 0.0250 & 0.1400 & 1 & 37 & 00 & 00 & 60 & 0 . & 297 \\
\hline 242 & 0.0600 & & 0.0500 & & 0.0010 & & & & & & & & & & 93 \\
\hline 243 & 0.0700 & 0.0868 & 0.0500 & 0.0500 & 0.0030 & 0.0250 & 0.0250 & 0.1200 & 0.4502 & 0.0042 & 0.0000 & 0.0000 & 0.0460 & 0.0300 & 0.0397 \\
\hline 244 & & & & & & & & & & & 0.0000 & & & 0.0200 & \\
\hline 245 & & & & & & & & & & & & & 0.0460 & & 0.0201 \\
\hline 246 & 0.0601 & 0.1102 & 0.0652 & 0.0501 & 0.0010 & 0.0100 & 0.0251 & 0.1202 & 0.4803 & 0.0040 & 0.0000 & 0.0000 & 0.0351 & 0.0301 & 0.0085 \\
\hline 247 & 0.0620 & 0.0800 & 0.0700 & 0.0500 & .0010 & 0.0100 & 0.0250 & 0.1401 & 0.4802 & 0.0035 & 0.0000 & 0.0000 & 0.0350 & 0.0300 & 0.0132 \\
\hline
\end{tabular}


Table B.2. Glass Oxide Compositions (mass fractions) ${ }^{(a)}$ for the 281 Glasses Used to Develop a Model for Viscosity at $1150^{\circ} \mathrm{C}$ (contd)

\begin{tabular}{|c|c|c|c|c|c|c|c|c|c|c|c|c|c|c|c|}
\hline \multirow{2}{*}{$\begin{array}{c}\text { Row } \\
\#^{(\mathbf{b})}\end{array}$} & \multicolumn{15}{|c|}{ Component } \\
\hline & $\mathbf{A l}_{2} \mathbf{O}_{3}$ & $\mathbf{B}_{2} \mathbf{O}_{3}$ & $\mathrm{CaO}$ & $\mathrm{Fe}_{2} \mathrm{O}_{3}$ & $\mathbf{K}_{2} \mathbf{O}$ & $\mathbf{L i}_{2} \mathbf{O}$ & MgO & $\mathrm{Na}_{2} \mathrm{O}$ & $\mathrm{SiO}_{2}$ & $\mathrm{SO}_{3}$ & $\mathrm{SnO}_{2}$ & $\mathbf{V}_{2} \mathbf{O}_{5}$ & ZnO & $\mathrm{ZrO}_{2}$ & Others1 \\
\hline 248 & 0.0623 & 0.1102 & 528 & 0.0501 & .0010 & 0.0100 & 0150 & & .4807 & 0.0040 & 0.0000 & 0.0000 & 0.0351 & 0.0200 & 0.0387 \\
\hline 249 & .0700 & 0.1091 & 0500 & .0300 & 0010 & .0100 & 0150 & & 4754 & 0.0037 & 0000 & .0000 & .0460 & & \\
\hline 250 & & 603 & & & & & & & & & & & & & \\
\hline 251 & & & & & & & & & & & & & & & \\
\hline 252 & 653 & 0970 & 611 & & 0020 & 167 & 203 & & 4697 & 0.0038 & & & & & \\
\hline 253 & 0609 & & & & & & & & & & & & & & \\
\hline 254 & 903 & 602 & & 03 & & & & & 60 & & & & 02 & & \\
\hline 255 & & & & & & & & & & & & & & & \\
\hline 256 & & & & & & & & & & & & & & & \\
\hline 257 & & & & & & & & & & & & & & & \\
\hline 258 & 00 & & & & & & & & 4001 & & & & & & \\
\hline 259 & 44 & 7 & & & 00 & & & & & & & & & & \\
\hline 260 & & & & & & & & & & & & & & & \\
\hline 261 & & & & & & & & & & & & & & & \\
\hline 262 & 610 & 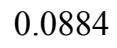 & & & 44 & 00 & & 66 & 32 & & 00 & & & & \\
\hline 263 & 649 & & & & 20 & & & & & & & & & & \\
\hline 264 & & 0.1006 & 642 & & & & & & & & & & & & \\
\hline 265 & & & & & & & & & & & & & & & \\
\hline 266 & & & & & & & & & & & & & & & \\
\hline 267 & 611 & & 0.0232 & & 0475 & & & & & & & & & & \\
\hline 268 & 695 & 0.0875 & 0.0197 & 0.0436 & 41 & 00 & 44 & & & & 00 & & 41 & & \\
\hline 269 & & & & & & & & & & & 00 & & & & \\
\hline 270 & & & & & & & & & & & & & & & \\
\hline 271 & & & & & & & & & & & & & & & \\
\hline 272 & 0.0610 & 0.1000 & 0.0202 & 0.0 & 0.0499 & 0.0000 & 48 & 0. & 0.4296 & 0.0 & 00 & 0. & 0. & 00 & 87 \\
\hline 273 & & & & & & & & & & & & & & & \\
\hline 274 & 0.0611 & 0.1001 & 0.0252 & 0.0551 & 0.0050 & 0.0000 & 0.0148 & 0.1966 & 0.4553 & 0.0038 & 0.0000 & 0.0000 & 0.0350 & 0.0300 & 0.0178 \\
\hline 275 & & 0.0980 & 0.0246 & & & & & & & & & & & & 0.0180 \\
\hline 276 & & & & & & & & & & & & & & 0.0300 & \\
\hline 277 & 0.0600 & 0.0982 & 0.0361 & 0.0541 & 0.0054 & 0.0049 & 0.0145 & 0.1899 & 0.4510 & 0.0046 & 0.0000 & 0.0000 & 0.0343 & 0.0294 & 0.0175 \\
\hline 278 & 0.0611 & 0.1002 & 0.0640 & 0.0551 & 0.0050 & 0.0323 & 0.0151 & 0.1252 & 0.4541 & 0.0055 & 0.0000 & 0.0000 & 0.0351 & 0.0301 & 0.0173 \\
\hline
\end{tabular}


Table B.2. Glass Oxide Compositions (mass fractions) ${ }^{(\mathrm{a})}$ for the 281 Glasses Used to Develop a Model for Viscosity at $1150^{\circ} \mathrm{C}$ (contd)

\begin{tabular}{|c|c|c|c|c|c|c|c|c|c|c|c|c|c|c|c|}
\hline \multirow{2}{*}{$\begin{array}{c}\text { Row } \\
\#^{(\mathbf{b})} \\
\end{array}$} & \multicolumn{15}{|c|}{ Component } \\
\hline & $\mathrm{Al}_{2} \mathrm{O}_{3}$ & $\mathbf{B}_{2} \mathbf{O}_{3}$ & $\mathrm{CaO}$ & $\mathrm{Fe}_{2} \mathrm{O}_{3}$ & $\mathbf{K}_{2} \mathbf{O}$ & $\mathbf{L i}_{2} \mathbf{O}$ & MgO & $\mathrm{Na}_{2} \mathrm{O}$ & $\mathrm{SiO}_{2}$ & $\mathrm{SO}_{3}$ & $\mathrm{SnO}_{2}$ & $\mathbf{V}_{2} \mathbf{O}_{5}$ & $\mathrm{ZnO}$ & $\mathrm{ZrO}_{2}$ & Others1 \\
\hline 279 & 0.0603 & 0.0988 & 0.0632 & 0.0544 & 0.0054 & 0.0317 & 0.0149 & 0.1355 & 0.4481 & 0.0059 & 0.0000 & 0.0000 & 0.0346 & 0.0296 & 0.0175 \\
\hline 280 & 0.0607 & 0.0995 & 0.0688 & 0.0547 & 0.0054 & 0.0409 & 0.0237 & 0.0895 & 0.4692 & 0.0069 & 0.0000 & 0.0000 & 0.0348 & 0.0298 & 0.0162 \\
\hline 281 & 0.0747 & 0.0851 & 0.0353 & 0.0000 & 0.0388 & 0.0000 & 0.0118 & 0.1845 & 0.4751 & 0.0035 & 0.0000 & 0.0000 & 0.0309 & 0.0313 & 0.0291 \\
\hline
\end{tabular}

(a) The mass fractions were rounded to four decimal places for display in this table. Hence, the 15 values in a row may not sum exactly to 1.0000 . The mass fractions of the glass components to more decimal places were used when fitting the viscosity at $1150^{\circ} \mathrm{C}$ model, and hence the results of fitting the model using the rounded compositions in this table may not yield exactly the same results.

(b) The glass names corresponding to the row numbers are listed in Table B.1. 
Table B.3. Viscosity at $1150^{\circ} \mathrm{C}$ Values and Temperature-Viscosity Pairs One to Seven for the 281 Glasses Used to Develop a Model for Viscosity at $1150^{\circ} \mathrm{C}$

\begin{tabular}{|c|c|c|c|c|c|c|c|c|c|c|c|c|c|c|c|}
\hline \multirow{2}{*}{$\begin{array}{c}\text { Row } \\
\#^{(a)}\end{array}$} & \multirow[b]{2}{*}{$\eta_{1150}^{(\mathrm{b})}$} & \multicolumn{14}{|c|}{ Temperature $\left({ }^{\circ} \mathrm{C}\right)$ and Viscosity (Poise) Pairs (Ti, Vi) } \\
\hline & & T1 & V1 & T2 & $\mathrm{V} 2$ & T3 & V3 & T4 & V4 & T5 & V5 & T6 & V6 & T7 & V7 \\
\hline 1 & 21.16 & 951 & 167.77 & 1049 & 52.59 & 1147 & 21.79 & 1246 & 10.60 & NA & NA & NA & NA & NA & NA \\
\hline 2 & 18.89 & 950 & 148.95 & 1048 & 46.80 & 1146 & 19.66 & 1245 & 9.61 & NA & NA & $\mathrm{NA}$ & NA & NA & NA \\
\hline 3 & 23.83 & 951 & 219.54 & 1049 & 62.58 & 1146 & 24.71 & 1245 & 11.71 & NA & NA & NA & NA & NA & NA \\
\hline 4 & 31.51 & 949 & 355.06 & 1047 & 92.19 & 1145 & 32.59 & 1244 & 14.88 & NA & NA & NA & NA & NA & NA \\
\hline 5 & 25.52 & 951 & 207.21 & 1050 & 62.90 & 1150 & 25.80 & 1250 & 12.40 & NA & NA & NA & NA & NA & NA \\
\hline 6 & 35.36 & 952 & 340.68 & 1050 & 97.93 & 1147 & 35.94 & 1246 & 16.22 & NA & NA & NA & NA & NA & NA \\
\hline 7 & 26.38 & 947 & 247.46 & 1047 & 69.39 & 1147 & 27.23 & 1246 & 12.99 & NA & NA & NA & NA & NA & NA \\
\hline 8 & 32.83 & 946 & 403.76 & 1046 & 101.52 & 1145 & 34.27 & 1244 & 14.49 & NA & NA & NA & NA & NA & NA \\
\hline 9 & 43.23 & 949 & 565.33 & 1047 & 136.62 & 1145 & 44.95 & 1244 & 19.06 & NA & NA & NA & NA & NA & NA \\
\hline 10 & 51.74 & 950 & 700.63 & 1047 & 169.15 & 1143 & 54.00 & 1241 & 23.28 & NA & NA & NA & NA & NA & NA \\
\hline 11 & 49.59 & 945 & 601.70 & 1043 & 155.45 & 1140 & 54.21 & 1238 & 23.53 & NA & NA & NA & NA & NA & NA \\
\hline 12 & 58.02 & 947 & 781.20 & 1044 & 188.08 & 1141 & 62.67 & 1239 & 27.10 & NA & NA & NA & NA & NA & NA \\
\hline 13 & 20.96 & 952 & 176.51 & 1052 & 52.13 & 1151 & 20.92 & 1252 & 9.82 & NA & NA & NA & NA & NA & NA \\
\hline 14 & 24.93 & 951 & 222.36 & 1050 & 62.83 & 1149 & 25.22 & 1248 & 12.47 & NA & NA & NA & NA & NA & NA \\
\hline 15 & 26.18 & 949 & 261.98 & 1047 & 71.03 & 1146 & 27.03 & 1245 & 13.01 & NA & NA & NA & NA & NA & NA \\
\hline 16 & 33.87 & 950 & 338.38 & 1049 & 90.45 & 1148 & 34.21 & 1248 & 16.56 & NA & NA & NA & NA & NA & NA \\
\hline 17 & 27.71 & 949 & 249.60 & 1049 & 70.56 & 1150 & 27.96 & 1251 & 13.35 & NA & NA & NA & NA & NA & NA \\
\hline 18 & 37.95 & 948 & 375.17 & 1047 & 106.03 & 1145 & 39.34 & 1245 & 17.95 & NA & NA & NA & NA & NA & NA \\
\hline 19 & 35.47 & 953 & 339.79 & 1052 & 94.06 & 1151 & 35.06 & 1251 & 16.13 & NA & NA & NA & NA & NA & NA \\
\hline 20 & 37.31 & 949 & 488.72 & 1047 & 117.43 & 1144 & 38.93 & 1242 & 17.01 & NA & NA & NA & NA & NA & NA \\
\hline 21 & 36.66 & 950 & 471.67 & 1050 & 111.09 & 1149 & 36.36 & 1250 & 15.78 & NA & NA & NA & NA & NA & NA \\
\hline 22 & 49.07 & 948 & 642.08 & 1045 & 158.30 & 1143 & 52.26 & 1241 & 22.02 & NA & NA & NA & NA & NA & NA \\
\hline 23 & 50.55 & 952 & 668.13 & 1051 & 154.05 & 1150 & 50.35 & 1250 & 21.06 & NA & NA & NA & NA & NA & NA \\
\hline 24 & 26.81 & 949 & 257.62 & 1049 & 72.43 & 1148 & 27.28 & 1247 & 12.49 & NA & NA & NA & NA & NA & NA \\
\hline 25 & 35.98 & 947 & 363.80 & 1047 & 100.47 & 1146 & 36.68 & 1245 & 17.33 & NA & NA & NA & NA & NA & NA \\
\hline 26 & 30.70 & 947 & 289.58 & 1047 & 79.90 & 1146 & 31.00 & 1245 & 16.26 & NA & NA & NA & NA & NA & NA \\
\hline 27 & 39.16 & 952 & 356.80 & 1053 & 102.11 & 1153 & 37.90 & 1253 & 17.32 & NA & NA & NA & NA & NA & NA \\
\hline 28 & 28.92 & 951 & 259.68 & 1051 & 74.58 & 1150 & 28.87 & 1249 & 13.70 & NA & NA & NA & NA & NA & NA \\
\hline 29 & 47.08 & 949 & 478.41 & 1048 & 131.97 & 1147 & 47.73 & 1245 & 22.33 & NA & NA & NA & NA & NA & NA \\
\hline 30 & 38.09 & 949 & 372.13 & 1050 & 103.67 & 1149 & 37.80 & 1249 & 17.58 & NA & NA & NA & NA & NA & NA \\
\hline
\end{tabular}


Table B.3. Viscosity at $1150^{\circ} \mathrm{C}$ Values and Temperature-Viscosity Pairs One to Seven for the 281 Glasses Used to Develop a Model for Viscosity at $1150^{\circ} \mathrm{C}$ (contd)

\begin{tabular}{|c|c|c|c|c|c|c|c|c|c|c|c|c|c|c|c|}
\hline \multirow{2}{*}{$\begin{array}{c}\text { Row } \\
\#^{(a)}\end{array}$} & \multirow[b]{2}{*}{$\eta_{1150}{ }^{(\mathrm{b})}$} & \multicolumn{14}{|c|}{ Temperature $\left({ }^{\circ} \mathrm{C}\right)$ and Viscosity (Poise) Pairs (Ti, Vi) } \\
\hline & & T1 & V1 & $\mathrm{T} 2$ & $\mathrm{~V} 2$ & T3 & V3 & T4 & V4 & T5 & V5 & T6 & V6 & T7 & V7 \\
\hline 31 & 35.12 & 949 & 344.08 & 1049 & 96.38 & 1149 & 35.31 & 1248 & 16.03 & NA & NA & NA & NA & NA & NA \\
\hline 32 & 24.88 & 946 & 250.25 & 1044 & 70.21 & 1142 & 26.60 & 1241 & 12.39 & NA & NA & NA & NA & NA & NA \\
\hline 33 & 29.09 & 946 & 296.91 & 1044 & 80.24 & 1142 & 30.65 & 1241 & 15.35 & NA & NA & NA & NA & NA & NA \\
\hline 34 & 21.78 & 947 & 226.42 & 1045 & 61.43 & 1144 & 23.12 & 1243 & 10.56 & NA & NA & NA & NA & NA & NA \\
\hline 35 & 22.20 & 948 & 246.22 & 1046 & 63.85 & 1145 & 23.13 & 1249 & 10.33 & NA & NA & NA & NA & NA & NA \\
\hline 36 & 56.77 & 971 & 499.59 & 1063 & 141.39 & 1160 & 52.21 & 1256 & 23.40 & NA & NA & NA & NA & NA & NA \\
\hline 37 & 66.90 & 960 & 694.28 & 1058 & 182.37 & 1157 & 62.27 & 1255 & 26.63 & NA & NA & NA & NA & NA & NA \\
\hline 38 & 61.42 & 952 & 771.52 & 1042 & 198.97 & 1129 & 75.73 & 1219 & 33.99 & NA & NA & NA & NA & NA & NA \\
\hline 39 & 127.89 & 954 & 1898.86 & 1056 & 402.50 & 1158 & 116.41 & 1260 & 43.62 & NA & NA & NA & NA & NA & NA \\
\hline 40 & 123.97 & 959 & 1510.79 & 1061 & 352.12 & 1162 & 108.94 & 1264 & 41.17 & NA & NA & NA & NA & NA & NA \\
\hline 41 & 101.39 & 961 & 1619.00 & 1061 & 302.04 & 1160 & 94.18 & 1260 & 33.79 & NA & NA & NA & NA & NA & NA \\
\hline 42 & 43.75 & 962 & 500.75 & 1062 & 114.77 & 1162 & 38.61 & 1262 & 17.63 & NA & NA & NA & NA & NA & NA \\
\hline 43 & 46.68 & 974 & 439.77 & 1071 & 114.80 & 1167 & 38.84 & 1264 & 16.54 & NA & NA & NA & NA & NA & NA \\
\hline 44 & 110.40 & 975 & 1118.82 & 1075 & 267.47 & 1175 & 84.48 & 1274 & 33.42 & NA & NA & NA & NA & NA & NA \\
\hline 45 & 128.01 & 976 & 1411.66 & 1073 & 313.54 & 1170 & 107.89 & 1267 & 40.04 & NA & NA & NA & NA & NA & NA \\
\hline 46 & 119.79 & 964 & 1542.94 & 1063 & 334.38 & 1161 & 109.82 & 1260 & 40.18 & NA & NA & NA & NA & NA & NA \\
\hline 47 & 144.65 & 968 & 1828.14 & 1066 & 382.11 & 1164 & 132.45 & 1262 & 47.19 & NA & NA & NA & NA & NA & NA \\
\hline 48 & 65.18 & 952 & 877.79 & 1052 & 201.81 & 1152 & 63.78 & 1252 & 25.37 & NA & NA & NA & NA & NA & NA \\
\hline 49 & 95.18 & 953 & 1388.50 & 1051 & 303.10 & 1150 & 96.34 & 1248 & 38.00 & NA & NA & NA & NA & NA & NA \\
\hline 50 & 71.41 & 959 & 933.36 & 1055 & 219.32 & 1150 & 70.86 & 1245 & 29.38 & NA & NA & NA & NA & NA & NA \\
\hline 51 & 60.29 & 961 & 787.65 & 1061 & 174.15 & 1160 & 53.59 & 1260 & 21.73 & NA & NA & NA & NA & NA & NA \\
\hline 52 & 56.59 & 958 & 791.73 & 1059 & 168.63 & 1159 & 51.00 & 1260 & 20.16 & NA & NA & NA & NA & NA & NA \\
\hline 53 & 54.22 & 959 & 739.50 & 1060 & 157.21 & 1160 & 48.53 & 1261 & 19.62 & NA & NA & NA & NA & NA & NA \\
\hline 54 & 58.03 & 951 & 932.11 & 1053 & 184.85 & 1157 & 54.08 & 1259 & 21.04 & NA & NA & NA & NA & NA & NA \\
\hline 55 & 55.79 & 953 & 858.47 & 1055 & 173.41 & 1159 & 50.90 & 1261 & 19.73 & NA & NA & NA & NA & NA & NA \\
\hline 56 & 82.74 & 957 & 1029.58 & 1060 & 231.27 & 1163 & 72.57 & 1266 & 28.65 & NA & NA & NA & NA & NA & NA \\
\hline 57 & 76.72 & 965 & 825.39 & 1065 & 197.34 & 1164 & 67.15 & 1264 & 27.86 & NA & NA & NA & NA & NA & NA \\
\hline
\end{tabular}


Table B.3. Viscosity at $1150^{\circ} \mathrm{C}$ Values and Temperature-Viscosity Pairs One to Seven for the 281 Glasses Used to Develop a Model for Viscosity at $1150^{\circ} \mathrm{C}$ (contd)

\begin{tabular}{|c|c|c|c|c|c|c|c|c|c|c|c|c|c|c|c|}
\hline \multirow{2}{*}{$\begin{array}{c}\text { Row } \\
\#^{(a)}\end{array}$} & \multirow[b]{2}{*}{$\eta_{1150}^{(\mathrm{b})}$} & \multicolumn{14}{|c|}{ Temperature $\left({ }^{\circ} \mathrm{C}\right)$ and Viscosity (Poise) Pairs (Ti, Vi) } \\
\hline & & T1 & V1 & $\mathbf{T 2}$ & V2 & T3 & V3 & T4 & V4 & T5 & V5 & T6 & V6 & T7 & V7 \\
\hline 58 & 65.25 & 951 & 808.51 & 1052 & 195.22 & 1153 & 63.30 & 1254 & 25.39 & NA & NA & NA & NA & NA & NA \\
\hline 59 & 74.78 & 956 & 931.52 & 1052 & 231.41 & 1149 & 74.43 & 1245 & 31.58 & NA & NA & NA & NA & NA & NA \\
\hline 60 & 26.72 & 957 & 221.74 & 1056 & 64.02 & 1156 & 25.84 & 1255 & 12.25 & NA & NA & NA & NA & NA & NA \\
\hline 61 & 74.32 & 966 & 864.61 & 1066 & 193.68 & 1166 & 63.50 & 1266 & 26.49 & NA & NA & NA & NA & NA & NA \\
\hline 62 & 33.63 & 956 & 295.59 & 1056 & 83.92 & 1155 & 32.10 & 1255 & 15.10 & NA & NA & NA & NA & NA & NA \\
\hline 63 & 27.84 & 960 & 242.79 & 1060 & 66.51 & 1160 & 25.74 & 1260 & 12.13 & NA & NA & NA & NA & NA & NA \\
\hline 64 & 35.60 & 955 & 361.31 & 1057 & 92.36 & 1158 & 32.63 & 1260 & 15.22 & NA & NA & NA & NA & NA & NA \\
\hline 65 & 29.83 & 956 & 275.71 & 1058 & 74.61 & 1159 & 27.26 & 1261 & 12.74 & NA & NA & NA & NA & NA & NA \\
\hline 66 & 30.84 & 956 & 332.24 & 1058 & 81.50 & 1159 & 28.38 & 1261 & 12.27 & NA & NA & NA & NA & NA & NA \\
\hline 67 & 29.02 & 959 & 285.51 & 1059 & 74.30 & 1160 & 26.45 & 1260 & 11.97 & NA & NA & NA & NA & NA & NA \\
\hline 68 & 23.23 & 962 & 202.46 & 1064 & 55.00 & 1165 & 20.36 & 1267 & 9.12 & NA & NA & NA & NA & NA & NA \\
\hline 69 & 19.60 & 985 & 97.94 & 1082 & 35.27 & 1179 & 15.68 & 1276 & 7.93 & NA & NA & NA & NA & NA & NA \\
\hline 70 & 22.07 & 959 & 158.43 & 1057 & 50.69 & 1155 & 21.34 & 1254 & 10.45 & NA & NA & NA & NA & NA & NA \\
\hline 71 & 16.99 & 962 & 104.97 & 1061 & 35.53 & 1160 & 15.88 & 1260 & 8.28 & NA & NA & NA & NA & NA & NA \\
\hline 72 & 19.31 & 959 & 139.79 & 1059 & 43.81 & 1159 & 18.02 & 1260 & 8.76 & NA & NA & NA & NA & NA & NA \\
\hline 73 & 23.05 & 963 & 158.79 & 1062 & 49.30 & 1161 & 21.23 & 1261 & 11.22 & NA & NA & NA & NA & NA & NA \\
\hline 74 & 17.07 & 958 & 143.45 & 1052 & 43.28 & 1148 & 17.52 & 1243 & 8.48 & NA & NA & NA & NA & NA & NA \\
\hline 75 & 17.39 & 978 & 122.05 & 1068 & 37.08 & 1158 & 16.75 & 1248 & 8.50 & NA & NA & NA & NA & NA & NA \\
\hline 76 & 17.25 & 969 & 93.10 & 1062 & 35.58 & 1157 & 16.52 & 1251 & 8.63 & NA & NA & NA & NA & NA & NA \\
\hline 77 & 21.51 & 992 & 104.09 & 1088 & 36.82 & 1184 & 16.64 & 1280 & 8.28 & NA & NA & NA & NA & NA & NA \\
\hline 78 & 19.59 & 964 & 127.03 & 1058 & 45.57 & 1153 & 19.04 & 1248 & 9.19 & NA & NA & NA & NA & NA & NA \\
\hline 79 & 21.84 & 986 & 106.21 & 1077 & 39.70 & 1169 & 19.27 & 1260 & 10.54 & NA & NA & NA & NA & NA & NA \\
\hline 80 & 21.54 & 977 & 144.46 & 1073 & 44.89 & 1169 & 18.29 & 1265 & 9.19 & NA & NA & NA & NA & NA & NA \\
\hline 81 & 40.04 & 957 & 386.23 & 1057 & 103.68 & 1158 & 36.09 & 1260 & 17.69 & NA & NA & NA & NA & NA & NA \\
\hline 82 & 33.61 & 957 & 325.44 & 1057 & 87.22 & 1158 & 31.23 & 1260 & 13.77 & NA & NA & NA & NA & NA & NA \\
\hline 83 & 32.57 & 956 & 308.91 & 1057 & 83.22 & 1157 & 30.46 & 1257 & 13.95 & NA & NA & NA & NA & NA & NA \\
\hline 84 & 27.50 & 958 & 254.92 & 1058 & 69.00 & 1158 & 25.82 & 1259 & 11.51 & NA & NA & NA & NA & NA & NA \\
\hline 85 & 20.78 & 957 & 159.47 & 1057 & 48.20 & 1158 & 19.25 & 1259 & 9.97 & NA & NA & NA & NA & NA & NA \\
\hline 86 & 28.83 & 954 & 282.76 & 1054 & 73.95 & 1156 & 27.34 & 1257 & 13.07 & NA & NA & NA & NA & NA & NA \\
\hline
\end{tabular}


Table B.3. Viscosity at $1150^{\circ} \mathrm{C}$ Values and Temperature-Viscosity Pairs One to Seven for the 281 Glasses Used to Develop a Model for Viscosity at $1150^{\circ} \mathrm{C}$ (contd)

\begin{tabular}{|c|c|c|c|c|c|c|c|c|c|c|c|c|c|c|c|}
\hline \multirow{2}{*}{$\begin{array}{c}\text { Row } \\
\#^{(\text {a) }}\end{array}$} & \multirow[b]{2}{*}{$\eta_{1150}^{(\mathrm{b})}$} & \multicolumn{14}{|c|}{ Temperature $\left({ }^{\circ} \mathrm{C}\right)$ and Viscosity (Poise) Pairs (Ti, Vi) } \\
\hline & & $\mathbf{T 1}$ & V1 & $\mathbf{T} 2$ & V2 & T3 & V3 & T4 & V4 & T5 & V5 & T6 & V6 & T7 & V7 \\
\hline 87 & 24.47 & 955 & 222.67 & 1057 & 60.62 & 1160 & 22.56 & 1262 & 10.30 & NA & NA & NA & NA & NA & NA \\
\hline 88 & 26.37 & 957 & 243.00 & 1058 & 64.77 & 1160 & 24.35 & 1261 & 11.35 & NA & NA & NA & NA & NA & NA \\
\hline 89 & 26.33 & 955 & 247.18 & 1057 & 64.56 & 1159 & 24.45 & 1261 & 11.68 & NA & NA & NA & NA & NA & NA \\
\hline 90 & 25.23 & 946 & 247.81 & 1044 & 69.08 & 1142 & 26.94 & 1241 & 13.01 & NA & NA & NA & NA & NA & NA \\
\hline 91 & 175.66 & 1214 & 79.10 & 1264 & 50.10 & 1314 & 32.90 & 1363 & 18.90 & 1412 & 13.90 & 1413 & 13.50 & 1462 & 9.50 \\
\hline 92 & 37.19 & 1139 & 40.80 & 1189 & 25.50 & 1239 & 16.40 & 1288 & 9.50 & 1337 & 6.80 & 1337 & 6.90 & 1387 & 4.80 \\
\hline 93 & 61.40 & 1140 & 66.50 & 1189 & 40.60 & 1239 & 26.40 & 1289 & 14.30 & 1338 & 10.20 & 1338 & 10.40 & 1388 & 7.20 \\
\hline 94 & 21.61 & 1089 & 41.60 & 1139 & 24.90 & 1189 & 15.80 & 1238 & 9.50 & 1287 & 6.60 & 1287 & 6.70 & 1336 & 4.70 \\
\hline 95 & 40.62 & 1140 & 43.90 & 1189 & 27.60 & 1239 & 18.40 & 1288 & 10.50 & 1337 & 7.30 & 1338 & 7.60 & 1387 & 5.20 \\
\hline 96 & 65.48 & 1139 & 74.50 & 1189 & 43.00 & 1238 & 26.00 & 1287 & 16.50 & 1287 & 16.60 & 1336 & 11.20 & 1337 & 11.20 \\
\hline 97 & 50.47 & 1089 & 108.80 & 1139 & 58.00 & 1189 & 32.00 & 1238 & 19.50 & 1238 & 19.70 & 1287 & 12.80 & 1287 & 12.90 \\
\hline 98 & 73.72 & 1139 & 85.20 & 1189 & 46.60 & 1238 & 27.10 & 1287 & 16.50 & 1287 & 16.50 & 1336 & 10.80 & 1337 & 10.80 \\
\hline 99 & 142.26 & 1188 & 86.90 & 1238 & 53.20 & 1287 & 29.80 & 1336 & 19.90 & 1336 & 20.30 & 1386 & 13.60 & 1386 & 14.40 \\
\hline 100 & 38.64 & 1089 & 78.60 & 1138 & 45.10 & 1188 & 25.60 & 1237 & 16.70 & 1238 & 16.40 & 1286 & 11.50 & 1287 & 11.00 \\
\hline 101 & 45.80 & 1089 & 95.20 & 1138 & 55.00 & 1187 & 29.50 & 1236 & 19.60 & 1237 & 19.00 & 1286 & 12.80 & 1286 & 13.60 \\
\hline 102 & 63.22 & 1139 & 71.30 & 1188 & 43.10 & 1238 & 24.60 & 1287 & 16.00 & 1287 & 16.50 & 1337 & 10.90 & 1337 & 11.70 \\
\hline 103 & 78.42 & 1138 & 89.40 & 1188 & 53.20 & 1237 & 31.70 & 1287 & 20.50 & 1287 & 21.00 & 1336 & 13.60 & 1336 & 14.50 \\
\hline 104 & 26.02 & 1090 & 50.70 & 1140 & 29.40 & 1189 & 17.20 & 1239 & 11.50 & 1239 & 11.60 & 1288 & 7.70 & 1288 & 8.00 \\
\hline 105 & 31.76 & 1089 & 62.80 & 1138 & 36.20 & 1188 & 21.30 & 1238 & 14.20 & 1238 & 14.30 & 1287 & 9.40 & 1287 & 9.70 \\
\hline 106 & 242.41 & 1188 & 154.50 & 1237 & 91.30 & 1287 & 56.30 & 1336 & 35.80 & 1386 & 23.60 & 1386 & 25.00 & 1436 & 15.70 \\
\hline 107 & 19.93 & 1089 & 36.40 & 1138 & 22.60 & 1188 & 13.80 & 1237 & 9.40 & 1237 & 9.50 & 1286 & 6.40 & 1286 & 6.60 \\
\hline 108 & 4.05 & 891 & 63.70 & 941 & 32.40 & 991 & 18.30 & 1040 & 11.00 & 1089 & 6.80 & 1089 & 6.80 & 1139 & 4.40 \\
\hline 109 & 134.21 & 1189 & 72.50 & 1239 & 42.10 & 1288 & 26.10 & 1338 & 14.40 & 1388 & 10.00 & 1389 & 9.70 & 1438 & 6.90 \\
\hline 110 & 178.98 & 1186 & 108.90 & 1236 & 60.10 & 1286 & 32.60 & 1336 & 19.80 & 1336 & 20.00 & 1386 & 12.90 & 1386 & 12.90 \\
\hline 111 & 145.29 & 1189 & 83.10 & 1239 & 47.70 & 1288 & 26.70 & 1338 & 16.50 & 1338 & 17.00 & 1388 & 10.50 & 1388 & 11.30 \\
\hline 112 & 36.94 & 1094 & 77.30 & 1145 & 39.70 & 1194 & 21.80 & 1244 & 13.30 & 1244 & 13.40 & 1294 & 8.10 & 1294 & 8.40 \\
\hline 113 & 70.99 & 1091 & 143.30 & 1141 & 78.60 & 1191 & 45.60 & 1241 & 28.20 & 1291 & 17.80 & 1341 & 12.00 & 1391 & 8.20 \\
\hline 114 & 54.93 & 1142 & 60.00 & 1192 & 35.80 & 1242 & 21.90 & 1292 & 14.90 & 1292 & 14.60 & 1342 & 10.00 & 1342 & 10.40 \\
\hline 115 & 69.30 & 1141 & 76.30 & 1191 & 45.30 & 1240 & 24.10 & 1290 & 15.70 & 1290 & 15.90 & 1340 & 10.60 & 1340 & 11.20 \\
\hline
\end{tabular}


Table B.3. Viscosity at $1150^{\circ} \mathrm{C}$ Values and Temperature-Viscosity Pairs One to Seven for the 281 Glasses Used to Develop a Model for Viscosity at $1150^{\circ} \mathrm{C}$ (contd)

\begin{tabular}{|c|c|c|c|c|c|c|c|c|c|c|c|c|c|c|c|}
\hline \multirow{2}{*}{$\begin{array}{c}\text { Row } \\
\#^{(a)}\end{array}$} & \multirow[b]{2}{*}{$\eta_{1150}{ }^{(\mathrm{b})}$} & \multicolumn{14}{|c|}{ Temperature $\left({ }^{\circ} \mathrm{C}\right)$ and Viscosity (Poise) Pairs (Ti, Vi) } \\
\hline & & T1 & V1 & $\mathbf{T 2}$ & V2 & T3 & V3 & T4 & V4 & T5 & V5 & T6 & V6 & T7 & V7 \\
\hline 116 & 93.69 & 1190 & 54.50 & 1239 & 33.10 & 1289 & 19.60 & 1339 & 13.30 & 1339 & 13.40 & 1388 & 9.30 & 1389 & 9.00 \\
\hline 117 & 44.24 & 1045 & 153.40 & 1144 & 48.50 & 1243 & 19.40 & 1342 & 7.40 & 1343 & 9.20 & 1392 & 5.80 & 1442 & 4.40 \\
\hline 118 & 89.30 & 1095 & 179.90 & 1145 & 94.60 & 1244 & 32.20 & 1343 & 12.30 & 1343 & 12.60 & 1393 & 8.20 & 1443 & 5.80 \\
\hline 119 & 77.02 & 1070 & 198.30 & 1119 & 109.40 & 1220 & 39.60 & 1318 & 14.40 & 1319 & 16.90 & 1368 & 10.60 & 1418 & 8.10 \\
\hline 120 & 47.14 & 1046 & 161.00 & 1145 & 49.70 & 1244 & 19.10 & 1342 & 8.70 & NA & NA & NA & NA & NA & NA \\
\hline 121 & 37.44 & 997 & 244.20 & 1096 & 69.40 & 1195 & 23.70 & 1294 & 9.60 & 1294 & 10.30 & 1344 & 7.10 & NA & NA \\
\hline 122 & 64.55 & 1138 & 76.80 & 1186 & 40.90 & 1236 & 24.80 & 1236 & 25.90 & 1285 & 15.60 & 1285 & 16.50 & 1286 & 17.10 \\
\hline 123 & 83.40 & 1092 & 179.30 & 1142 & 96.10 & 1191 & 50.80 & 1241 & 29.80 & 1241 & 31.10 & 1290 & 17.90 & 1290 & 19.30 \\
\hline 124 & 61.91 & 1091 & 133.50 & 1141 & 72.70 & 1190 & 38.60 & 1239 & 24.70 & 1240 & 23.70 & 1289 & 15.70 & 1290 & 14.90 \\
\hline 125 & 95.48 & 1138 & 111.10 & 1187 & 62.80 & 1236 & 31.80 & 1286 & 20.00 & 1286 & 20.80 & 1336 & 12.50 & 1336 & 13.90 \\
\hline 126 & 11.03 & 941 & 158.70 & 992 & 72.60 & 1041 & 35.90 & 1090 & 20.10 & 1091 & 20.10 & 1140 & 12.20 & 1141 & 11.90 \\
\hline 127 & 35.51 & $1088^{(\mathrm{c})}$ & $78.70^{(\mathrm{c})}$ & 1138 & 40.00 & 1187 & 24.90 & 1187 & 25.90 & 1236 & 15.80 & 1237 & 17.00 & 1237 & 18.80 \\
\hline 128 & 99.43 & 1143 & 108.10 & 1193 & 60.30 & 1243 & 30.10 & 1292 & 19.90 & 1293 & 18.80 & 1342 & 12.20 & 1342 & 13.40 \\
\hline 129 & 91.92 & 1187 & 59.90 & 1237 & 35.30 & 1286 & 21.80 & 1336 & 14.00 & 1336 & 14.20 & 1386 & 9.60 & 1386 & 9.70 \\
\hline 130 & 61.16 & 1142 & 67.30 & 1192 & 38.30 & 1242 & 22.60 & 1291 & 14.20 & 1292 & 14.00 & 1341 & 9.20 & 1341 & 9.50 \\
\hline 131 & 83.18 & 1191 & 54.90 & 1241 & 33.00 & 1291 & 20.90 & 1291 & 21.00 & 1340 & 13.70 & 1340 & 13.90 & 1342 & 13.60 \\
\hline 132 & 152.36 & 1187 & 90.30 & 1237 & 51.90 & 1286 & 31.30 & 1336 & 17.90 & 1386 & 11.70 & 1386 & 12.20 & 1435 & 7.60 \\
\hline 133 & 11.61 & 940 & 203.90 & 990 & 89.40 & 1040 & 41.90 & 1089 & 22.40 & 1090 & 21.30 & 1139 & 12.70 & 1140 & 12.80 \\
\hline 134 & 64.71 & 1188 & 40.80 & 1237 & 23.60 & 1286 & 15.80 & 1287 & 15.30 & 1336 & 10.30 & 1336 & 11.10 & 1337 & 11.90 \\
\hline 135 & 61.35 & 1142 & 67.30 & 1192 & 38.50 & 1243 & 22.50 & 1292 & 14.10 & 1293 & 14.00 & 1341 & 9.40 & 1342 & 9.60 \\
\hline 136 & 89.69 & 1195 & 46.90 & 1245 & 22.40 & 1294 & 14.20 & 1295 & 13.70 & 1344 & 8.60 & 1345 & 9.10 & 1345 & 9.00 \\
\hline 137 & 5.60 & 941 & 76.50 & 992 & 35.00 & 1041 & 17.30 & 1091 & 9.80 & 1091 & 9.90 & 1140 & 6.00 & 1141 & 5.90 \\
\hline 138 & 55.09 & 1090 & 116.80 & 1140 & 64.70 & 1188 & 35.00 & 1238 & 21.30 & 1238 & 21.40 & 1287 & 13.60 & 1287 & 13.70 \\
\hline 139 & 18.44 & 1090 & 33.40 & 1144 & 20.60 & 1190 & 12.60 & 1240 & 8.40 & 1240 & 8.40 & 1289 & 5.90 & 1290 & 6.00 \\
\hline 140 & 17.30 & 1040 & 54.70 & 1090 & 30.80 & 1090 & 31.30 & 1139 & 18.60 & 1139 & 18.80 & 1140 & 20.10 & 1188 & 12.10 \\
\hline 141 & 3.62 & 1230 & 1.84 & 1155 & 3.44 & 1058 & 9.28 & 958 & 33.25 & NA & NA & NA & NA & NA & NA \\
\hline 142 & 6.43 & 1235 & 3.07 & 1139 & 7.25 & 1043 & 20.09 & 948 & 76.08 & NA & NA & NA & NA & NA & NA \\
\hline 143 & 4.88 & 1250 & 2.07 & 1152 & 4.76 & 1053 & 14.07 & 955 & 55.43 & NA & NA & NA & NA & NA & NA \\
\hline 144 & 4.09 & 1261 & 1.63 & 1161 & 3.65 & 1061 & 10.39 & 961 & 37.85 & NA & NA & NA & NA & NA & NA \\
\hline
\end{tabular}


Table B.3. Viscosity at $1150^{\circ} \mathrm{C}$ Values and Temperature-Viscosity Pairs One to Seven for the 281 Glasses Used to Develop a Model for Viscosity at $1150^{\circ} \mathrm{C}$ (contd)

\begin{tabular}{|c|c|c|c|c|c|c|c|c|c|c|c|c|c|c|c|}
\hline \multirow{2}{*}{$\begin{array}{c}\text { Row } \\
\#^{(a)}\end{array}$} & \multirow[b]{2}{*}{$\eta_{1150}^{(\mathrm{b})}$} & \multicolumn{14}{|c|}{ Temperature $\left({ }^{\circ} \mathrm{C}\right)$ and Viscosity (Poise) Pairs (Ti, Vi) } \\
\hline & & T1 & V1 & $\mathbf{T 2}$ & V2 & T3 & V3 & T4 & V4 & T5 & V5 & T6 & V6 & T7 & V7 \\
\hline 145 & 5.79 & 1251 & 2.43 & 1152 & 5.66 & 1052 & 16.42 & 953 & 61.55 & NA & NA & NA & NA & NA & NA \\
\hline 146 & 4.85 & 1253 & 2.18 & 1153 & 4.64 & 1051 & 12.98 & 950 & 45.86 & NA & NA & NA & NA & NA & NA \\
\hline 147 & 6.15 & 1251 & 2.58 & 1152 & 6.00 & 1052 & 17.30 & 952 & 63.80 & NA & NA & NA & NA & NA & NA \\
\hline 148 & 5.41 & 1241 & 2.55 & 1139 & 6.09 & 1037 & 17.20 & 935 & 70.87 & NA & NA & NA & NA & NA & NA \\
\hline 149 & 5.24 & 1225 & 2.62 & 1128 & 6.64 & 1031 & 20.51 & 935 & 90.16 & NA & NA & NA & NA & NA & NA \\
\hline 150 & 4.07 & 1220 & 2.33 & 1125 & 5.07 & 1031 & 13.28 & 936 & 46.18 & NA & NA & NA & NA & NA & NA \\
\hline 151 & 3.47 & 1241 & 1.72 & 1144 & 3.64 & 1047 & 9.41 & 950 & 31.88 & NA & NA & NA & NA & NA & NA \\
\hline 152 & 3.32 & 1239 & 1.66 & 1141 & 3.57 & 1043 & 9.55 & 945 & 33.39 & NA & NA & NA & NA & NA & NA \\
\hline 153 & 5.95 & 1251 & 2.51 & 1153 & 5.78 & 1053 & 16.51 & 955 & 59.60 & NA & NA & NA & NA & NA & NA \\
\hline 154 & 3.45 & 1244 & 1.66 & 1146 & 3.57 & 1048 & 9.25 & 950 & 30.95 & NA & NA & NA & NA & NA & NA \\
\hline 155 & 4.18 & 1251 & 1.92 & 1151 & 4.05 & 1051 & 11.21 & 951 & 39.04 & NA & NA & NA & NA & NA & NA \\
\hline 156 & 9.34 & 1262 & 3.35 & 1162 & 8.10 & 1062 & 26.21 & 962 & 111.50 & NA & NA & NA & NA & NA & NA \\
\hline 157 & 5.22 & 1247 & 2.30 & 1149 & 5.28 & 1051 & 15.13 & 953 & 60.78 & NA & NA & NA & NA & NA & NA \\
\hline 158 & 5.58 & 1271 & 2.14 & 1169 & 4.63 & 1067 & 13.02 & 965 & 46.38 & NA & NA & NA & NA & NA & NA \\
\hline 159 & 4.55 & 1220 & 2.58 & 1126 & 5.69 & 1032 & 15.15 & 938 & 55.85 & NA & NA & NA & NA & NA & NA \\
\hline 160 & 4.36 & 1253 & 1.93 & 1153 & 4.16 & 1053 & 11.56 & 953 & 39.63 & NA & NA & NA & NA & NA & NA \\
\hline 161 & 3.51 & 1192 & 2.44 & 1143 & 3.81 & 1044 & 9.58 & 944 & 31.43 & NA & NA & NA & NA & NA & NA \\
\hline 162 & 5.44 & 1189 & 3.90 & 1085 & 10.16 & 985 & 33.20 & 935 & 67.79 & NA & NA & NA & NA & NA & NA \\
\hline 163 & 3.47 & 1249 & 1.62 & 1150 & 3.49 & 1051 & 9.08 & 952 & 32.29 & NA & NA & NA & NA & NA & NA \\
\hline 164 & 5.08 & 1241 & 2.42 & 1145 & 5.28 & 1050 & 14.25 & 954 & 51.51 & NA & NA & NA & NA & NA & NA \\
\hline 165 & 6.27 & 1261 & 2.41 & 1161 & 5.58 & 1061 & 16.18 & 960 & 59.86 & NA & NA & NA & NA & NA & NA \\
\hline 166 & 9.40 & 1261 & 3.43 & 1161 & 8.31 & 1061 & 25.89 & 961 & 104.93 & NA & NA & NA & NA & NA & NA \\
\hline 167 & 7.09 & 1228 & 3.54 & 1126 & 9.13 & 1023 & 28.13 & 921 & 124.17 & NA & NA & NA & NA & NA & NA \\
\hline 168 & 6.57 & 1239 & 3.06 & 1143 & 7.12 & 1046 & 19.82 & 950 & 77.16 & NA & NA & NA & NA & NA & NA \\
\hline 169 & 7.79 & 1233 & 3.71 & 1138 & 8.72 & 1042 & 25.76 & 948 & 96.30 & NA & NA & NA & NA & NA & NA \\
\hline 170 & 5.49 & 1230 & 2.69 & 1133 & 6.65 & 1034 & 19.29 & 936 & 82.63 & NA & NA & NA & NA & NA & NA \\
\hline 171 & 7.12 & 1233 & 3.49 & 1134 & 8.31 & 1034 & 24.72 & 935 & 100.18 & NA & NA & NA & NA & NA & NA \\
\hline 172 & 2.86 & 1258 & 1.20 & 1159 & 2.68 & 1056 & 7.23 & 956 & 25.79 & NA & NA & NA & NA & NA & NA \\
\hline 173 & 2.71 & 1225 & 1.45 & 1131 & 3.32 & 1038 & 8.39 & 945 & 30.20 & NA & NA & NA & NA & NA & NA \\
\hline
\end{tabular}


Table B.3. Viscosity at $1150^{\circ} \mathrm{C}$ Values and Temperature-Viscosity Pairs One to Seven for the 281 Glasses Used to Develop a Model for Viscosity at $1150^{\circ} \mathrm{C}$ (contd)

\begin{tabular}{|c|c|c|c|c|c|c|c|c|c|c|c|c|c|c|c|}
\hline \multirow{2}{*}{$\begin{array}{c}\text { Row } \\
\#^{(a)}\end{array}$} & \multirow[b]{2}{*}{$\eta_{1150}^{(\mathrm{b})}$} & \multicolumn{14}{|c|}{ Temperature $\left({ }^{\circ} \mathrm{C}\right)$ and Viscosity (Poise) Pairs (Ti, Vi) } \\
\hline & & T1 & V1 & $\mathbf{T 2}$ & V2 & T3 & V3 & T4 & V4 & T5 & V5 & T6 & V6 & T7 & V7 \\
\hline 174 & 4.08 & 1243 & 1.93 & 1143 & 4.36 & 1043 & 12.33 & 943 & 49.74 & NA & NA & NA & NA & NA & NA \\
\hline 175 & 3.46 & 1257 & 1.51 & 1156 & 3.33 & 1056 & 8.81 & 957 & 34.56 & NA & NA & NA & NA & NA & NA \\
\hline 176 & 5.34 & 1264 & 1.96 & 1164 & 4.61 & 1064 & 13.79 & 964 & 53.09 & NA & NA & NA & NA & NA & NA \\
\hline 177 & 4.48 & 1265 & 1.70 & 1162 & 3.95 & 1060 & 11.92 & 959 & 47.33 & NA & NA & NA & NA & NA & NA \\
\hline 178 & 7.65 & 1266 & 2.73 & 1166 & 6.48 & 1066 & 19.71 & 967 & 80.52 & NA & NA & NA & NA & NA & NA \\
\hline 179 & 5.77 & 1264 & 2.11 & 1164 & 4.97 & 1064 & 15.08 & 964 & 59.94 & NA & NA & NA & NA & NA & NA \\
\hline 180 & 3.67 & 1247 & 1.66 & 1147 & 3.81 & 1047 & 10.28 & 947 & 37.35 & NA & NA & NA & NA & NA & NA \\
\hline 181 & 3.75 & 1239 & 1.76 & 1141 & 4.13 & 1043 & 11.42 & 946 & 42.16 & NA & NA & NA & NA & NA & NA \\
\hline 182 & 3.89 & 1238 & 1.91 & 1140 & 4.31 & 1042 & 11.35 & 945 & 40.52 & NA & NA & NA & NA & NA & NA \\
\hline 183 & 4.20 & 1250 & 1.94 & 1150 & 4.11 & 1050 & 11.60 & 950 & 42.20 & NA & NA & NA & NA & NA & NA \\
\hline 184 & 3.55 & 1246 & 1.54 & 1146 & 3.75 & 1046 & 10.75 & 947 & 43.05 & NA & NA & NA & NA & NA & NA \\
\hline 185 & 3.34 & 1257 & 1.35 & 1159 & 3.06 & 1059 & 8.66 & 958 & 32.24 & NA & NA & NA & NA & NA & NA \\
\hline 186 & 3.24 & 1261 & 1.38 & 1159 & 3.00 & 1057 & 8.15 & 956 & 30.66 & NA & NA & NA & NA & NA & NA \\
\hline 187 & 3.36 & 1270 & 1.34 & 1168 & 2.87 & 1066 & 7.55 & 963 & 25.99 & NA & NA & NA & NA & NA & NA \\
\hline 188 & 6.35 & 1252 & 3.29 & 1152 & 6.01 & 1052 & 16.91 & 967 & 57.25 & NA & NA & NA & NA & NA & NA \\
\hline 189 & 4.17 & 1256 & 1.83 & 1156 & 4.01 & 1056 & 10.98 & 971 & 37.49 & NA & NA & NA & NA & NA & NA \\
\hline 190 & 3.99 & 1241 & 1.89 & 1141 & 4.46 & 1041 & 12.26 & 951 & 45.68 & NA & NA & NA & NA & NA & NA \\
\hline 191 & 5.43 & 1252 & 2.28 & 1152 & 5.30 & 1052 & 15.55 & 952 & 61.41 & NA & NA & NA & NA & NA & NA \\
\hline 192 & 3.88 & 1253 & 1.65 & 1153 & 3.70 & 1053 & 10.70 & 946 & 42.59 & NA & NA & NA & NA & NA & NA \\
\hline 193 & 3.29 & 1269 & 1.26 & 1169 & 2.75 & 1069 & 7.45 & 969 & 25.43 & NA & NA & NA & NA & NA & NA \\
\hline 194 & 5.35 & 1253 & 2.21 & 1155 & 4.99 & 1058 & 14.90 & 962 & 56.30 & NA & NA & NA & NA & NA & NA \\
\hline 195 & 5.12 & 1268 & 1.87 & 1168 & 4.25 & 1068 & 12.47 & 968 & 47.07 & NA & NA & NA & NA & NA & NA \\
\hline 196 & 5.46 & 1255 & 2.25 & 1155 & 5.18 & 1055 & 14.94 & 957 & 55.27 & NA & NA & NA & NA & NA & NA \\
\hline 197 & 4.78 & 1250 & 2.15 & 1149 & 5.04 & 1049 & 13.58 & 968 & 47.82 & NA & NA & NA & NA & NA & NA \\
\hline 198 & 4.73 & 1256 & 1.89 & 1156 & 4.43 & 1055 & 13.27 & 955 & 52.27 & NA & NA & NA & NA & NA & NA \\
\hline 199 & 5.38 & 1244 & 2.36 & 1144 & 5.89 & 1043 & 16.68 & 943 & 70.38 & NA & NA & NA & NA & NA & NA \\
\hline 200 & 5.43 & 1227 & 2.85 & 1131 & 6.47 & 1036 & 18.73 & 941 & 75.71 & NA & NA & NA & NA & NA & NA \\
\hline 201 & 4.80 & 1245 & 2.20 & 1146 & 5.01 & 1047 & 14.12 & 948 & 57.81 & NA & NA & NA & NA & NA & NA \\
\hline 202 & 5.49 & 1244 & 2.48 & 1144 & 5.87 & 1043 & 17.23 & 942 & 74.00 & NA & NA & NA & NA & NA & NA \\
\hline
\end{tabular}


Table B.3. Viscosity at $1150^{\circ} \mathrm{C}$ Values and Temperature-Viscosity Pairs One to Seven for the 281 Glasses Used to Develop a Model for Viscosity at $1150^{\circ} \mathrm{C}$ (contd)

\begin{tabular}{|c|c|c|c|c|c|c|c|c|c|c|c|c|c|c|c|}
\hline \multirow{2}{*}{$\begin{array}{c}\text { Row } \\
\#^{(a)}\end{array}$} & \multirow[b]{2}{*}{$\eta_{1150}^{(\mathrm{b})}$} & \multicolumn{14}{|c|}{ Temperature $\left({ }^{\circ} \mathrm{C}\right)$ and Viscosity (Poise) Pairs (Ti, Vi) } \\
\hline & & T1 & V1 & $\mathbf{T 2}$ & V2 & T3 & V3 & T4 & V4 & T5 & V5 & T6 & V6 & T7 & V7 \\
\hline 203 & 5.15 & 1246 & 2.36 & 1146 & 5.41 & 1046 & 14.57 & 946 & 54.35 & NA & NA & NA & NA & NA & NA \\
\hline 204 & 3.93 & 1243 & 1.84 & 1143 & 4.20 & 1043 & 11.65 & 943 & 43.72 & NA & NA & NA & NA & NA & NA \\
\hline 205 & 4.28 & 1258 & 1.77 & 1159 & 3.89 & 1059 & 11.00 & 959 & 40.05 & NA & NA & NA & NA & NA & NA \\
\hline 206 & 3.89 & 1255 & 1.54 & 1162 & 3.49 & 1062 & 9.68 & 963 & 33.16 & NA & NA & NA & NA & NA & NA \\
\hline 207 & 3.58 & 1252 & 1.69 & 1152 & 3.50 & 1053 & 9.41 & 953 & 37.70 & NA & NA & NA & NA & NA & NA \\
\hline 208 & 1.40 & 1238 & 0.72 & 1143 & 1.50 & 1047 & 3.63 & 952 & 11.49 & NA & NA & NA & NA & NA & NA \\
\hline 209 & 1.30 & 1239 & 0.75 & 1142 & 1.37 & 1045 & 2.91 & 948 & 7.34 & NA & NA & NA & NA & NA & NA \\
\hline 210 & 1.44 & 1246 & 0.76 & 1148 & 1.47 & 1051 & 3.24 & 954 & 9.14 & NA & NA & NA & NA & NA & NA \\
\hline 211 & 4.73 & 1234 & 2.51 & 1138 & 5.19 & 1042 & 13.19 & 945 & 43.06 & NA & NA & NA & NA & NA & NA \\
\hline 212 & 6.58 & 1245 & 3.08 & 1148 & 6.76 & 1051 & 17.63 & 955 & 62.40 & NA & NA & NA & NA & NA & NA \\
\hline 213 & 2.57 & 1247 & 1.25 & 1150 & 2.58 & 1052 & 6.46 & 955 & 21.49 & NA & NA & NA & NA & NA & NA \\
\hline 214 & 3.29 & 1237 & 1.58 & 1143 & 3.51 & 1049 & 9.42 & 955 & 33.20 & NA & NA & NA & NA & NA & NA \\
\hline 215 & 2.91 & 1243 & 1.44 & 1141 & 3.13 & 1039 & 8.53 & 939 & 30.65 & NA & NA & NA & NA & NA & NA \\
\hline 216 & 7.43 & 1243 & 3.07 & 1146 & 7.17 & 1049 & 27.19 & 952 & 114.67 & NA & NA & NA & NA & NA & NA \\
\hline 217 & 2.08 & 1244 & 0.96 & 1147 & 2.14 & 1051 & 5.99 & 953 & 25.32 & NA & NA & NA & NA & NA & NA \\
\hline 218 & 2.11 & 1240 & 1.05 & 1142 & 2.25 & 1045 & 5.84 & 948 & 19.60 & NA & NA & NA & NA & NA & NA \\
\hline 219 & 2.14 & 1242 & 1.06 & 1145 & 2.23 & 1048 & 5.82 & 952 & 19.89 & NA & NA & NA & NA & NA & NA \\
\hline 220 & 9.89 & 1245 & 4.01 & 1144 & 10.63 & 1043 & 35.33 & 943 & 169.66 & NA & NA & NA & NA & NA & NA \\
\hline 221 & 5.79 & 1238 & 2.73 & 1139 & 6.44 & 1040 & 19.16 & 942 & 79.79 & NA & NA & NA & NA & NA & NA \\
\hline 222 & 7.87 & 1238 & 4.00 & 1142 & 8.42 & 1046 & 21.82 & 951 & 75.12 & NA & NA & NA & NA & NA & NA \\
\hline 223 & 8.63 & 1240 & 4.08 & 1142 & 9.27 & 1044 & 25.56 & 947 & 89.10 & NA & NA & NA & NA & NA & NA \\
\hline 224 & 7.71 & 1236 & 3.78 & 1139 & 8.29 & 1043 & 23.91 & 946 & 83.61 & NA & NA & NA & NA & NA & NA \\
\hline 225 & 3.55 & 1243 & 1.81 & 1147 & 3.61 & 1051 & 9.03 & 957 & 29.00 & NA & NA & NA & NA & NA & NA \\
\hline 226 & 9.20 & 1241 & 4.33 & 1143 & 10.33 & 1044 & 30.93 & 945 & 213.07 & NA & NA & NA & NA & NA & NA \\
\hline 227 & 7.90 & 1248 & 3.42 & 1150 & 7.81 & 1052 & 22.85 & 955 & 86.02 & NA & NA & NA & NA & NA & NA \\
\hline 228 & 1.79 & 1249 & 0.83 & 1152 & 1.79 & 1053 & 4.55 & 956 & 16.21 & NA & NA & NA & NA & NA & NA \\
\hline 229 & 3.46 & 1246 & 1.73 & 1149 & 3.42 & 1052 & 8.72 & 955 & 27.72 & NA & NA & NA & NA & NA & NA \\
\hline 230 & 2.12 & 1247 & 1.01 & 1149 & 2.01 & 1050 & 5.69 & 952 & 15.89 & NA & NA & NA & NA & NA & NA \\
\hline 231 & 4.19 & 1248 & 2.04 & 1149 & 4.22 & 1050 & 10.58 & 951 & 34.56 & NA & NA & NA & NA & NA & NA \\
\hline
\end{tabular}


Table B.3. Viscosity at $1150^{\circ} \mathrm{C}$ Values and Temperature-Viscosity Pairs One to Seven for the 281 Glasses Used to Develop a Model for Viscosity at $1150^{\circ} \mathrm{C}$ (contd)

\begin{tabular}{|c|c|c|c|c|c|c|c|c|c|c|c|c|c|c|c|}
\hline \multirow{2}{*}{$\begin{array}{c}\text { Row } \\
\#^{(a)}\end{array}$} & \multirow[b]{2}{*}{$\eta_{1150}^{(\mathrm{b})}$} & \multicolumn{14}{|c|}{ Temperature $\left({ }^{\circ} \mathrm{C}\right)$ and Viscosity (Poise) Pairs (Ti, Vi) } \\
\hline & & T1 & V1 & $\mathbf{T 2}$ & V2 & T3 & V3 & T4 & V4 & T5 & V5 & T6 & V6 & T7 & V7 \\
\hline 232 & 1.89 & 1245 & 0.97 & 1148 & 1.92 & 1051 & 4.57 & 954 & 13.96 & NA & NA & NA & NA & NA & NA \\
\hline 233 & 1.61 & 1244 & 0.87 & 1147 & 1.67 & 1050 & 3.65 & 954 & 10.49 & NA & NA & NA & NA & NA & NA \\
\hline 234 & 2.46 & 1249 & 1.12 & 1149 & 2.50 & 1050 & 6.83 & 950 & 26.99 & NA & NA & NA & NA & NA & NA \\
\hline 235 & 3.69 & 1237 & 1.90 & 1140 & 3.98 & 1044 & 10.65 & 947 & 38.51 & NA & NA & NA & NA & NA & NA \\
\hline 236 & 3.20 & 1237 & 1.58 & 1142 & 3.44 & 1047 & 9.05 & 951 & 31.80 & NA & NA & NA & NA & NA & NA \\
\hline 237 & 5.42 & 1234 & 2.66 & 1138 & 6.05 & 1042 & 16.68 & 945 & 59.66 & NA & NA & NA & NA & NA & NA \\
\hline 238 & 4.92 & 1230 & 2.53 & 1135 & 5.61 & 1041 & 15.19 & 946 & 53.19 & NA & NA & NA & NA & NA & NA \\
\hline 239 & 1.32 & 1254 & 0.60 & 1154 & 1.30 & 1054 & 3.21 & 954 & 11.06 & NA & NA & NA & NA & NA & NA \\
\hline 240 & 7.24 & 1236 & 3.43 & 1140 & 7.93 & 1044 & 23.16 & 947 & 92.95 & NA & NA & NA & NA & NA & NA \\
\hline 241 & 6.69 & 1241 & 2.87 & 1143 & 7.30 & 1046 & 22.26 & 948 & 102.19 & NA & NA & NA & NA & NA & NA \\
\hline 242 & 5.49 & 1233 & 2.75 & 1134 & 6.32 & 1036 & 18.33 & 937 & 72.12 & NA & NA & NA & NA & NA & NA \\
\hline 243 & 4.43 & 1244 & 1.98 & 1147 & 4.55 & 1051 & 12.67 & 954 & 46.71 & NA & NA & NA & NA & NA & NA \\
\hline 244 & 7.34 & 1246 & 3.15 & 1149 & 7.49 & 1052 & 21.75 & 956 & 90.11 & NA & NA & NA & NA & NA & NA \\
\hline 245 & 6.62 & 1240 & 3.01 & 1146 & 6.90 & 1052 & 19.32 & 959 & 71.78 & NA & NA & NA & NA & NA & NA \\
\hline 246 & 7.62 & 1243 & 3.28 & 1144 & 8.09 & 1045 & 25.45 & 945 & 115.99 & NA & NA & NA & NA & NA & NA \\
\hline 247 & 7.06 & 1235 & 3.20 & 1143 & 7.58 & 1051 & 22.76 & 960 & 94.11 & NA & NA & NA & NA & NA & NA \\
\hline 248 & 8.65 & 1249 & 3.66 & 1151 & 8.62 & 1053 & 25.73 & 956 & 114.31 & NA & NA & NA & NA & NA & NA \\
\hline 249 & 7.47 & 1249 & 3.24 & 1149 & 7.51 & 1048 & 22.20 & 948 & 87.94 & NA & NA & NA & NA & NA & NA \\
\hline 250 & 12.27 & 1246 & 5.21 & 1149 & 12.70 & 1052 & 36.38 & 956 & 156.23 & NA & NA & NA & NA & NA & NA \\
\hline 251 & 5.81 & 1243 & 2.68 & 1146 & 6.04 & 1049 & 17.39 & 953 & 72.10 & NA & NA & NA & NA & NA & NA \\
\hline 252 & 6.24 & 1248 & 2.61 & 1154 & 5.90 & 1060 & 17.10 & 966 & 62.45 & NA & NA & NA & NA & NA & NA \\
\hline 253 & 5.11 & 1246 & 2.42 & 1149 & 5.15 & 1052 & 13.87 & 955 & 53.15 & NA & NA & NA & NA & NA & NA \\
\hline 254 & 4.04 & 1248 & 1.68 & 1150 & 4.00 & 1056 & 10.51 & 958 & 31.43 & NA & NA & NA & NA & NA & NA \\
\hline 255 & 11.16 & 1254 & 4.14 & 1155 & 10.59 & 1056 & 34.74 & 957 & 165.99 & NA & NA & NA & NA & NA & NA \\
\hline 256 & 1.19 & 1259 & 0.60 & 1158 & 1.12 & 1057 & 2.45 & 956 & 6.59 & NA & NA & NA & NA & NA & NA \\
\hline 257 & 2.54 & 1245 & 1.18 & 1148 & 2.58 & 1052 & 7.00 & 956 & 26.27 & NA & NA & NA & NA & NA & NA \\
\hline 258 & 4.94 & 1244 & 2.11 & 1144 & 5.25 & 1044 & 17.31 & 944 & 87.21 & NA & NA & NA & NA & NA & NA \\
\hline 259 & 11.64 & 1252 & 4.19 & 1152 & 11.39 & 1052 & 38.68 & 1002 & 89.42 & 952 & 199.67 & NA & NA & NA & NA \\
\hline 260 & 7.40 & 1225 & 3.52 & 1128 & 9.40 & 1030 & 32.84 & 932 & 162.66 & NA & NA & NA & NA & NA & NA \\
\hline
\end{tabular}


Table B.3. Viscosity at $1150^{\circ} \mathrm{C}$ Values and Temperature-Viscosity Pairs One to Seven for the 281 Glasses Used to Develop a Model for Viscosity at $1150^{\circ} \mathrm{C}$ (contd)

\begin{tabular}{|c|c|c|c|c|c|c|c|c|c|c|c|c|c|c|c|}
\hline \multirow{2}{*}{$\begin{array}{c}\text { Row } \\
\#^{(a)}\end{array}$} & \multirow[b]{2}{*}{$\eta_{1150}^{(b)}$} & \multicolumn{14}{|c|}{ Temperature $\left({ }^{\circ} \mathrm{C}\right)$ and Viscosity (Poise) Pairs (Ti, Vi) } \\
\hline & & T1 & V1 & $\mathbf{T 2}$ & V2 & T3 & V3 & $\mathbf{T 4}$ & V4 & T5 & V5 & T6 & V6 & $\mathbf{T 7}$ & V7 \\
\hline 261 & 12.65 & 1252 & 4.38 & 1150 & 12.64 & 1048 & 46.24 & 946 & 232.90 & NA & NA & NA & NA & NA & NA \\
\hline 262 & 7.01 & 1250 & 2.94 & 1151 & 6.89 & 1051 & 20.90 & 952 & 84.53 & NA & NA & NA & NA & NA & NA \\
\hline 263 & 5.19 & 1255 & 2.19 & 1155 & 4.87 & 1056 & 14.03 & 956 & 52.52 & NA & NA & NA & NA & NA & NA \\
\hline 264 & 4.89 & 1251 & 2.19 & 1151 & 4.74 & 1052 & 13.40 & 953 & 47.89 & NA & NA & NA & NA & NA & NA \\
\hline 265 & 8.42 & 1256 & 3.28 & 1156 & 7.85 & 1056 & 24.51 & 957 & 103.15 & NA & NA & NA & NA & NA & NA \\
\hline 266 & 4.16 & 1248 & 1.84 & 1153 & 3.95 & 1057 & 10.56 & 951 & 35.76 & NA & NA & NA & NA & NA & NA \\
\hline 267 & 5.94 & 1251 & 2.61 & 1150 & 5.95 & 1049 & 16.78 & 949 & 63.66 & NA & NA & NA & NA & NA & NA \\
\hline 268 & 4.75 & 1260 & 1.99 & 1158 & 4.39 & 1057 & 11.96 & 956 & 41.27 & NA & NA & NA & NA & NA & NA \\
\hline 269 & 5.10 & 1258 & 2.16 & 1157 & 4.79 & 1057 & 12.75 & 957 & 43.94 & NA & NA & NA & NA & NA & NA \\
\hline 270 & 5.95 & 1260 & 2.45 & 1159 & 5.46 & 1058 & 15.12 & 956 & 55.48 & NA & NA & NA & NA & NA & NA \\
\hline 271 & 3.18 & 1242 & 1.63 & 1142 & 3.41 & 1040 & 8.48 & 939 & 27.18 & NA & NA & NA & NA & NA & NA \\
\hline 272 & 5.25 & 1249 & 2.37 & 1149 & 5.28 & 1051 & 14.37 & 952 & 52.58 & NA & NA & NA & NA & NA & NA \\
\hline 273 & 3.31 & 1211 & 2.13 & 1109 & 4.61 & 1006 & 12.04 & 903 & 41.92 & NA & NA & NA & NA & NA & NA \\
\hline 274 & 5.35 & 1255 & 2.27 & 1159 & 4.94 & 1062 & 13.07 & 966 & 45.15 & NA & NA & NA & NA & NA & NA \\
\hline 275 & 4.43 & 1255 & 1.94 & 1159 & 4.10 & 1062 & 10.38 & 965 & 33.60 & NA & NA & NA & NA & NA & NA \\
\hline 276 & 5.85 & 1253 & 2.60 & 1158 & 5.39 & 1062 & 14.15 & 967 & 47.06 & NA & NA & NA & NA & NA & NA \\
\hline 277 & 3.90 & 1252 & 1.71 & 1157 & 3.66 & 1062 & 9.25 & 966 & 29.52 & NA & NA & NA & NA & NA & NA \\
\hline 278 & 2.35 & 1226 & 1.39 & 1124 & 2.86 & 1021 & 7.07 & 917 & 22.29 & NA & NA & NA & NA & NA & NA \\
\hline 279 & 2.14 & 1245 & 1.13 & 1145 & 2.22 & 1045 & 5.18 & 944 & 15.42 & NA & NA & NA & NA & NA & NA \\
\hline 280 & 2.53 & 1243 & 1.27 & 1147 & 2.59 & 1051 & 6.28 & 954 & 19.48 & NA & NA & NA & NA & NA & NA \\
\hline 281 & 10.77 & 1248 & 4.45 & 1148 & 11.13 & 1048 & 33.04 & 948 & 137.07 & NA & NA & NA & NA & NA & NA \\
\hline
\end{tabular}

(a) The glass names corresponding to the row numbers are listed in Table B.1.

(b) The $\eta_{1150}$ and the Vi values were rounded to two decimal places.

(c) This temperature-viscosity pair was judged to be an outlier and was not used to determine the $\eta_{1150}$ value for this glass. 
Table B.4. Temperature-Viscosity Pairs Eight to Eleven for the 281 Glasses Used to Develop a Model for Viscosity at $1150^{\circ} \mathrm{C}$

\begin{tabular}{|c|c|c|c|c|c|c|c|c|}
\hline \multirow{2}{*}{$\begin{array}{c}\text { Row } \\
\#^{(\mathbf{a})}\end{array}$} & \multicolumn{8}{|c|}{ Temperature $\left({ }^{\circ} \mathrm{C}\right)$ and Viscosity (Poise) Pairs (Ti, Vi) } \\
\hline & T8 & $\mathbf{V 8}$ & T9 & V9 & T10 & V10 & T11 & V11 \\
\hline 1 & NA & NA & NA & NA & NA & NA & NA & NA \\
\hline 2 & NA & NA & NA & NA & NA & NA & NA & NA \\
\hline 3 & NA & NA & NA & NA & NA & NA & NA & NA \\
\hline 4 & NA & NA & NA & NA & NA & NA & NA & NA \\
\hline 5 & NA & NA & NA & NA & NA & NA & NA & NA \\
\hline 6 & NA & NA & NA & NA & NA & NA & NA & NA \\
\hline 7 & NA & NA & NA & NA & NA & NA & NA & NA \\
\hline 8 & NA & NA & NA & NA & NA & NA & NA & NA \\
\hline 9 & NA & NA & NA & NA & NA & NA & NA & NA \\
\hline 10 & NA & NA & NA & NA & NA & NA & NA & NA \\
\hline 11 & NA & NA & NA & NA & NA & NA & NA & NA \\
\hline 12 & NA & NA & NA & NA & NA & NA & NA & NA \\
\hline 13 & NA & NA & NA & NA & NA & NA & NA & NA \\
\hline 14 & NA & NA & NA & NA & NA & NA & NA & NA \\
\hline 15 & NA & NA & NA & NA & NA & NA & NA & NA \\
\hline 16 & NA & NA & NA & NA & NA & NA & NA & NA \\
\hline 17 & NA & NA & NA & NA & NA & NA & NA & NA \\
\hline 18 & NA & NA & NA & NA & NA & NA & NA & NA \\
\hline 19 & NA & NA & NA & NA & NA & NA & NA & NA \\
\hline 20 & NA & NA & NA & NA & NA & NA & NA & NA \\
\hline 21 & NA & NA & NA & NA & NA & NA & NA & NA \\
\hline 22 & NA & NA & NA & NA & NA & NA & NA & NA \\
\hline 23 & NA & NA & NA & NA & NA & NA & NA & NA \\
\hline 24 & NA & NA & NA & NA & NA & NA & NA & NA \\
\hline 25 & NA & NA & NA & NA & NA & NA & NA & NA \\
\hline 26 & NA & NA & NA & NA & NA & NA & NA & NA \\
\hline 27 & NA & NA & NA & NA & NA & NA & NA & NA \\
\hline 28 & NA & NA & NA & NA & NA & NA & NA & NA \\
\hline 29 & NA & NA & NA & NA & NA & NA & NA & NA \\
\hline 30 & NA & NA & NA & NA & NA & NA & NA & NA \\
\hline
\end{tabular}


Table B.4. Temperature-Viscosity Pairs Eight to Eleven for the 281 Glasses Used to Develop a Model for Viscosity at $1150^{\circ} \mathrm{C}$

\begin{tabular}{|c|c|c|c|c|c|c|c|c|}
\hline \multirow{2}{*}{$\begin{array}{c}\text { Row } \\
\#^{(\text {a) }}\end{array}$} & \multicolumn{8}{|c|}{ Temperature $\left({ }^{\circ} \mathrm{C}\right)$ and Viscosity (Poise) Pairs (Ti, Vi) } \\
\hline & T8 & V8 & T9 & V9 & T10 & V10 & T11 & V11 \\
\hline 31 & NA & NA & NA & NA & NA & NA & NA & NA \\
\hline 32 & NA & NA & $\mathrm{NA}$ & NA & NA & NA & NA & NA \\
\hline 33 & NA & NA & NA & NA & NA & NA & NA & NA \\
\hline 34 & NA & NA & NA & NA & NA & NA & NA & NA \\
\hline 35 & NA & NA & NA & NA & NA & NA & NA & NA \\
\hline 36 & NA & NA & NA & NA & NA & NA & NA & NA \\
\hline 37 & NA & NA & NA & NA & NA & NA & NA & NA \\
\hline 38 & NA & NA & NA & NA & NA & NA & NA & NA \\
\hline 39 & NA & NA & NA & NA & NA & NA & NA & NA \\
\hline 40 & NA & NA & NA & NA & NA & NA & NA & NA \\
\hline 41 & NA & NA & NA & NA & NA & NA & NA & NA \\
\hline 42 & NA & NA & NA & NA & NA & NA & NA & NA \\
\hline 43 & NA & NA & NA & NA & NA & NA & NA & NA \\
\hline 44 & NA & NA & NA & NA & NA & NA & NA & NA \\
\hline 45 & NA & NA & NA & NA & NA & NA & NA & NA \\
\hline 46 & NA & NA & NA & NA & NA & NA & NA & NA \\
\hline 47 & NA & NA & NA & NA & NA & NA & NA & NA \\
\hline 48 & NA & NA & NA & NA & NA & NA & NA & NA \\
\hline 49 & NA & NA & NA & NA & NA & NA & NA & NA \\
\hline 50 & NA & NA & NA & NA & NA & NA & NA & NA \\
\hline 51 & NA & NA & NA & NA & NA & NA & NA & NA \\
\hline 52 & NA & NA & NA & NA & NA & NA & NA & NA \\
\hline 53 & NA & NA & NA & NA & NA & NA & NA & NA \\
\hline 54 & NA & NA & NA & NA & NA & NA & NA & NA \\
\hline 55 & NA & NA & NA & NA & NA & NA & NA & NA \\
\hline 56 & NA & NA & NA & NA & NA & NA & NA & NA \\
\hline 57 & NA & NA & NA & NA & NA & NA & NA & NA \\
\hline 58 & NA & NA & NA & NA & NA & NA & NA & NA \\
\hline 59 & NA & NA & NA & NA & NA & NA & NA & NA \\
\hline 60 & NA & NA & NA & NA & NA & NA & NA & NA \\
\hline
\end{tabular}


Table B.4. Temperature-Viscosity Pairs Eight to Eleven for the 281 Glasses Used to Develop a Model for Viscosity at $1150^{\circ} \mathrm{C}$

\begin{tabular}{|c|c|c|c|c|c|c|c|c|}
\hline \multirow{2}{*}{$\begin{array}{c}\text { Row } \\
\#^{(\text {a) }}\end{array}$} & \multicolumn{8}{|c|}{ Temperature $\left({ }^{\circ} \mathrm{C}\right)$ and Viscosity (Poise) Pairs (Ti, Vi) } \\
\hline & T8 & V8 & T9 & V9 & T10 & V10 & T11 & V11 \\
\hline 61 & NA & NA & NA & NA & NA & NA & NA & NA \\
\hline 62 & NA & NA & NA & NA & NA & NA & NA & NA \\
\hline 63 & NA & NA & NA & NA & NA & NA & NA & NA \\
\hline 64 & NA & NA & NA & NA & NA & NA & NA & NA \\
\hline 65 & NA & NA & NA & NA & NA & NA & NA & NA \\
\hline 66 & NA & NA & NA & NA & NA & NA & NA & NA \\
\hline 67 & NA & NA & NA & NA & NA & NA & NA & NA \\
\hline 68 & NA & NA & NA & NA & NA & NA & NA & NA \\
\hline 69 & NA & NA & NA & NA & NA & NA & NA & NA \\
\hline 70 & NA & NA & NA & NA & NA & NA & NA & NA \\
\hline 71 & NA & NA & NA & NA & NA & NA & NA & NA \\
\hline 72 & NA & NA & NA & NA & NA & NA & NA & NA \\
\hline 73 & NA & NA & NA & NA & NA & NA & NA & NA \\
\hline 74 & NA & NA & NA & NA & NA & NA & NA & NA \\
\hline 75 & NA & NA & NA & NA & NA & NA & NA & NA \\
\hline 76 & NA & NA & NA & NA & NA & NA & NA & NA \\
\hline 77 & NA & NA & NA & NA & NA & NA & NA & NA \\
\hline 78 & NA & NA & NA & NA & NA & NA & NA & NA \\
\hline 79 & NA & NA & NA & NA & NA & NA & NA & NA \\
\hline 80 & NA & NA & NA & NA & NA & NA & NA & NA \\
\hline 81 & NA & NA & NA & NA & NA & NA & NA & NA \\
\hline 82 & NA & NA & NA & NA & NA & NA & NA & NA \\
\hline 83 & NA & NA & NA & NA & NA & NA & NA & NA \\
\hline 84 & NA & NA & NA & NA & NA & NA & NA & NA \\
\hline 85 & NA & NA & NA & NA & NA & NA & NA & NA \\
\hline 86 & NA & NA & NA & NA & NA & NA & NA & NA \\
\hline 87 & NA & NA & NA & NA & NA & NA & NA & NA \\
\hline 88 & NA & NA & NA & NA & NA & NA & NA & NA \\
\hline 89 & NA & NA & NA & NA & NA & NA & NA & NA \\
\hline 90 & NA & NA & NA & NA & NA & NA & NA & NA \\
\hline 91 & 1462 & 10.10 & 1464 & 11.10 & $1516^{(b)}$ & $9.70^{(\mathrm{b})}$ & NA & NA \\
\hline
\end{tabular}


Table B.4. Temperature-Viscosity Pairs Eight to Eleven for the 281 Glasses Used to Develop a Model for Viscosity at $1150^{\circ} \mathrm{C}$

\begin{tabular}{|c|c|c|c|c|c|c|c|c|}
\hline \multirow{2}{*}{$\begin{array}{c}\text { Row } \\
\#^{(a)}\end{array}$} & \multicolumn{8}{|c|}{ Temperature $\left({ }^{\circ} \mathrm{C}\right)$ and Viscosity (Poise) Pairs (Ti, Vi) } \\
\hline & T8 & V8 & T9 & V9 & T10 & V10 & T11 & V11 \\
\hline 92 & 1387 & 5.00 & 1388 & 5.60 & 1437 & 3.70 & 1488 & 2.90 \\
\hline 93 & 1388 & 7.60 & 1388 & 8.90 & 1438 & 6.00 & 1489 & 5.00 \\
\hline 94 & 1337 & 4.90 & 1338 & 5.30 & 1387 & 3.70 & 1437 & 2.90 \\
\hline 95 & 1388 & 5.80 & 1388 & 6.60 & 1437 & 4.40 & 1488 & 3.50 \\
\hline 96 & 1338 & 11.40 & 1387 & 7.60 & 1437 & 5.50 & 1487 & 3.90 \\
\hline 97 & 1288 & 12.90 & 1337 & 8.40 & 1387 & 5.80 & 1438 & 4.00 \\
\hline 98 & 1338 & 10.80 & 1387 & 7.30 & 1437 & 4.90 & 1487 & 3.30 \\
\hline 99 & 1388 & 15.50 & 1436 & 10.10 & 1487 & 7.40 & 1538 & 5.60 \\
\hline 100 & 1287 & 12.20 & 1337 & 8.00 & 1387 & 5.90 & 1437 & 4.30 \\
\hline 101 & 1287 & 14.80 & 1336 & 9.40 & 1386 & 6.90 & 1436 & 5.10 \\
\hline 102 & 1337 & 12.60 & 1387 & 8.40 & 1437 & 6.20 & NA & NA \\
\hline 103 & 1337 & 15.00 & 1386 & 10.00 & 1437 & 7.30 & NA & NA \\
\hline 104 & 1289 & 8.30 & 1338 & 5.60 & 1388 & 4.10 & NA & NA \\
\hline 105 & 1287 & 9.90 & 1337 & 6.90 & 1387 & 4.90 & NA & NA \\
\hline 106 & 1436 & 17.70 & 1436 & 16.70 & NA & NA & NA & NA \\
\hline 107 & 1287 & 6.70 & 1336 & 4.60 & 1387 & 3.30 & NA & NA \\
\hline 108 & 1139 & 4.40 & 1140 & 4.40 & 1189 & 3.00 & NA & NA \\
\hline 109 & 1438 & 7.50 & 1438 & 7.70 & 1488 & 5.70 & NA & NA \\
\hline 110 & 1386 & 13.10 & 1436 & 8.40 & 1486 & 5.70 & 1536 & 4.00 \\
\hline 111 & 1388 & 11.90 & 1438 & 7.80 & 1488 & 5.50 & NA & NA \\
\hline 112 & 1294 & 8.50 & 1344 & 5.40 & 1344 & 5.70 & NA & NA \\
\hline 113 & NA & NA & NA & NA & NA & NA & NA & NA \\
\hline 114 & 1343 & 10.70 & 1392 & 7.30 & 1443 & 5.50 & NA & NA \\
\hline 115 & 1341 & 12.40 & 1390 & 7.90 & 1442 & 6.00 & NA & NA \\
\hline 116 & 1390 & 10.20 & 1439 & 7.10 & 1489 & 5.40 & NA & NA \\
\hline 117 & 1492 & 3.70 & NA & NA & NA & NA & NA & NA \\
\hline 118 & NA & NA & NA & NA & NA & NA & NA & NA \\
\hline 119 & NA & NA & NA & NA & NA & NA & NA & NA \\
\hline 120 & NA & NA & NA & NA & NA & NA & NA & NA \\
\hline 121 & NA & NA & NA & NA & NA & NA & NA & NA \\
\hline 122 & 1336 & 11.20 & 1385 & 7.60 & 1436 & 5.30 & NA & NA \\
\hline
\end{tabular}


Table B.4. Temperature-Viscosity Pairs Eight to Eleven for the 281 Glasses Used to Develop a Model for Viscosity at $1150^{\circ} \mathrm{C}$

\begin{tabular}{|c|c|c|c|c|c|c|c|c|}
\hline \multirow{2}{*}{$\begin{array}{c}\text { Row } \\
\#^{(a)} \\
\end{array}$} & \multicolumn{8}{|c|}{ Temperature $\left({ }^{\circ} \mathrm{C}\right)$ and Viscosity (Poise) Pairs (Ti, Vi) } \\
\hline & T8 & V8 & T9 & V9 & T10 & V10 & T11 & V11 \\
\hline 123 & 1292 & 19.80 & 1343 & 13.00 & 1392 & 8.60 & NA & NA \\
\hline 124 & 1290 & 16.10 & 1340 & 10.80 & 1392 & 7.80 & NA & NA \\
\hline 125 & 1336 & 15.00 & 1386 & 9.70 & 1436 & 6.90 & NA & NA \\
\hline 126 & 1141 & 12.40 & 1190 & 7.50 & 1240 & 5.20 & NA & NA \\
\hline 127 & 1286 & 12.00 & 1336 & 8.60 & 1386 & 6.30 & NA & NA \\
\hline 128 & 1344 & 14.40 & 1393 & 8.80 & 1444 & 6.30 & NA & NA \\
\hline 129 & 1386 & 9.70 & 1436 & 6.60 & 1487 & 4.70 & NA & NA \\
\hline 130 & 1342 & 9.50 & 1392 & 6.30 & 1442 & 4.30 & NA & NA \\
\hline 131 & 1392 & 9.40 & 1441 & 6.20 & 1492 & 4.30 & NA & NA \\
\hline 132 & 1436 & 8.20 & 1436 & 8.50 & 1485 & 6.00 & NA & NA \\
\hline 133 & 1140 & 13.10 & 1189 & 7.90 & 1240 & 5.40 & NA & NA \\
\hline 134 & 1386 & 8.00 & 1437 & 5.90 & 1488 & 4.80 & NA & NA \\
\hline 135 & 1343 & 9.80 & 1392 & 6.60 & 1443 & 4.60 & NA & NA \\
\hline 136 & 1395 & 5.80 & 1446 & 3.90 & NA & NA & NA & NA \\
\hline 137 & 1141 & 6.20 & 1190 & 3.90 & 1241 & 2.90 & NA & NA \\
\hline 138 & 1288 & 13.90 & 1337 & 9.10 & 1387 & 6.30 & 1438 & 4.40 \\
\hline 139 & 1291 & 6.40 & 1344 & 4.40 & 1390 & 3.20 & NA & NA \\
\hline 140 & 1237 & 8.20 & 1238 & 8.60 & 1287 & 5.80 & 1337 & 4.10 \\
\hline 141 & NA & NA & NA & NA & NA & NA & NA & NA \\
\hline 142 & NA & NA & NA & NA & NA & NA & NA & NA \\
\hline 143 & NA & NA & NA & NA & NA & NA & NA & NA \\
\hline 144 & NA & NA & NA & NA & NA & NA & NA & NA \\
\hline 145 & NA & NA & NA & NA & NA & NA & NA & NA \\
\hline 146 & NA & NA & NA & NA & NA & NA & NA & NA \\
\hline 147 & NA & NA & NA & NA & NA & NA & NA & NA \\
\hline 148 & NA & NA & NA & NA & NA & NA & NA & NA \\
\hline 149 & NA & NA & NA & NA & NA & NA & NA & NA \\
\hline 150 & NA & NA & NA & NA & NA & NA & NA & NA \\
\hline 151 & NA & NA & NA & NA & NA & NA & NA & NA \\
\hline 152 & NA & NA & NA & NA & NA & NA & NA & NA \\
\hline 153 & NA & NA & NA & NA & NA & NA & NA & NA \\
\hline
\end{tabular}


Table B.4. Temperature-Viscosity Pairs Eight to Eleven for the 281 Glasses Used to Develop a Model for Viscosity at $1150^{\circ} \mathrm{C}$

\begin{tabular}{|c|c|c|c|c|c|c|c|c|}
\hline \multirow{2}{*}{$\begin{array}{c}\text { Row } \\
\#^{(a)}\end{array}$} & \multicolumn{8}{|c|}{ Temperature $\left({ }^{\circ} \mathrm{C}\right)$ and Viscosity (Poise) Pairs (Ti, Vi) } \\
\hline & T8 & V8 & T9 & V9 & T10 & V10 & T11 & V11 \\
\hline 154 & NA & NA & NA & NA & NA & NA & NA & NA \\
\hline 155 & NA & NA & NA & NA & NA & NA & NA & NA \\
\hline 156 & NA & NA & NA & NA & NA & NA & NA & NA \\
\hline 157 & NA & NA & NA & NA & NA & NA & NA & NA \\
\hline 158 & NA & NA & NA & NA & NA & NA & NA & NA \\
\hline 159 & NA & NA & NA & NA & NA & NA & NA & NA \\
\hline 160 & NA & NA & NA & NA & NA & NA & NA & NA \\
\hline 161 & NA & NA & NA & NA & NA & NA & NA & NA \\
\hline 162 & NA & NA & NA & NA & NA & NA & NA & NA \\
\hline 163 & NA & NA & NA & NA & NA & NA & NA & NA \\
\hline 164 & NA & NA & NA & NA & NA & NA & NA & NA \\
\hline 165 & NA & NA & NA & NA & NA & NA & NA & NA \\
\hline 166 & NA & NA & NA & NA & NA & NA & NA & NA \\
\hline 167 & NA & NA & NA & NA & NA & NA & NA & NA \\
\hline 168 & NA & NA & NA & NA & NA & NA & NA & NA \\
\hline 169 & NA & NA & NA & NA & NA & NA & NA & NA \\
\hline 170 & NA & NA & NA & NA & NA & NA & NA & NA \\
\hline 171 & NA & NA & NA & NA & NA & NA & NA & NA \\
\hline 172 & NA & NA & NA & NA & NA & NA & NA & NA \\
\hline 173 & NA & NA & NA & NA & NA & NA & NA & NA \\
\hline 174 & NA & NA & NA & NA & NA & NA & NA & NA \\
\hline 175 & NA & NA & NA & NA & NA & NA & NA & NA \\
\hline 176 & NA & NA & NA & NA & NA & NA & NA & NA \\
\hline 177 & NA & NA & NA & NA & NA & NA & NA & NA \\
\hline 178 & NA & NA & NA & NA & NA & NA & NA & NA \\
\hline 179 & NA & NA & NA & NA & NA & NA & NA & NA \\
\hline 180 & NA & NA & NA & NA & NA & NA & NA & NA \\
\hline 181 & NA & NA & NA & NA & NA & NA & NA & NA \\
\hline 182 & NA & NA & NA & NA & NA & NA & NA & NA \\
\hline 183 & NA & NA & NA & NA & NA & NA & NA & NA \\
\hline 184 & NA & NA & NA & NA & NA & NA & NA & NA \\
\hline
\end{tabular}


Table B.4. Temperature-Viscosity Pairs Eight to Eleven for the 281 Glasses Used to Develop a Model for Viscosity at $1150^{\circ} \mathrm{C}$

\begin{tabular}{|c|c|c|c|c|c|c|c|c|}
\hline \multirow{2}{*}{$\begin{array}{c}\text { Row } \\
\#^{(a)}\end{array}$} & \multicolumn{8}{|c|}{ Temperature $\left({ }^{\circ} \mathrm{C}\right)$ and Viscosity (Poise) Pairs (Ti, Vi) } \\
\hline & T8 & V8 & T9 & V9 & T10 & V10 & T11 & V11 \\
\hline 185 & NA & NA & NA & NA & NA & NA & NA & NA \\
\hline 186 & NA & NA & NA & NA & NA & NA & NA & NA \\
\hline 187 & NA & NA & NA & NA & NA & NA & NA & NA \\
\hline 188 & NA & NA & NA & NA & NA & NA & NA & NA \\
\hline 189 & NA & NA & NA & NA & NA & NA & NA & NA \\
\hline 190 & NA & NA & NA & NA & NA & NA & NA & NA \\
\hline 191 & NA & NA & NA & NA & NA & NA & NA & NA \\
\hline 192 & NA & NA & NA & NA & NA & NA & NA & NA \\
\hline 193 & NA & NA & NA & NA & NA & NA & NA & NA \\
\hline 194 & NA & NA & NA & NA & NA & NA & NA & NA \\
\hline 195 & NA & NA & NA & NA & NA & NA & NA & NA \\
\hline 196 & NA & NA & NA & NA & NA & NA & NA & NA \\
\hline 197 & NA & NA & NA & NA & NA & NA & NA & NA \\
\hline 198 & NA & NA & NA & NA & NA & NA & NA & NA \\
\hline 199 & NA & NA & NA & NA & NA & NA & NA & NA \\
\hline 200 & NA & NA & NA & NA & NA & NA & NA & NA \\
\hline 201 & NA & NA & NA & NA & NA & NA & NA & NA \\
\hline 202 & NA & NA & NA & NA & NA & NA & NA & NA \\
\hline 203 & NA & NA & NA & NA & NA & NA & NA & NA \\
\hline 204 & NA & NA & NA & NA & NA & NA & NA & NA \\
\hline 205 & NA & NA & NA & NA & NA & NA & NA & NA \\
\hline 206 & NA & NA & NA & NA & NA & NA & NA & NA \\
\hline 207 & NA & NA & NA & NA & NA & NA & NA & NA \\
\hline 208 & NA & NA & NA & NA & NA & NA & NA & NA \\
\hline 209 & NA & NA & NA & NA & NA & NA & NA & NA \\
\hline 210 & NA & NA & NA & NA & NA & NA & NA & NA \\
\hline 211 & NA & NA & NA & NA & NA & NA & NA & NA \\
\hline 212 & NA & NA & NA & NA & NA & NA & NA & NA \\
\hline 213 & NA & NA & NA & NA & NA & NA & NA & NA \\
\hline 214 & NA & NA & NA & NA & NA & NA & NA & NA \\
\hline 215 & NA & NA & NA & NA & NA & NA & NA & NA \\
\hline
\end{tabular}


Table B.4. Temperature-Viscosity Pairs Eight to Eleven for the 281 Glasses Used to Develop a Model for Viscosity at $1150^{\circ} \mathrm{C}$

\begin{tabular}{|c|c|c|c|c|c|c|c|c|}
\hline \multirow{2}{*}{$\begin{array}{c}\text { Row } \\
\#^{(a)}\end{array}$} & \multicolumn{8}{|c|}{ Temperature $\left({ }^{\circ} \mathrm{C}\right)$ and Viscosity (Poise) Pairs (Ti, Vi) } \\
\hline & T8 & V8 & T9 & V9 & T10 & V10 & T11 & V11 \\
\hline 216 & NA & NA & NA & NA & NA & NA & NA & NA \\
\hline 217 & NA & NA & NA & NA & NA & NA & NA & NA \\
\hline 218 & NA & NA & NA & NA & NA & NA & NA & NA \\
\hline 219 & NA & NA & NA & NA & NA & NA & NA & NA \\
\hline 220 & NA & NA & NA & NA & NA & NA & NA & NA \\
\hline 221 & NA & NA & NA & NA & NA & NA & NA & NA \\
\hline 222 & NA & NA & NA & NA & NA & NA & NA & NA \\
\hline 223 & NA & NA & NA & NA & NA & NA & NA & NA \\
\hline 224 & NA & NA & NA & NA & NA & NA & NA & NA \\
\hline 225 & NA & NA & NA & NA & NA & NA & NA & NA \\
\hline 226 & NA & NA & NA & NA & NA & NA & NA & NA \\
\hline 227 & NA & NA & NA & NA & NA & NA & NA & NA \\
\hline 228 & NA & NA & NA & NA & NA & NA & NA & NA \\
\hline 229 & NA & NA & NA & NA & NA & NA & NA & NA \\
\hline 230 & NA & NA & NA & NA & NA & NA & NA & NA \\
\hline 231 & NA & NA & NA & NA & NA & NA & NA & NA \\
\hline 232 & NA & NA & NA & NA & NA & NA & NA & NA \\
\hline 233 & NA & NA & NA & NA & NA & NA & NA & NA \\
\hline 234 & NA & NA & NA & NA & NA & NA & NA & NA \\
\hline 235 & NA & NA & NA & NA & NA & NA & NA & NA \\
\hline 236 & NA & NA & NA & NA & NA & NA & NA & NA \\
\hline 237 & NA & NA & NA & NA & NA & NA & NA & NA \\
\hline 238 & NA & NA & NA & NA & NA & NA & NA & NA \\
\hline 239 & NA & NA & NA & NA & NA & NA & NA & NA \\
\hline 240 & NA & NA & NA & NA & NA & NA & NA & NA \\
\hline 241 & NA & NA & NA & NA & NA & NA & NA & NA \\
\hline 242 & NA & NA & NA & NA & NA & NA & NA & NA \\
\hline 243 & NA & NA & NA & NA & NA & NA & NA & NA \\
\hline 244 & NA & NA & NA & NA & NA & NA & NA & NA \\
\hline 245 & NA & NA & NA & NA & NA & NA & NA & NA \\
\hline 246 & NA & NA & NA & NA & NA & NA & NA & NA \\
\hline
\end{tabular}


Table B.4. Temperature-Viscosity Pairs Eight to Eleven for the 281 Glasses Used to Develop a Model for Viscosity at $1150^{\circ} \mathrm{C}$

\begin{tabular}{|c|c|c|c|c|c|c|c|c|}
\hline \multirow{2}{*}{$\begin{array}{c}\text { Row } \\
\#^{(a)}\end{array}$} & \multicolumn{8}{|c|}{ Temperature $\left({ }^{\circ} \mathrm{C}\right)$ and Viscosity (Poise) Pairs (Ti, Vi) } \\
\hline & T8 & V8 & T9 & V9 & T10 & V10 & T11 & V11 \\
\hline 247 & NA & NA & NA & NA & $\mathrm{NA}$ & $\mathrm{NA}$ & NA & NA \\
\hline 248 & NA & NA & NA & NA & NA & NA & NA & NA \\
\hline 249 & NA & NA & NA & NA & NA & NA & NA & NA \\
\hline 250 & NA & NA & NA & NA & NA & NA & NA & NA \\
\hline 251 & NA & NA & NA & NA & NA & NA & NA & NA \\
\hline 252 & NA & NA & NA & NA & NA & NA & NA & NA \\
\hline 253 & NA & NA & NA & NA & NA & NA & NA & NA \\
\hline 254 & NA & NA & NA & NA & NA & NA & NA & NA \\
\hline 255 & NA & NA & NA & NA & NA & NA & NA & NA \\
\hline 256 & NA & NA & NA & NA & NA & NA & NA & NA \\
\hline 257 & NA & NA & NA & NA & NA & NA & NA & NA \\
\hline 258 & NA & NA & NA & NA & NA & NA & NA & NA \\
\hline 259 & NA & NA & NA & NA & NA & NA & NA & NA \\
\hline 260 & NA & NA & NA & NA & NA & NA & NA & NA \\
\hline 261 & NA & NA & NA & NA & NA & NA & NA & NA \\
\hline 262 & NA & NA & NA & NA & NA & NA & NA & NA \\
\hline 263 & NA & NA & NA & NA & NA & NA & NA & NA \\
\hline 264 & NA & NA & NA & NA & NA & NA & NA & NA \\
\hline 265 & NA & NA & NA & NA & NA & NA & NA & NA \\
\hline 266 & NA & NA & NA & NA & NA & NA & NA & NA \\
\hline 267 & NA & NA & NA & NA & NA & NA & NA & NA \\
\hline 268 & NA & NA & NA & NA & NA & NA & NA & NA \\
\hline 269 & NA & NA & NA & NA & NA & NA & NA & NA \\
\hline 270 & NA & NA & NA & NA & NA & NA & NA & NA \\
\hline 271 & NA & NA & NA & NA & NA & NA & NA & NA \\
\hline 272 & NA & NA & NA & NA & NA & NA & NA & NA \\
\hline 273 & NA & NA & NA & NA & NA & NA & NA & NA \\
\hline 274 & NA & NA & NA & NA & NA & NA & NA & NA \\
\hline 275 & NA & NA & NA & NA & NA & NA & NA & NA \\
\hline 276 & NA & NA & NA & NA & NA & NA & NA & NA \\
\hline 277 & NA & NA & NA & NA & NA & NA & NA & NA \\
\hline
\end{tabular}


Table B.4. Temperature-Viscosity Pairs Eight to Eleven for the 281 Glasses Used to Develop a Model for Viscosity at $1150^{\circ} \mathrm{C}$

\begin{tabular}{ccccccccc}
\hline Row & \multicolumn{8}{c}{ Temperature $\left({ }^{\circ} \mathbf{C}\right)$} \\
\cline { 2 - 8 }$\#^{\text {(a) }}$ & T8 & V8 & T9 & V9 & T10 & V10 & T11 & V11 \\
\hline 278 & NA & NA & NA & NA & NA & NA & NA & NA \\
279 & NA & NA & NA & NA & NA & NA & NA & NA \\
280 & NA & NA & NA & NA & NA & NA & NA & NA \\
281 & NA & NA & NA & NA & NA & NA & NA & NA \\
\hline (a) The glass names corresponding to the row numbers are listed in Table B.1.
\end{tabular}

(b) This temperature-viscosity pair was judged to be an outlier and was not used to determine the $\eta_{1150}$ value for this glass. 

Appendix C

Derivation of the Nonlinear Multiple-Component Constraint Involving $\mathrm{SO}_{3}$ Solubility 



\section{Appendix C}

\section{Derivation of the Nonlinear Multiple-Component Constraint Involving $\mathrm{SO}_{3}$ Solubility}

This appendix derives the final mathematical form of the multiple-component constraint (MCC) for $\mathrm{SO}_{3}$ solubility. We begin by substituting into the $\mathrm{SO}_{3}$ solubility constraint in Equation (5) a general formula representing the expression for $\mathrm{SL}_{\mathrm{SO}_{3}}$ in Equation (3):

$$
g_{\mathrm{SO}_{3}}=\frac{S L_{\mathrm{SO}_{3}}}{100} \leq \frac{1}{100}\left[\sum_{i \neq S O_{3}}^{14} a_{i} x_{i}+b\left(x_{L_{2} \mathrm{O}}\right)^{2}\right]
$$

where the $a_{i}$ and $b$ coefficient values are listed in Equation (3). All notation in this appendix is as defined in the main body of this report. Then, using Equation (4) to write the $x_{i} \mathrm{~s}$ in terms of the $g_{i}$ s yields

$$
g_{\mathrm{SO}_{3}} \leq \frac{1}{100}\left[\sum_{i \neq \mathrm{SO}_{3}}^{14} a_{i}\left(\frac{g_{i}}{1-g_{\mathrm{SO}_{3}}}\right)+b\left(\frac{g_{\mathrm{Li}_{2} \mathrm{O}}}{1-g_{\mathrm{SO}_{3}}}\right)^{2}\right]
$$

Multiplying both sides of Equation (C.2) by $100\left(1-g_{\mathrm{SO}_{3}}\right)$ and collecting all terms on one side yields

$$
\sum_{i \neq \mathrm{SO}_{3}}^{14} a_{i} g_{i}+b\left(\frac{g_{\mathrm{Li}_{2} \mathrm{O}}^{2}}{1-g_{\mathrm{SO}_{3}}}\right)-100\left(g_{\mathrm{SO}_{3}}\right)+100\left(g_{\mathrm{SO}_{3}}^{2}\right) \geq 0
$$

Now, expanding the first term using the low-activity waste (LAW) glass component names and the coefficient values yields

$$
\begin{aligned}
& -2.091901\left(g_{\mathrm{Al}_{2} \mathrm{O}_{3}}\right)+3.0440748\left(g_{\mathrm{B}_{2} \mathrm{O}_{3}}\right)+4.4422886\left(g_{\mathrm{CaO}}\right)-22.65353\left(g_{\mathrm{Cl}}\right) \\
& -13.14139\left(g_{\mathrm{Cr}_{2} \mathrm{O}_{3}}\right)+0.615785\left(g_{\mathrm{K}_{2} \mathrm{O}}\right)+2.4739255\left(g_{\mathrm{Li}_{2} \mathrm{O}}\right)+2.8972089\left(g_{\mathrm{Na}_{2} \mathrm{O}}\right) \\
& +4.606083\left(g_{\mathrm{P}_{2} \mathrm{O}_{5}}\right)+0.2407285\left(g_{\mathrm{SiO}_{2}}\right)-1.775325\left(g_{\mathrm{SnO}_{2}}\right)+7.5345478\left(g_{\mathrm{V}_{2} \mathrm{O}_{5}}\right) \\
& -1.871916\left(g_{\mathrm{ZrO}_{2}}\right)-0.280272\left(g_{\mathrm{Others}_{2}}\right)+260.20302\left[\left(g_{\mathrm{Li}_{2} \mathrm{O}}\right)^{2} /\left(1-g_{\mathrm{SO}_{3}}\right)\right] \\
& -100\left(g_{\mathrm{SO}_{3}}\right)+100\left(g_{\mathrm{SO}_{3}}\right)^{2} \geq 0
\end{aligned}
$$


Note that Equation (C.4) contains terms for three components not listed in Table 2.1, namely Cl, $\mathrm{Cr}_{2} \mathrm{O}_{3}$, and $\mathrm{P}_{2} \mathrm{O}_{5}$. These are three of the four components making up Others1, with only $\mathrm{F}$ not represented. Also, there are three components listed in Table 2.1 that do not appear in Equation (C.4), namely $\mathrm{Fe}_{2} \mathrm{O}_{3}, \mathrm{MgO}$, and $\mathrm{ZnO}$. Hence, $g_{\text {Others } 2}=g_{\mathrm{F}}+g_{\mathrm{Fe}_{2} \mathrm{O}_{3}}+g_{\mathrm{MgO}}+g_{\mathrm{ZnO}}$. Based on Table 2.2, we have the relationships $g_{C l}=0.155315\left(g_{\text {Others } 1}\right), g_{\mathrm{Cr}_{2} \mathrm{O}_{3}}=0.104383\left(g_{\text {Others } 1}\right)$, $g_{F}=0.235786\left(g_{\text {Others } 1}\right)$, and $g_{P_{2} O_{5}}=0.504516\left(g_{\text {Others } 1}\right)$. Substituting all of these relationships into Equation (C.4) and collecting like terms produces the final form of the $\mathrm{SO}_{3}$-solubility $\mathrm{MCC}$ expressed in terms of the mass fractions of the 15 LAW glass components in Table 2.1:

$$
\begin{aligned}
& -2.091901\left(g_{\mathrm{Al}_{2} \mathrm{O}_{3}}\right)+3.0440748\left(g_{\mathrm{B}_{2} \mathrm{O}_{3}}\right)+4.4422886\left(g_{\mathrm{CaO}}\right)-0.280272\left(g_{\mathrm{Fe}_{2} \mathrm{O}_{3}}\right) \\
& +0.615785\left(g_{\mathrm{K}_{2} \mathrm{O}}\right)+2.4739255\left(g_{\mathrm{Li}_{2} \mathrm{O}}\right)-0.280272\left(g_{\mathrm{MgO}}\right)+2.8972089\left(g_{\mathrm{Na}_{2} \mathrm{O}}\right) \\
& +0.2407285\left(g_{\mathrm{SiO}_{2}}\right)-100\left(g_{\mathrm{SO}_{3}}\right)-1.775325\left(g_{\mathrm{SnO}_{2}}\right)+7.5345478\left(g_{\mathrm{V}_{2} \mathrm{O}_{5}}\right) \\
& -0.280272\left(g_{\mathrm{ZnO}_{\mathrm{O}}}\right)-1.871916\left(g_{\mathrm{ZrO}_{2}}\right)-2.632412\left(g_{\text {Others } 1}\right) \\
& +260.20302\left[\left(g_{\mathrm{Li}_{2} \mathrm{O}}\right)^{2} /\left(1-g_{\mathrm{SO}_{3}}\right)\right]+100\left(g_{\mathrm{SO}_{3}}\right)^{2} \geq 0 .
\end{aligned}
$$

This inequality can be written in the condensed form given by Equation (6), where the $c_{i}(i=1$, $2, \ldots, 15)$ and $b$ in that equation are the coefficients listed in Equation (C.5). 


\section{Appendix D}

Derivation of the Intersection of a Nonlinear MultipleComponent Constraint and an Edge that Connects Two Vertices Outside and Inside the Constraint 



\section{Appendix D}

\section{Derivation of the Intersection of a Nonlinear Multiple- Component Constraint and an Edge that Connects Two Vertices Outside and Inside the Constraint}

The intersection of the edge connecting two vertices A and B given by

$$
g_{i}=\alpha g_{A i}+(1-\alpha) g_{B i}=\alpha\left(g_{A i}-g_{B i}\right)+g_{B i}
$$

with the nonlinear surface

$$
\sum_{i=1}^{15} c_{i} g_{i}+b\left(\frac{g_{L_{2} O}^{2}}{1-g_{\mathrm{SO}_{3}}}\right)+100\left(g_{\mathrm{SO}_{3}}^{2}\right)=0
$$

associated with the nonlinear multiple-component constraint in Equation (6) in the main text is derived in this appendix. Substituting Equation (D.1) into Equation (D.2) yields

$$
\begin{aligned}
& \sum_{i=1}^{15} c_{i}\left[\alpha\left(g_{A, i}-g_{B, i}\right)+g_{B, i}\right]+b\left(\frac{\left[\alpha\left(g_{A, L i O_{2}}-g_{B, L i O_{2}}\right)+g_{B, L i O_{2}}\right]^{2}}{1-\left[\alpha\left(g_{A, S O_{3}}-g_{B, S O_{3}}\right)+g_{B, S O_{3}}\right]}\right) \\
& +100\left(\left[\alpha\left(g_{A, S O_{3}}-g_{B, S O_{3}}\right)+g_{B, S O_{3}}\right]^{2}\right)=0 .
\end{aligned}
$$

Multiplying out the squared expression in the last term and collecting terms by powers of $\alpha$ yields

$$
\begin{aligned}
& {\left[100\left(g_{A, S O_{3}}-g_{B, S O_{3}}\right)^{2}\right] \alpha^{2}+\left[\sum_{i=1}^{15} c_{i}\left(g_{A, i}-g_{B, i}\right)+200\left(g_{A, S O_{3}}-g_{B, S O_{3}}\right)\left(g_{B, S O_{3}}\right)\right] \alpha} \\
& +\left[\sum_{i=1}^{15} c_{i} g_{B, i}+100\left(g_{B, S O_{3}}\right)^{2}\right]+b\left(\frac{\left[\alpha\left(g_{A, L i O_{2}}-g_{B, L i O_{2}}\right)+g_{B, L i O_{2}}\right]^{2}}{1-\left[\alpha\left(g_{A, S O_{3}}-g_{B, S O_{3}}\right)+x_{B, S O_{3}}\right]}\right)=0 .
\end{aligned}
$$





\section{Appendix E}

\section{The 147 Existing Low-Activity Waste Glass Compositions}





\section{Appendix E}

\section{The 147 Existing Low-Activity Waste Glass Compositions}

Table E.1 lists the 147 existing low-activity waste (LAW) glass compositions within the outer-layer single-component constraints (SCCs) and multiple-component constraints (MCCs) that were augmented when selecting the 18 outer-layer and 13 inner-layer points for the layered design. Table E.2 lists the glass names that correspond to the row numbers in Table E.1. 
Table E. 1. The 147 Existing LAW Glass Compositions (mass fractions) Within the Outer-Layer Region SCCs and MCCs Given in Tables 2.1 and 2.3

\begin{tabular}{|c|c|c|c|c|c|c|c|c|c|c|c|c|c|c|c|}
\hline \multirow{2}{*}{$\begin{array}{c}\text { Row } \\
\#^{(a)}\end{array}$} & \multicolumn{15}{|c|}{ Component } \\
\hline & $\mathrm{Al}_{2} \mathbf{O}_{3}$ & $\mathbf{B}_{2} \mathbf{O}_{3}$ & $\mathrm{CaO}$ & $\mathrm{Fe}_{2} \mathrm{O}_{3}$ & $\mathbf{K}_{2} \mathbf{O}$ & $\mathbf{L i}_{2} \mathbf{O}$ & MgO & $\mathrm{Na}_{2} \mathrm{O}$ & $\mathrm{SiO}_{2}$ & $\mathrm{SO}_{3}$ & $\mathrm{SnO}_{2}$ & $\mathrm{~V}_{2} \mathrm{O}_{5}$ & $\mathrm{ZnO}$ & $\mathrm{ZrO}_{2}$ & Others1 \\
\hline 1 & 0.1017 & .1369 & 0.0565 & 0.0100 & 0.0051 & 0.0000 & 0.0100 & 0.2302 & 0.3661 & 0.0067 & 0.0000 & 0.0100 & 0.0300 & 0.0300 & 0.0067 \\
\hline 2 & 0.1066 & 1280 & 0.0799 & 0091 & 0051 & 0000 & 0.0091 & 0.2301 & 3488 & 0068 & .0000 & .0098 & .0300 & 300 & 0067 \\
\hline 3 & 0.1066 & 1130 & 0800 & 0091 & 0051 & 0.0000 & 0091 & 0.2302 & 0.3488 & 66 & .0000 & 98 & 300 & & \\
\hline 4 & & & & & & & & & & & & & & & \\
\hline 5 & & 1129 & & & & & & & & & & & 0.0300 & 0.0300 & 0067 \\
\hline 6 & 0.1366 & 0.0980 & 0.0799 & & & 0.0000 & 0.0091 & 0.2301 & 0.3488 & 0.0067 & 0.0000 & & 0.0300 & 300 & 067 \\
\hline 7 & 0.1086 & 0926 & 0.0798 & 0091 & 0.0056 & 0.0000 & 0.0091 & 0.2501 & 0.3534 & 0.0069 & 0.0000 & 0.0094 & 0.0235 & 0.0445 & 0.0073 \\
\hline 8 & & & & & & & & & & & & & & & \\
\hline 9 & & & & & & & & & & & & & & & \\
\hline 10 & & & & & & 0.0000 & 0.0091 & & & 0 & 0.0000 & & 0.0145 & & 067 \\
\hline 11 & 0.1215 & 0979 & 0.0799 & 0.0091 & 0.0051 & 0.0000 & 0.0091 & 0.2301 & 0.3689 & 0.0070 & 0.0000 & 0.0150 & 0.0195 & 300 & 0.0067 \\
\hline 12 & & & & & & & & & & & & & & & \\
\hline 13 & & & & & & & & & & & & & & & \\
\hline 14 & & & & & & & & & & & & & & & \\
\hline 15 & 1066 & 1281 & 0.0649 & .0091 & 0.0051 & 0.0000 & 0.0091 & 0.2 & 0.3 & 0.0061 & 0.0100 & $0 .($ & 0.0300 & 300 & 117 \\
\hline 16 & & 0.1281 & & & & 0.0000 & 0.0091 & 0.2 & & 0.0 & 01 & & 300 & 00 & 17 \\
\hline 17 & & & & & & & & & & 0.0061 & & & 300 & & 17 \\
\hline 18 & & & & & & & & & & & & & & & \\
\hline 19 & 0.1216 & & & & & & 0.0091 & & 0.3490 & 0.0061 & 0.0000 & 0.0098 & 0.0300 & 300 & 117 \\
\hline 20 & 0.1216 & 0.1130 & 0.0598 & 0.0091 & 0.0051 & 0.0000 & 0.0091 & 0.2 & 0.3588 & 0.0068 & 0.0000 & 0.0098 & 0.0300 & & 0.0067 \\
\hline 21 & & & 0.0549 & & & 0.0000 & 0.0091 & 0.2 & 0.3590 & 0.0062 & 0.0000 & 0.0098 & 0.0300 & 400 & 0.0117 \\
\hline 22 & 0.1087 & & & & & & & & & 0.0058 & 0.0100 & & & & 0.0073 \\
\hline 23 & 0.1087 & 0.0777 & 0.0649 & 0.0091 & 0.0056 & 0.0000 & 0.0091 & 0.2504 & 0.3537 & 0.0058 & 0.0100 & 0.0094 & 0.0235 & 0.0596 & 0.0124 \\
\hline 24 & 0.1186 & 0.0777 & & 0.0091 & & 0.0000 & & & & 0.0062 & 0.0000 & & 0.0235 & 0.0596 & 0.0073 \\
\hline 25 & 0.1187 & 0.0777 & 0.0549 & 0.0091 & 0.0056 & 0.0000 & 0.0091 & 0.2504 & 0.3637 & 0.0059 & 0.0000 & 0.0094 & 0.0235 & 0.0596 & 0.0124 \\
\hline 26 & 0.1019 & 0.1372 & 0.0804 & 0.0100 & 0.0015 & 0.0000 & & 0.2005 & 0.3672 & 0.0094 & 0.0000 & 0.0100 & 0.0301 & & 0.0117 \\
\hline 27 & 0.1019 & 0.1304 & 0.0805 & 0.0100 & 0.0015 & 0.0000 & 0.0100 & 0.2006 & 0.3673 & 0.0089 & 0.0000 & 0.0100 & 0.0301 & 0.0369 & 0.0117 \\
\hline 28 & 0.0866 & 0.1371 & 0.0804 & 0.0100 & 0.0015 & 0.0000 & 0.0100 & 0.2004 & 0.3669 & 0.0100 & 0.0000 & 0.0100 & 0.0301 & 0.0453 & 0.0117 \\
\hline
\end{tabular}


Table E.1. The 147 Existing LAW Glass Compositions (mass fractions) Within the Outer-Layer Region SCCs and MCCs Given in Tables 2.1 and 2.3 (contd)

\begin{tabular}{|c|c|c|c|c|c|c|c|c|c|c|c|c|c|c|c|}
\hline \multirow{2}{*}{$\begin{array}{c}\text { Row } \\
\#^{\text {(a) }}\end{array}$} & \multicolumn{15}{|c|}{ Component } \\
\hline & $\mathrm{Al}_{2} \mathbf{O}_{3}$ & $\mathrm{~B}_{2} \mathbf{O}_{3}$ & $\mathrm{CaO}$ & $\mathrm{Fe}_{2} \mathrm{O}_{3}$ & $\mathbf{K}_{2} \mathbf{O}$ & $\mathbf{L i}_{2} \mathbf{O}$ & MgO & $\mathrm{Na}_{2} \mathrm{O}$ & $\mathrm{SiO}_{2}$ & $\mathrm{SO}_{3}$ & $\mathrm{SnO}_{2}$ & $\mathbf{V}_{2} \mathbf{O}_{5}$ & ZnO & $\mathrm{ZrO}_{2}$ & Others1 \\
\hline 29 & 0.0714 & 0.1373 & .0805 & 0.0100 & 0.0015 & 0.0000 & 100 & 0.2007 & 0.3674 & 0.0087 & 0.0000 & & 0.0301 & 0.0606 & 0.0117 \\
\hline 30 & & & 350 & 0101 & & & & & & & & & & & \\
\hline 31 & & & & & & & & & & & 0.0100 & & & & \\
\hline 32 & 0.1000 & 0.0900 & 0.0304 & 0.0101 & 0.0056 & 0.0000 & 0.0135 & 0.2500 & 0.4131 & 0.0019 & 0.0000 & 0.0000 & 0.0236 & 80 & 0.0139 \\
\hline 33 & & & & & & & & & & & & & & & \\
\hline 34 & & & & & & & & & & & & & & & \\
\hline 35 & & & & & & & & & & & & & & & \\
\hline 36 & 0.1090 & & 0.0652 & & & & & & & & 0.0200 & & 0.0236 & & \\
\hline 37 & 0 & 30 & 52 & & & 0.0 & & & & & 68 & & 36 & & \\
\hline 38 & & & & & & & & & & & & & & & \\
\hline 39 & & & & & & & & & & & & & & & \\
\hline 40 & 3 & 007 & 0.0201 & 0 & 5 & 0.00 & 2 & 0.2 & 0.40 & 0.0 & 0.0272 & & 0.0242 & & \\
\hline 41 & & & & & & 0.0 & & & & & & & 47 & & \\
\hline 42 & & & & & & & & & & & & & & & \\
\hline 43 & & & & & & & & & & & & & & & \\
\hline 44 & & & & & & & & & & & & & & & \\
\hline 45 & & & & & & & & & & & 76 & & 76 & & \\
\hline 46 & & & & & & & & & & & & & 76 & & \\
\hline 47 & & & & & & & & & & & & & & & \\
\hline 48 & & & & & & & & & & & & & & & \\
\hline 49 & & & & & & & & & & & & & & & \\
\hline 50 & & & & & & & & & 9 & & & & & & \\
\hline 51 & & & & & & & & & & & & & & & \\
\hline 52 & & & & & & & & & & & & & 0.0289 & & \\
\hline 53 & & & & & & & & & & & & & 0.0299 & & \\
\hline 54 & & 0.0896 & 0.0320 & 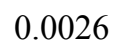 & 0.0051 & 0.0 & 1 & 0.2 & 5 & 0. & 0.0247 & 94 & 0.0287 & & 14 \\
\hline 55 & & & & & & & & & & & & & & & \\
\hline 56 & 0.0727 & 0.1008 & 0.0422 & 0.0047 & & 0.0000 & & & & 0.0082 & 0.0197 & 0.0094 & 0.0288 & 0.0490 & \\
\hline 57 & 0.0838 & 0.1120 & 0.0523 & & & & & 0.2320 & 0.3656 & 0.0088 & 0.0147 & 0.0094 & 0.0288 & 0.0389 & 0.0115 \\
\hline 58 & 0.0636 & 0.0879 & 0.0315 & 0.0026 & 0.0053 & 0.0000 & 0.0099 & 0.2419 & & 0.0085 & 0.0242 & 0.0092 & 0.0282 & 0.0579 & 0.0116 \\
\hline 59 & 0.0636 & 0.0827 & 0.0314 & 0.0026 & 0.0053 & 0.0000 & 0.0198 & 0.2418 & 0.4128 & 0.0087 & 0.0242 & 0.0092 & 0.0282 & 0.0579 & 0.0116 \\
\hline
\end{tabular}


Table E.1. The 147 Existing LAW Glass Compositions (mass fractions) Within the Outer-Layer Region SCCs and MCCs Given in Tables 2.1 and 2.3 (contd)

\begin{tabular}{|c|c|c|c|c|c|c|c|c|c|c|c|c|c|c|c|}
\hline \multirow{2}{*}{$\begin{array}{c}\text { Row } \\
\#^{\text {(a) }}\end{array}$} & \multicolumn{15}{|c|}{ Component } \\
\hline & $\mathrm{Al}_{2} \mathrm{O}_{3}$ & $\mathrm{~B}_{2} \mathbf{O}_{3}$ & $\mathrm{CaO}$ & $\mathrm{Fe}_{2} \mathrm{O}_{3}$ & $\mathbf{K}_{2} \mathbf{O}$ & $\mathbf{L i}_{2} \mathbf{O}$ & MgO & $\mathrm{Na}_{2} \mathrm{O}$ & $\mathrm{SiO}_{2}$ & $\mathrm{SO}_{3}$ & $\mathrm{SnO}_{2}$ & $\mathrm{~V}_{2} \mathrm{O}_{5}$ & ZnO & $\mathrm{ZrO}_{2}$ & Others1 \\
\hline 60 & 0.0636 & 0.0827 & 0.0314 & 0.0026 & 0.0053 & 0.0000 & 5099 & 02418 & 0.4175 & 0000 & 0.0268 & 0 & 0.0282 & 0.0605 & 0.0116 \\
\hline 61 & 695 & & & & & & 0098 & & & & & & & & \\
\hline 62 & & & & & & & & & & & & & & & \\
\hline 63 & 0.0998 & 0.0898 & 0.0249 & 0.0101 & 0.0056 & 0.0000 & 0.0135 & 0.2494 & 0.4121 & 0.0042 & 0.0100 & 0.0000 & 0.0235 & 0.0479 & \\
\hline 64 & & & & & & & 0135 & & 4121 & & 00 & & & & \\
\hline 65 & & & & & & & & & & & & & & & \\
\hline 66 & & & & & & & & & & & & & & & \\
\hline 67 & 1087 & 00 & 0147 & & & & & & & & & & 0.0236 & & \\
\hline 68 & 1086 & 77 & 50 & & & 0.0000 & 91 & & & 5 & 99 & & 35 & & \\
\hline 69 & & & & & & & & & & & & & & & \\
\hline 70 & & & & & & & & & & & & & & & \\
\hline 71 & 0.1076 & 0 & 0.0203 & 00 & 54 & $0 \Omega 0$ & 93 & & 0.4095 & 0.0 & 0.0275 & & 0.0245 & & \\
\hline 72 & & 6 & 01 & & & 0.0 & 92 & & 57 & & 72 & & 42 & & \\
\hline 73 & & & & & & & & & & & & & & & \\
\hline 74 & & & & & & & & & & & & & & & \\
\hline 75 & & & & & & & & & & & & & & & \\
\hline 76 & & & 99 & & & & & & & & & & 36 & & \\
\hline 77 & & & & & & & & & & & & & & & \\
\hline 78 & & & & & & & & & & & & & & & \\
\hline 79 & & & & & & & & & & & & & & & \\
\hline 80 & & & & & & & & & & & & & & & \\
\hline 81 & & & & & & 0 & & & & & & & & & \\
\hline 82 & & & & & & & & & & & & & & & \\
\hline 83 & & & & & & & & & & & & & 237 & & \\
\hline 84 & & & & & & & & & & & & & & & \\
\hline 85 & & & & 0.0 & 0.00 & 0.0 & 0 & 0.2 & 53 & 0.0 & 99 & & 0.0297 & 0.0 & 46 \\
\hline 86 & & & & & & & & & & & & & & & \\
\hline 87 & 0.1004 & & 0.0191 & 0.0097 & & 0.0000 & & 0.2358 & 0.4012 & 0.0048 & 0.0100 & 0.0200 & 0.0237 & 0.0604 & \\
\hline 88 & 0.1065 & 0.1165 & & & & 0.0000 & 0.0090 & 0.2346 & & 0.0068 & 0.0099 & & 0.0297 & 0.0345 & 0.0146 \\
\hline 89 & 0.1063 & 0.1117 & 0.0646 & 0.0091 & 0.0054 & 0.0000 & 0.0091 & 0.2346 & 0.3480 & 0.0070 & 0.0100 & 0.0148 & 0.0299 & 0.0349 & 0.0146 \\
\hline 90 & 0.1004 & 0.0852 & 0.0191 & 0.0097 & 0.0054 & 0.0000 & 0.0093 & 0.2356 & 0.4009 & 0.0056 & 0.0100 & 0.0200 & 0.0237 & 0.0604 & 0.0148 \\
\hline
\end{tabular}


Table E.1. The 147 Existing LAW Glass Compositions (mass fractions) Within the Outer-Layer Region SCCs and MCCs Given in Tables 2.1 and 2.3 (contd)

\begin{tabular}{|c|c|c|c|c|c|c|c|c|c|c|c|c|c|c|c|}
\hline \multirow{2}{*}{$\begin{array}{c}\text { Row } \\
\#^{(a)}\end{array}$} & \multicolumn{15}{|c|}{ Component } \\
\hline & $\mathrm{Al}_{2} \mathrm{O}_{3}$ & $\mathbf{B}_{2} \mathbf{O}_{3}$ & $\mathrm{CaO}$ & $\mathrm{Fe}_{2} \mathrm{O}_{3}$ & $\mathrm{~K}_{2} \mathrm{O}$ & $\mathbf{L i}_{2} \mathbf{O}$ & MgO & $\mathrm{Na}_{2} \mathrm{O}$ & $\mathrm{SiO}_{2}$ & $\mathrm{SO}_{3}$ & $\mathrm{SnO}_{2}$ & $\mathbf{V}_{2} \mathbf{O}_{5}$ & $\mathrm{ZnO}$ & $\mathrm{ZrO}_{2}$ & Others1 \\
\hline 91 & 0.1015 & 01204 & 0.0801 & 0.0100 & 0.0016 & $0 \Omega 0 \Omega 0$ & & & 0.3714 & 0.0106 & 0.0000 & 0.0100 & 0.0300 & 0.0300 & 0.0147 \\
\hline 92 & 9913 & 0762 & 804 & 5 & & & 00 & & 40 & 77 & 0 & 0 & 251 & & \\
\hline 93 & 0812 & 0.0862 & & & & & & & & & & & & & \\
\hline 94 & .1019 & 0.1209 & .0804 & 0.0030 & .0016 & 0.0000 & 0.0100 & 0.2103 & 0.3797 & 0.0085 & 0.0000 & 0.0100 & 0.0301 & 0.0301 & 0.0134 \\
\hline 95 & 1020 & 1005 & 0804 & .0030 & & & & & 3798 & & & 00 & 01 & & \\
\hline 96 & & & & & & & & & & & & & & & \\
\hline 97 & & & & & & & & & & & & & & & \\
\hline 98 & 1001 & 0.0948 & 0734 & 0.0029 & & & & 0.2296 & 0.3668 & & & & & & \\
\hline 99 & 58 & 0.0951 & 735 & 0.0029 & 18 & 00 & 097 & 01 & 3676 & 0.0 & 00 & 0.0 & 0.0299 & 02 & \\
\hline 100 & & & & & & & & & & & & & & & \\
\hline 101 & & & & & & & & & & & & & & & \\
\hline 102 & 0812 & 0.0862 & 1003 & 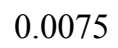 & 0016 & 75 & 00 & 02 & 0.3943 & 0.0089 & 00 & 0.0 & 0.0251 & & \\
\hline 103 & 0761 & ח 0006 & 47 & 4 & & & & 2 & 0.4146 & 0.0 & & & 22 & & \\
\hline & & & & & & & & & & & & & & & \\
\hline 105 & & & & & & & & & & & & & & & \\
\hline 106 & & & & & & & & & & & & & & & \\
\hline 107 & & & & & & & & 2 & & & & & 96 & & \\
\hline 108 & & & & & & & & & & & & & & & \\
\hline & & & & & & & & & & & & & & & \\
\hline 110 & & & & & & & & & & & & & & & \\
\hline 111 & & & & & & & & & & & & & & & \\
\hline 112 & & & & 4 & & & & & 77 & & & & 22 & & \\
\hline 113 & & & & & & & & & & & & & & & \\
\hline 114 & & & & & & & & & & & & & & & \\
\hline & & & & & & & & & & & & & & & \\
\hline 116 & 995 & 0.0967 & 0.0992 & 0.0030 & 45 & 72 & & 0 . & 0.4302 & 0.0 & & 0.0125 & 0.0298 & & \\
\hline 117 & & & & & & & & & & & & & & & 70 \\
\hline 118 & 0.0867 & 0.0958 & 0.0980 & & & & & 0.1210 & 0.4250 & & & & 0.0293 & & 0.0070 \\
\hline 119 & 0.0972 & & & & & & & & & 0.0108 & & 0.0121 & 0.0290 & 0.0387 & 0.0071 \\
\hline 120 & & 0.0945 & 0.0967 & 0.0029 & 0.0055 & & 0.0098 & & 0.4194 & 0.0113 & 0.0085 & 0.0249 & 0.0290 & 0.0387 & 0.0071 \\
\hline 121 & 0.0865 & 0.0956 & 0.0978 & 0.0030 & 0.0050 & 0.0438 & 0.0099 & 0.1207 & 0.4240 & 0.0132 & 0.0000 & 0.0252 & 0.0293 & 0.0390 & 0.0069 \\
\hline
\end{tabular}


Table E.1. The 147 Existing LAW Glass Compositions (mass fractions) Within the Outer-Layer Region SCCs and MCCs Given in Tables 2.1 and 2.3 (contd)

\begin{tabular}{|c|c|c|c|c|c|c|c|c|c|c|c|c|c|c|c|}
\hline \multirow{2}{*}{$\begin{array}{c}\text { Row } \\
\#^{(a)}\end{array}$} & \multicolumn{15}{|c|}{ Component } \\
\hline & $\mathbf{A l}_{2} \mathbf{O}_{3}$ & $\mathbf{B}_{2} \mathbf{O}_{3}$ & $\mathrm{CaO}$ & $\mathrm{Fe}_{2} \mathrm{O}_{3}$ & $\mathbf{K}_{2} \mathbf{O}$ & $\mathbf{L i}_{2} \mathbf{O}$ & MgO & $\mathrm{Na}_{2} \mathrm{O}$ & $\mathrm{SiO}_{2}$ & $\mathrm{SO}_{3}$ & $\mathrm{SnO}_{2}$ & $\mathbf{V}_{2} \mathbf{O}_{5}$ & $\mathrm{ZnO}$ & $\mathrm{ZrO}_{2}$ & Others1 \\
\hline 122 & 0.0764 & 0.0890 & 0.0977 & 0.0030 & 0.0050 & 0.0352 & 0.0099 & 0.1206 & 0.4204 & 0.0143 & 0.0085 & 0.0251 & 0.0293 & 0.0390 & 0.0266 \\
\hline 123 & 0.0866 & 0.0957 & 0.1064 & 0.0030 & 0.0050 & 0.0352 & 0.0099 & 0.1208 & 0.4244 & 0.0124 & 0.0000 & 0.0252 & 0.0293 & 0.0391 & 0.0069 \\
\hline 124 & 0.0867 & 0.0957 & 0.0980 & 0.0030 & 0.0050 & 0.0353 & 0.0099 & 0.1209 & 0.4247 & 0.0116 & 0.0060 & 0.0277 & 0.0293 & 0.0391 & 0.0070 \\
\hline 125 & 0.0860 & 0.0950 & 0.1056 & 0.0000 & 0.0050 & 0.0350 & 0.0000 & 0.1199 & 0.4212 & 0.0197 & 0.0100 & 0.0272 & 0.0291 & 0.0395 & 0.0069 \\
\hline 126 & 0.0860 & 0.0950 & 0.1057 & 0.0000 & 0.0050 & 0.0371 & 0.0000 & 0.1200 & 0.4213 & 0.0196 & 0.0100 & 0.0250 & 0.0291 & 0.0395 & 0.0069 \\
\hline 127 & 0.1008 & 0.0984 & 0.0788 & 0.0028 & 0.0017 & 0.0000 & 0.0100 & 0.2201 & 0.3720 & 0.0125 & 0.0000 & 0.0196 & 0.0296 & 0.0398 & 0.0138 \\
\hline 128 & 0.1064 & 0.1277 & 0.0648 & 0.0090 & 0.0051 & 0.0000 & 0.0090 & 0.2296 & 0.3480 & 0.0080 & 0.0100 & 0.0097 & 0.0299 & 0.0299 & 0.0127 \\
\hline 129 & 0.1064 & 0.1277 & 0.0648 & 0.0090 & 0.0051 & 0.0000 & 0.0090 & 0.2296 & 0.3480 & 0.0080 & 0.0100 & 0.0097 & 0.0299 & 0.0299 & 0.0127 \\
\hline 130 & 0.1064 & 0.1278 & 0.0648 & 0.0090 & 0.0051 & 0.0000 & 0.0090 & 0.2297 & 0.3482 & 0.0077 & 0.0100 & 0.0097 & 0.0299 & 0.0299 & 0.0128 \\
\hline 131 & 0.1064 & 0.1278 & 0.0648 & 0.0090 & 0.0051 & 0.0000 & 0.0090 & 0.2297 & 0.3482 & 0.0077 & 0.0100 & 0.0097 & 0.0299 & 0.0299 & 0.0128 \\
\hline 132 & 0.1063 & 0.1277 & 0.0647 & 0.0090 & 0.0051 & 0.0000 & 0.0090 & 0.2296 & 0.3480 & 0.0083 & 0.0100 & 0.0097 & 0.0299 & 0.0299 & 0.0128 \\
\hline 133 & 0.0695 & 0.0822 & 0.0313 & 0.0026 & 0.0052 & 0.0000 & 0.0098 & 0.2401 & 0.4157 & 0.0076 & 0.0267 & 0.0092 & 0.0282 & 0.0603 & 0.0115 \\
\hline 134 & 0.0758 & 0.0983 & 0.1004 & 0.0024 & 0.0054 & 0.0249 & 0.0104 & 0.1602 & 0.4134 & 0.0138 & 0.0000 & 0.0174 & 0.0321 & 0.0354 & 0.0099 \\
\hline 135 & 0.0946 & 0.0861 & 0.0332 & 0.0092 & 0.0054 & 0.0000 & 0.0092 & 0.2403 & 0.3929 & 0.0051 & 0.0273 & 0.0000 & 0.0243 & 0.0592 & 0.0131 \\
\hline 136 & 0.1003 & 0.0851 & 0.0191 & 0.0097 & 0.0054 & 0.0000 & 0.0093 & 0.2359 & 0.4004 & 0.0061 & 0.0100 & 0.0200 & 0.0236 & 0.0603 & 0.0148 \\
\hline 137 & 0.0998 & 0.0848 & 0.0189 & 0.0096 & 0.0011 & 0.0000 & 0.0093 & 0.2401 & 0.3990 & 0.0081 & 0.0100 & 0.0199 & 0.0236 & 0.0601 & 0.0156 \\
\hline 138 & 0.1017 & 0.1204 & 0.0803 & 0.0100 & 0.0016 & 0.0000 & 0.0100 & 0.2104 & 0.3719 & 0.0089 & 0.0000 & 0.0100 & 0.0301 & 0.0301 & 0.0146 \\
\hline 139 & 0.1017 & 0.1369 & 0.0803 & 0.0100 & 0.0015 & 0.0000 & 0.0100 & 0.2002 & 0.3665 & 0.0102 & 0.0000 & 0.0100 & 0.0300 & 0.0300 & 0.0127 \\
\hline 140 & 0.1017 & 0.1369 & 0.0803 & 0.0100 & 0.0015 & 0.0000 & 0.0100 & 0.2002 & 0.3665 & 0.0102 & 0.0000 & 0.0100 & 0.0300 & 0.0300 & 0.0127 \\
\hline 141 & 0.1017 & 0.1369 & 0.0803 & 0.0100 & 0.0015 & 0.0000 & 0.0100 & 0.2002 & 0.3665 & 0.0102 & 0.0000 & 0.0100 & 0.0300 & 0.0300 & 0.0127 \\
\hline 142 & 0.1017 & 0.1369 & 0.0803 & 0.0100 & 0.0015 & 0.0000 & 0.0100 & 0.2002 & 0.3665 & 0.0102 & 0.0000 & 0.0100 & 0.0300 & 0.0300 & 0.0127 \\
\hline 143 & 0.0666 & 0.0875 & 0.0332 & 0.0019 & 0.0053 & 0.0000 & 0.0092 & 0.2402 & 0.4237 & 0.0061 & 0.0274 & 0.0000 & 0.0274 & 0.0597 & 0.0117 \\
\hline 144 & 0.0873 & 0.0964 & 0.0987 & 0.0023 & 0.0050 & 0.0441 & 0.0099 & 0.1201 & 0.4276 & 0.0076 & 0.0000 & 0.0253 & 0.0295 & 0.0393 & 0.0070 \\
\hline 145 & 0.0866 & 0.0957 & 0.0979 & 0.0023 & 0.0050 & 0.0439 & 0.0099 & 0.1202 & 0.4245 & 0.0135 & 0.0000 & 0.0251 & 0.0293 & 0.0391 & 0.0069 \\
\hline 146 & 0.1008 & 0.0984 & 0.0789 & 0.0028 & 0.0017 & 0.0000 & 0.0100 & 0.2199 & 0.3722 & 0.0126 & 0.0000 & 0.0196 & 0.0296 & 0.0398 & 0.0138 \\
\hline 147 & 0.0350 & 0.1373 & 0.0000 & 0.0030 & 0.0011 & 0.0500 & 0.0000 & 0.1431 & 0.4514 & 0.0010 & 0.0500 & 0.0400 & 0.0100 & 0.0600 & 0.0181 \\
\hline
\end{tabular}


Table E.2. Glass Names Corresponding to the Row Numbers of the 147 Existing LAW Glass Compositions in Table E.1

\begin{tabular}{|c|c|c|c|c|c|c|c|c|c|}
\hline Row \# & Glass Name & Row \# & Glass Name & Row \# & Glass Name & Row \# & Glass Name & Row \# & Glass Name \\
\hline 1 & LAWA171 & 31 & ORPLA2 & 61 & ORPLA38-1 & 91 & ORPLD1 & 121 & ORPLF7 \\
\hline 2 & LAWA172 & 32 & ORPLA3 & 62 & ORPLA1S4 & 92 & ORPLD2 & 122 & ORPLF9 \\
\hline 3 & LAWA173 & 33 & ORPLA5 & 63 & ORPLA2S4 & 93 & ORPLD3 & 123 & ORPLF10 \\
\hline 4 & LAWA174 & 34 & ORPLA6 & 64 & ORPLA3S4 & 94 & ORPLD4 & 124 & ORPLF11 \\
\hline 5 & LAWA175 & 35 & ORPLA7 & 65 & ORPLA5S4 & 95 & ORPLD5 & 125 & ORPLF13 \\
\hline 6 & LAWA176 & 36 & ORPLA9 & 66 & ORPLA6S4 & 96 & ORPLD6 & 126 & ORPLF14 \\
\hline 7 & LAWA179 & 37 & ORPLA10 & 67 & ORPLA7S4 & 97 & ORPLD7 & 127 & $10 \mathrm{~A}-\mathrm{G}-53 \mathrm{C}$ \\
\hline 8 & LAWA180 & 38 & ORPLA11 & 68 & ORPLA9S4 & 98 & ORPLD8 & 128 & EWV89BCCC \\
\hline 9 & LAWA183 & 39 & ORPLA12 & 69 & ORPLA10S4 & 99 & ORPLD9 & 129 & EWV-G-89B \\
\hline 10 & LAWA184 & 40 & ORPLA13 & 70 & ORPLA11S4 & 100 & ORPLD1S4 & 130 & EWV-G-93B \\
\hline 11 & LAWA185 & 41 & ORPLA14 & 71 & ORPLA12S4 & 101 & ORPLD2S4 & 131 & EWV93BCCC \\
\hline 12 & LAWA186 & 42 & ORPLA15 & 72 & ORPLA13S4 & 102 & ORPLD3S4 & 132 & EWV-G-108B \\
\hline 13 & LAWA187.1 & 43 & ORPLA16 & 73 & ORPLA14S4 & 103 & ORPLE1 & 133 & J10-G-24B \\
\hline 14 & LAWA187.2 & 44 & ORPLA17 & 74 & ORPLA15S4 & 104 & ORPLE2 & 134 & Q10-G-134A \\
\hline 15 & LAWA187CCC & 45 & ORPLA18 & 75 & ORPLA16S4 & 105 & ORPLE3 & 135 & R10-G-155A \\
\hline 16 & LAWA188 & 46 & ORPLA19 & 76 & ORPLA17S4 & 106 & ORPLE4 & 136 & S10-G-101B \\
\hline 17 & LAWA189 & 47 & ORPLA20 & 77 & ORPLB1 & 107 & ORPLE5 & 137 & S10-G-45A \\
\hline 18 & LAWA190 & 48 & ORPLA21 & 78 & ORPLB2 & 108 & ORPLE6 & 138 & T10-G-16A \\
\hline 19 & LAWA191 & 49 & ORPLA22 & 79 & ORPLB3 & 109 & ORPLE7 & 139 & WVY-G-95A-1 \\
\hline 20 & LAWA192 & 50 & ORPLA23 & 80 & ORPLB4 & 110 & ORPLE8 & 140 & WVY-G-95A-2 \\
\hline 21 & LAWA193 & 51 & ORPLA24 & 81 & ORPLB1S4 & 111 & ORPLE9 & 141 & WVY-G-95A-3 \\
\hline 22 & LAWA194 & 52 & ORPLA25 & 82 & ORPLB2S4 & 112 & ORPLE10 & 142 & WVY-G-95A-4 \\
\hline 23 & LAWA195 & 53 & ORPLA26 & 83 & ORPLB3S4 & 113 & ORPLE11 & 143 & Y10-G-146C \\
\hline 24 & LAWA196 & 54 & ORPLA33 & 84 & ORPLB4S4 & 114 & ORPLE12 & 144 & Z10-G-122B \\
\hline 25 & LAWA197 & 55 & ORPLA33-1 & 85 & ORPLC2 & 115 & ORPLF1 & 145 & Z10-G-153B \\
\hline 26 & LAWC100R1 & 56 & ORPLA34 & 86 & ORPLC4 & 116 & ORPLF2 & 146 & Z10-G-60C \\
\hline 27 & LAWC101 & 57 & ORPLA35 & 87 & ORPLC5 & 117 & ORPLF3 & 147 & S2-07 \\
\hline 28 & LAWC102 & 58 & ORPLA36 & 88 & ORPLC2S4 & 118 & ORPLF4 & & \\
\hline 29 & LAWC103 & 59 & ORPLA37 & 89 & ORPLC4S4 & 119 & ORPLF5 & & \\
\hline 30 & ORPLA1 & 60 & ORPLA38 & 90 & ORPLC5S4 & 120 & ORPLF6 & & \\
\hline
\end{tabular}



PNNL-24391

EWG-RPT-006, Rev. 0

\section{Distribution}

No. of

Copies

1 U.S. Department of Energy Office of River Protection

AA Kruger

1 Savannah River National Laboratory KM Fox

2 Vitreous State Laboratory Catholic University of America

IS Muller

IL Pegg
No. of

Copies

16 Pacific Northwest National Laboratory

CL Arendt

M Bliss

YS Chou

SK Cooley

JV Crum

DR Dixon

$T$ Jin

DS Kim

JO Kroll

DK Peeler

GF Piepel

RL Russell

MJ Schweiger

JD Vienna

JH Westsik, Jr.

Information Release 




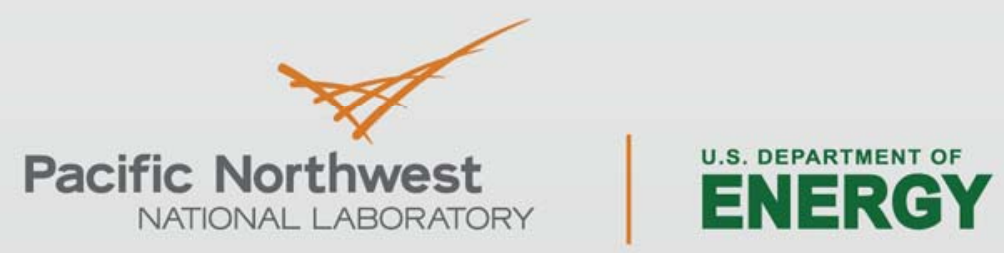

Proudly Operated by Battelle Since 1965

902 Battelle Boulevard

P.O. Box 999

Richland, WA 99352

1-888-375-PNNL (7665)

www.pnnl.gov 